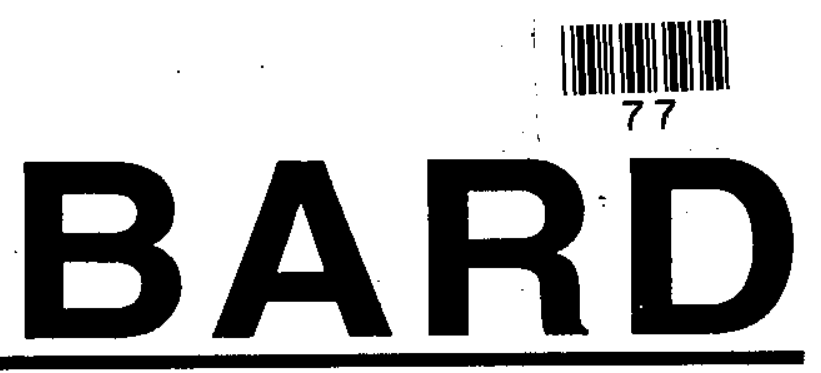

FINAL REPORT

PROJECT NO. IS-1920-90C

Microbial Activity in the Rhizosphere in Relation to the Iron Nutrition of Plants

Y. Chen, Y. Hadar, J.S. Buyer 
Appendix VI. BAFIO Cover Page for Scientific Reports

To be sent to BARD Office in Israel:

BARD, P.O. Box 6. Bet Llagan 50250, istael.

Date: $10 / 93$

BARD Project No. $15-1920-900$

Title Microbial fCtivisy in the Rhizosphere in Relation to the iron Nutrition of Plarts

All investigators' Narnes (Principal llsted first)

$\frac{\text { Yona Chen }}{\text { Yitzhak hiadar }}$

Project's starting date:

Type of Report: 1st Anrival

$$
\text { Yoma itiven }
$$

Slgnatude

Príncipal Investigator
Investigator's institutions

Hebrew Iniversity

Hebrew Lintversi ty

USDA, AFIS-BARC

1901

2nd Anrual

Final $x$

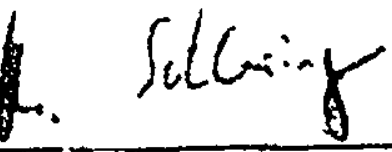

Signaturis

Institutio'?'s Authorizing Official 


\section{Microbial Activity in the Rhizosphere in \\ Relation to the Iron Nutrition of Plants}

Publications resulted from this project

2

Research carried out in the USA

Purification of siderophores and monoclonal antibodies production.

A method for detection of Pseudobactin, the siderophore

produced by a plant-growth-promoting Pseudomonas

strain, in the barley rhizosphere.

Microbial siderophores and rhizosphere ecology.

\section{Research carried out in Israel}

Chemical structure and biological activity of a

siderophore produced by Rhizopus arrhizus

Utilization by tomatoes of iron mediated by a sidero-

phore produced by Rhizopus aarhizus.

Potentiometric and fluorescent spectroscopic determinations of stability constants of the siderophore pseudobactin complexes with transition metals.

Utilization of the phytosiderophore mugineic acid as an iron source by rhizosphere fluorescent pseudomonads.

Iron uptake and molecular recognition in Pseudomonas putida: receptor mapping with Coprogen $B$, Ferrioxamine $B$ and their biomimetic analogs. 


\section{Microbial Activity in the Rhizosphere in Relation to the Iron Nutrition of Plants}

$\underline{\text { Abstract }}$ Iron is the fourth most abundant element in the soil, but since it forms insoluble hydroxides at neutral and basic $\mathrm{pH}$, it often falls short of meeting the basic requirements of plants and microorganisms. Most aerobic and facultative aerobic microorganisms possess a high-affinity $\mathrm{Fe}$ transport system in which siderophores are excreted and the consequent $\mathrm{Fe}$ complex is taken up via a cognate specific receptor and a transport pathway. The role of the siderophore in $\mathrm{Fe}$ uptake by plants and microorganisms was the focus of this study.

In this research Rhizopus arrhizus was found to produce a novel siderophore named Rhizoferrin when grown under Fe deficiency. This compound was purified and its chemical structure was elucidated. Fe-Rhizoferrin was found to alleviate $\mathrm{Fe}$ deficiency when applied to several plants grown in nutrient solutions. It was concluded that Fe-Rhizoferrin is the most efficient $\mathrm{Fe}$ source for plants when compared with other among microbial siderophores known to date and its activity equels that of the most efficient synthetic commercial iron fertilizer -Fe EDDHA.

Siderophores produced by several rhizosphere organisms including Rhizopus and Pseudomonas were purified. Monoclonal antibodies were produced and used to develop a method for detection of the siderophores produced by plant-growthpromoting microorganisms in $t$ barley rhizosphere

The presence of an Fe ferrichrome uptake system in fluorescent Pseudomonas spp. was demonstrated, and its structural requirements were mapped in $P$. putida with the help of biomimetic ferrichrome analogs Using competition experiments, it was shown that FOB, Cop B and FC share at least one common determinant in their uptake pathway. Since FC analogs did not affect FOB or Cop-mediated ${ }^{55} \mathrm{Fe}$ uptake, it could be concluded that these siderophores make use of a different receptor(s) than FC. Therefore, recognition of Cop B, FOB and FC proceeds through different receptors having different structural requirements. On the other hand, the phytosiderophores mugineic acid (MA and DMA), were utilized indirectly via ligand exchange by $P$. putida .

Receptors from different biological systems seem to differ in their structural requirements for siderophore recognition and uptake. The design of genus- or speciesspecific drugs, probes or chemicals, along with an understanding of plant-microbe and microbe-microbe relationships as well as developing methods to detect siderophores using monoclonal antibodies are useful for manipulating the composition of the rhizosphere microbial population for better plant growth, Fe-nutrition and protection from diseases. 


\section{Publications resulted from this project}

1. Buyer, J.S. Kratzek, M.G. and Sikora, 1. J. 1993. A method for detection of Pseudobactin, the siderophore produced by a plant-growth-promoting Pseudomonas strain, in the barley rhizosphere. Appl. Environ. Microbiol.59:677-681

2. Buyer, J.S. Kratzek, M.G. and Sikora, 1. J. 1993. Microbial siderophores and rhizosphere ecology. Pages 67-80, in "Biochmistry of Metal Micronutrients in the Rhizosphere". Edited by Manthey J.A., Crowely D.E., and Luster D.G.Lewis Publishers, Boca Raton.

3. Shenker, M., Oliver, I., Helmann, M. Hadar, Y. and Chen, Y. 1992. Utilization by tomatoes of iron mediated by siderophores produced by Rhyzopus arrhizus. J. Plant Nutr. 15:2173-2182.

4. Jurkevitch, E., Hadar, Y., Chen, Y., Chino, M. and Mori, S. 1993. Indirect utilization of the phytosiderophore mugineic acid as an iron source by rhizosphere fluorescent pseudomonads. BioMetals 6:119-123.

5. Chen, Y., Jurkevitch, E., Bar-Ness, E. and Hadar, Y. 1994.Stability constants of pseudobactin complexes with transition metals. Soil Sci. Soc. Am. J. 58:390396.

6. Jurkevitch, E., Hadar, Y., Chen, Y., Yakirevitch, P., Libman, J. and Shanzer, A. 1994. Iron uptake and molecular recognition in Pseudomonas putida: receptor mapping with ferrioxamine $B$, coprogen $B$ and their biomimetic analogs. Microbiology. 140:1697-1703.

7. Shenker, M., Ghirlando, R., Oliver, I., Helmann, M. Hadar, Y. and Chen, Y. 1995. Chemical structure and biological activity of a siderophoreproduced by Rhyzopus arrhizus. . Soil Sci. Soc. Am. J. ( in press) 


\section{Purification of and monoclonal antibodies production}

\section{Introduction}

Many agricultural crops worldwide, especially in semi-arid climates, suffer from Fe deficiency. Among plants sensitive to Fe deficiency are apples, avocado, bananas, barley, beans, citrus, cotton, grapes, oats, peanuts, pecans, potatoes, sorghum, soybeans, and numerous greenhouse flowers. Deficiency is usually recognized by chlorotic, or yellowed, intervein areas in new leaves and is typically found among sensitive crops grown in calcareous soils. Calcareous soils cover over $30 \%$ of the earth's land surface. Fe deficiency in extreme cases may lead to complete crop failure.

$\mathrm{Fe}$ acquisition is also an acute problem for microorganisms, which excrete siderophores (Fe chelating compounds) to acquire Fe. The rhizosphere organisms Pseudomonas putida strain B10 and Rhizopus arrhizus produce siderophores termed pseudobactin and raphorin, respectively. All fluorescent pseudomonads appear to produce siderophores structurally similar to, but not identical with, pseudobactin. The two compounds have been shown to be utilized by plants as an Fe source. Certain siderophores have been shown to play a role in biological control of plant disease and may make iron more available to higher plants. In particular, pseudobactin, the siderophore of plant growth promoting Pseudomonas putida strain B10, can reduce the incidence of take-all disease in barley and Fusarium wilt in flax. On the other hand, chrysobactin, the siderophore of the plant pathogen Erwinia chrysanthemi, is a virulence determinant. Thus specific siderophores may be either beneficial or detrimental to agriculture.

One of the major challenges to utilizing siderophores in agriculture is the lack of sensitive and specific assays for them in natural systems. There are no bioassays for pseudobactin or other siderophores produced by pseudomonads, and there have been no methods reported for quantitative extraction of siderophores from soil. Without methods for measuring siderophores we cannot determine such crucial factors as amount of siderophore produced, soil conditions affecting siderophore concentrations, effect of temperature on siderophore production, and variation in siderophore concentration along roots.

\section{Objectives}

The objectives of the U.S. research were

1. To perform localization studies on distribution of pseudobactin and raphorin in the rhizosphere using monoclonal antibodies.

2. To develop an assay for chrysobactin in infected plant tissues.

3. To develop improved purification and separation procedures for the siderophores.

III. Measurement of Pseudobactin in the Rhizosphere 


\section{A. Materials and Methods}

Barley plants were grown in Sassafrass soil limed to $\mathrm{pH} 7$ in a growth chamber at $22{ }^{\circ} \mathrm{C}$ using a 14 hour day/10 hour night cycle. In one series of experiments two week old plants were watered with the antibiotic resistant mutant $P$. putida Rif' $\mathrm{Nal}^{r}$ at $10^{7}, 10^{8}$, and $10^{\circ} \mathrm{cfu} /$ plant. After three days the plants were assayed as described below. In another series of experiments plants watered at $10^{\circ} \mathrm{cfu} / \mathrm{plant}$ were assayed at $3,8,15$, and 22 days. The final experiments involved coating the seeds with $P$. putida and planting in soil. After germination at $27^{\circ} \mathrm{C}$ the plants were grown at $22^{\circ} \mathrm{C}$ and assayed at $7,14,21$, and 28 days. All experiments were conducted in triplicate and included untreated (control) plants.

The plants were removed from the soil and tops cut off. The roots and adhering soil were cut into segments and mixed. In order to measure colonization approximately half of the sample was placed in a sterile Erlenmeyer flask and shaken with sterile nutrient solution at $4{ }^{\circ} \mathrm{C}$ for $15 \mathrm{~min}$. The slurry was diluted and spread on agar plates containing rifampicin, nalidixic acid, and cycloheximide. After 2 days at $30^{\circ} \mathrm{C}$ colonies were counted.

In order to assay for pseudobactin and ferric pseudobactin samples were extracted with liquefied phenol in Teflon centrifuge tubes. After centrifugation an aliquot of liquid phase was removed, frozen, and dried by sublimation under vacuum. The extract was suspended in buffer containing FeEDTA and ultrafiltered using a 3,000 molecular weight cut-off filter. The filtrate was assayed using a competitive enzyme-linked immunosorbent assay (ELISA). Ferric pseudobactin standards were added to extract from control plants in order to construct a standard curve.

\section{B. Results and discussion}

Phenol extraction of soil containing known amounts of siderophore gave $100 \%$ yield of pseudobactin and ferric pseudobactin. There were no interferences, apparently due to either denaturation of interfering substances or because they were insoluble in liquefied phenol.

Results of the various experiments are summarized in Tables 1,2, and 3. From Table 1, where all plants are the same age, it appears that siderophore concentration is proportional to the number of bacteria present. However, the age of the plant appears to be an important factor, as shown in Table 3 for seed-treated plants. Siderophore concentration increased from 1 to 3 weeks although the bacterial density was decreasing. This may be due to greater rhizosphere exudates in the older plants or it might be due to plant uptake of iron decreasing iron availability to the bacteria. We have also performed experiments on seed-treated plants in soil at $\mathrm{pH} 5,7$, and 8 .

These experiments have all been replicated and the samples stored at $-20^{\circ} \mathrm{C}$. However, they have not been analyzed because our ELISA has proven unreliable. After the results presented in this report were generated the ELISA stopped working altogether for two months, and since then has worked at greatly reduced sensitivity. We have tried changing every reagent and procedure but the ELISA is still not working satisfactorily. We will continue to work on this problem and, if it can be resolved, will 
acknowledge BARD's support in any resulting manuscripts.

\section{Purification and Separation of Pseudobactin}

\section{A. Materials and Methods}

Pseudobactin was prepared from culture of Pseudomonas B10 by centrifuging the cells and applying the supernatant to a column of XAD-16. The column was rinsed with water and the crude pseudobactin eluted with $50 \%$ methanol. After evaporation the pseudobactin was further purified by gel filtration on a G-15 column using a pyridineacetic acid buffer. The buffer was evaporated and the pseudobactin was finally purified by cation exchange chromatography on an LDC HPLC system with an ABI diode-array detector. A HEMA Bio-SB metal-free column $(250 \mathrm{~mm} \times 7.5 \mathrm{~mm})$ was used. The buffer system consisted of $1: 1$ pyridine-acetic acid, employing a step gradient from $0.038 \mathrm{M}$ to $0.2 \mathrm{M}$. Fractions were collected, evaporated, and evaluated by HPLC on the same system, ELISA, and capillary electrophoresis. Capillary electrophoresis was performed on a Beckman 2100 system.

\section{B. Results and Discussion}

Cation exchange HPLC of gel filtration purified pseudobactin revealed 4 peaks, as shown in Figure 1. Cation exchange HPLC had higher resolution and was far more reproducible than reverse phase HPLC (data not shown). In fact, this method was so reproducible we were able to automate our preparative HPLC with an autoinjector and fraction collector. This would have been impossible by previous methods.

Capillary electrophoresis of pseudobactin was performed using a borate buffer at $\mathrm{pH}$ 8. An electrophoreogram is shown in Figures 2. Each peak is well resolved and very sharp, indicating that capillary electrophoresis of siderophores may be a superior analytical method to HPLC. However, the method is no more sensitive than HPLC, and could not be used for analysis of rhizosphere samples. We then attempted to boost sensitivity by isotachophoretic pre-focusing (Fig. 3) and by isoelectric focusing (Fig. 4). While these are more sensitive than simple capillary electrophoresis they are still not sensitive enough to analyze rhizosphere samples. Laser-induced fluorescence detection would probably boost sensitivity ten or one hundred fold but is prohibitively expensive. We are continuing our work on capillary electrophoresis of siderophores and will acknowledge BARD's support when this work is published.

V. Monoclonal antibodies to raphorin and chrysobactin

\section{A. Materials and Methods}

Chrysobactin was synthesized by Marvin J. Miller at The University of Notre Dame. Chrysobactin, disuccinimidyl suberate, and the carrier protein (BSA or KLH) were combined. After 1 hour ultrafiltration was used to separate free chrysobactin and the conjugate was tested by ultraviolet spectrophotometry. Raphorin was obtained from 
Yona Chen. Raphorin, EDC, and carrier protein were reacted and ultrafiltered as described above. The conjugate was tested by capillary isoelectric focusing, capillary SDS gel electrophoresis, and free zone capillary electrophoresis, using the Beckman 2100 capillary electrophoresis system.

Chrysobactin was conjugated to BSA. The conjugate was detected by an increase in absorbance at 300-350 $\mathrm{nm}$. Raphorin was conjugated to BSA, but due to the low UV-visible absorbance of raphorin no attempt was made to measure conjugation spectrophotometrically. Instead, capillary electrophoresis was used in various modes. Isoelectric focusing was first attempted since we predicted that the isoelectric point of the protein would be lowered upon conjugation. Peaks were extremely broad, and the control containing BSA and EDC shifted relative to BSA alone, so this method was abandoned. SDS gel electrophoresis was tried next in order to detect an increase in molecular weight upon conjugation. The conjugate eluted at a lower apparent molecular weight, which we could explain only by the assumption that raphorin greatly altered the charge/mass ratio, making the protein more anionic. This was confirmed by capillary electrophoresis at $\mathrm{pH} 8$, where the conjugate was clearly more anionic than BSA or the BSA-EDC control. We conclude that raphorin was successfully conjugated to BSA.

Raphorin and chrysobactin BSA conjugates were injected into three mice after mixing with an adjuvant. After three injections at one month intervals one mouse was sacrificed and the spleen used in a fusion. There was a high incidence of fungal contamination so one month later the fusion was repeated with a second mouse. Hybridomas were screened by ELISA using KLH-raphorin and KLH-chrysobactin. Hybridoma cultures that tested positively were scaled up, retested, and cloned by limiting dilution. Clones were screened and positive clones were scaled up, retested, and stored in liquid nitrogen.

\section{B. Results and Discussion}

Preliminary screening of hybridomas indicated that antibodies were developed to both raphorin and chrysobactin. However, the antibodies to raphorin turned out to be nonspecific, and were probably all IgM antibodies that simply coated the ELISA plates we used. One antibody reactive to chrysobactin was characterized. It is an IgM which is useful in a competitive ELISA (Fig. 5). This ELISA may be useful for measuring chrysobactin production during infection of plants.

We are currently testing this antibody to determine if it can inhibit the growth of Erwinia chrysanthemi in vitro. If it is inhibitory it might be possible to clone the genes for the antibody into plants, thus inhibiting growth of the pathogen. A manuscript on this topic is in preparation at the present time and will include an acknowledgment of support by BARD.

\section{Chromatography of Raphorin}

Due to the difficulty in obtaining monoclonal antibodies to raphorin we attempted to develop novel chromatographic methods for measuring this compound. The lack of a 
chromophore, and the very weak color of the iron complex, render direct spectrophotometric detection almost useless. We therefore attempted two different methods for enhancing sensitivity.

Our first method involved HPLC with a novel post-column reaction scheme. Ferric raphorin was chromatographed on an anion-exchange column. The column eluate was mixed with pseudobactin before analysis on a fluorescence detector. Since pseudobactin is fluorescent and ferric pseudobactin is non-fluorescent we reasoned that ligand exchange with ferric raphorin should produce ferric pseudobactin which would give a negative peak in the fluorescence chromatogram. This method was unsuccessful due to baseline instability. Because we were continuously running the fluorescent compound, pseudobactin, through the detector, very slight changes in pumping rates produced large changes in the baseline. We added a pulse dampener to our system but that did not eliminate the problem. While the idea still seems sound we have no way to implement it with equipment currently available.

We then tried capillary electrophoresis of raphorin. Because raphorin is such a weak chromophore direct detection proved useless. We then tried indirect detection, in which raphorin displaced a strong chromophore from solution, producing a negative peak. We used phthalic acid for the strong chromophore. This method produced multiple artifacts including unreproducible peaks and wandering baselines. Indirect detection in this manner is generally considered difficult to accomplish because the mobilities of both the molecules of interest and the strong chromophore must be closely matched, which can be extremely difficult to do.

\section{New chromatographic material for pseudobactin}

A molecular imprinting technique was used to prepare a polymer containing specific binding sites to pseudobactin. Molecularly imprinted polymers rely on interactions between the molecule of interest and the monomer and cross-linker to produce binding sites upon polymerization. Pseudobactin, methacrylic acid, ethylene glycol dimethacrylate, and 2,2-azobis 2-methylpropionitrile were dissolved in dimethylsulfoxide and degassed. The solution was incubated at $60^{\circ} \mathrm{C}$ overnight under nitrogen. The polymeric solid was ground in a mortar and pestle and sieved. Pseudobactin was removed by washing with water. The polymer was packed in a chromatographic column.

The monomer and cross-linker used in this study have acid and alcohol functionalities on them which could interact with pseudobactin by ionic attraction to basic sites and by hydrogen bonding. When pseudobactin is loaded onto a column containing the ground and sieved polymer it is retained. Elution conditions are still being developed, but pseudobactin is bound, and elutes very slowly, when loaded in $\mathrm{H}_{2} \mathrm{O}, 1 \%$ acetic acid, $\mathrm{pH} 6.8$ buffer, or $\mathrm{pH} 7.5$ buffer. Figure 6 compares pseudobactin to the related siderophore pseudobactin 7SR1. It is clear that the column binds pseudobactin much more tightly than pseudobactin 7SR1.

This technique may be useful for concentrating pseudobactin from soil or rhizosphere extracts. Considerable development will be required to find generally useful chromatography conditions but preliminary results are very encouraging. This 
work is being carried out in collaboration with Wolfgang Hördt, a graduate student in Dr. Romheld's laboratory at the Inst. für Pflanzenernährung, Univ. Hohenheim, Stuttgart, Germany. When this work is published BARD's support will be acknowledged.

VIII. Papers resulting from this project

Buyer, J. S., Kratzke, M. G., and L. J. Sikora (1993) A method for detection of pseudobactin, the siderophore produced by a plant growth Pseudomonas, in the barley rhizosphere. Appl. Environ. Microbiol. 59:677-681.

Buyer, J. S., Kratzke, M. G., and L. J. Sikora (1994) Microbial siderophores and rhizosphere ecology. IN D. Crowley, D. Luster, and J. Manthey (eds), The biochemistry of metal micronutrients in the rhizosphere, Lewis Publishers, Chelsea, Michigan, pp. 6780 .

Lu, C., Buyer, J. S., Okonya, J., and M. J. Miller. Monoclonal antibodies to chrysobactin, a siderophore and virulence determinant in plant-pathogenic Erwinia chrysanthemi. manuscript in preparation. 
Table 1. Plants watered with $\underline{P}$. putida and assayed after three days.

\begin{tabular}{||l|l|l|l||}
\hline $\begin{array}{l}\text { Inoculum } \\
\text { cfu/plant }\end{array}$ & $\begin{array}{l}\text { Time (days after } \\
\text { inoculation) }\end{array}$ & $\begin{array}{l}\text { Colonization } \\
\text { log cfu/g dry wt. }\end{array}$ & $\begin{array}{l}\text { Siderophore } \\
\text { mol/g dry wt. }\end{array}$ \\
\hline $1 \times 10^{7}$ & 3 & 5.41 & $9.91 \times 10^{-12}$ \\
\hline $1 \times 10^{8}$ & 3 & 6.46 & $2.52 \times 10^{-11}$ \\
\hline $1 \times 10^{9}$ & 3 & 6.97 & $5.56 \times 10^{-10}$ \\
\hline
\end{tabular}

Table 2. Plants watered with $\mathrm{P}$. putida and assayed at intervals.

\begin{tabular}{||l|l|l|l||}
\hline $\begin{array}{l}\text { Inoculum } \\
\text { cfu/plant }\end{array}$ & $\begin{array}{l}\text { Time (days after } \\
\text { inoculation) }\end{array}$ & $\begin{array}{l}\text { Colonization } \\
\text { log cfu/g dry wt. }\end{array}$ & $\begin{array}{l}\text { Siderophore } \\
\text { mol/g dry wt. }\end{array}$ \\
\hline $1 \times 10^{9}$ & 3 & 6.91 & $6.45 \times 10^{-10}$ \\
\hline $1 \times 10^{9}$ & 8 & 6.57 & $6.11 \times 10^{-11}$ \\
\hline $1 \times 10^{9}$ & 15 & 5.09 & ND \\
\hline $1 \times 10^{9}$ & 22 & 5.17 & ND \\
\hline
\end{tabular}

ND: Not Determined yet. Samples are still being analyzed.

Table 3. Seeds inoculated with $P$. putida.

\begin{tabular}{||l|l|l|}
\hline $\begin{array}{l}\text { Time (days after } \\
\text { inoculation) }\end{array}$ & $\begin{array}{l}\text { Colonization } \\
\text { log cfu/g wet wt }\end{array}$ & $\begin{array}{l}\text { Siderophore } \\
\text { mol/g wet wt. }\end{array}$ \\
\hline 7 & 6.04 & none detectable \\
\hline 14 & 5.68 & $1.42 \times 10^{-12}$ \\
\hline 21 & 4.57 & $2.62 \times 10^{-11}$ \\
\hline 28 & 4.25 & $7.69 \times 10^{-12}$ \\
\hline
\end{tabular}


Fig. 2

NAMB CEAN LEV REP TYPB DIRECTORY

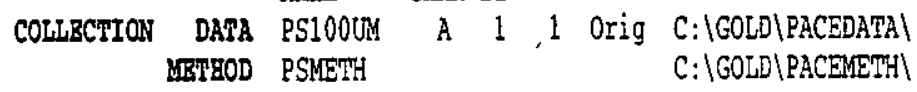

TIME DATE

INJECTION 08:08:48 25 JUN 1993

ANALYSIS 08:12:53 $25 \mathrm{JUN} 1993$

REPORT 07:35:40 $29 \mathrm{JUL} 1994$
SALPLB TABLB
PS
C: \GOLD\SAMPLTBL\
SYSTEM 1: SYSTEM1

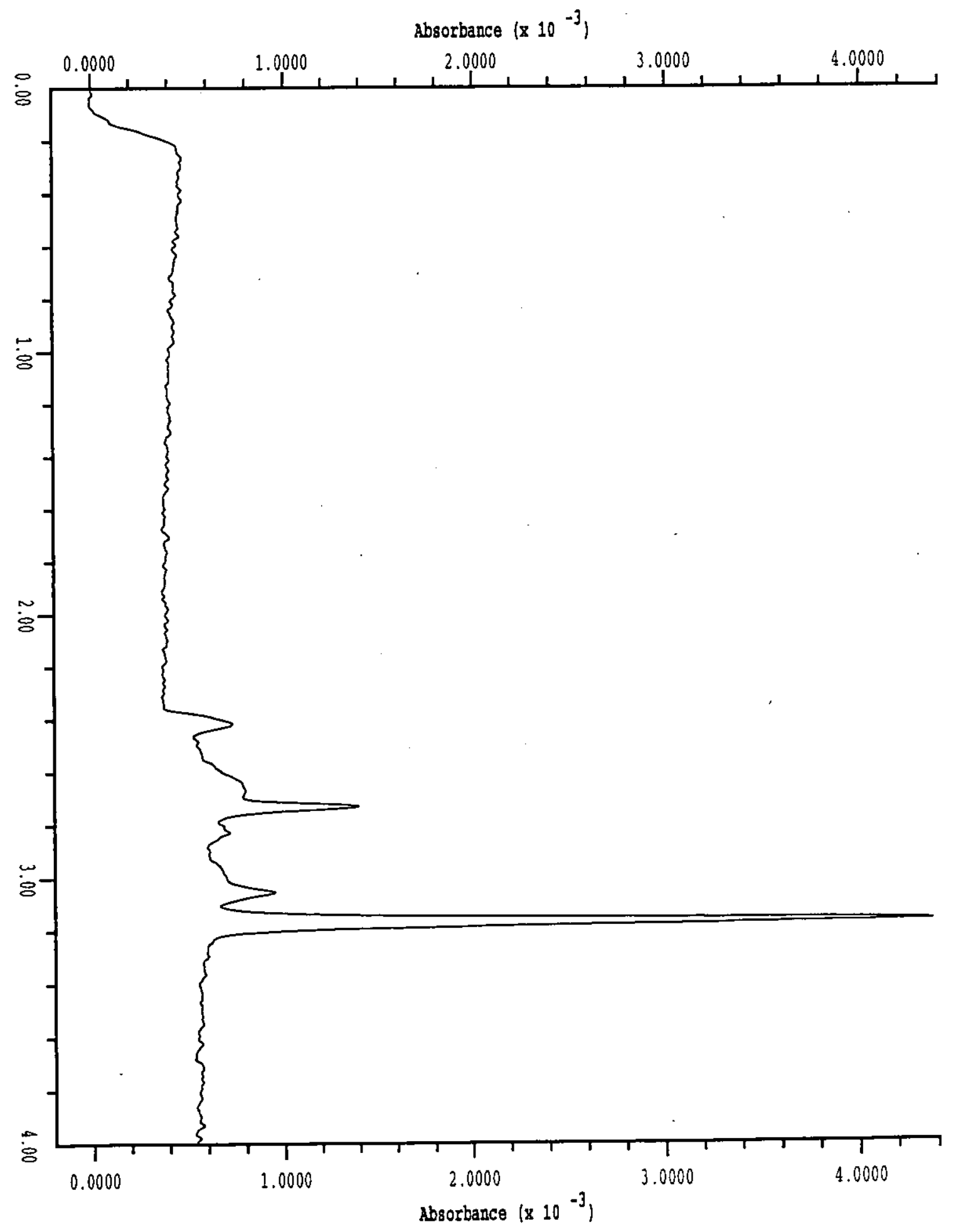


Fig. 1

Absorbance
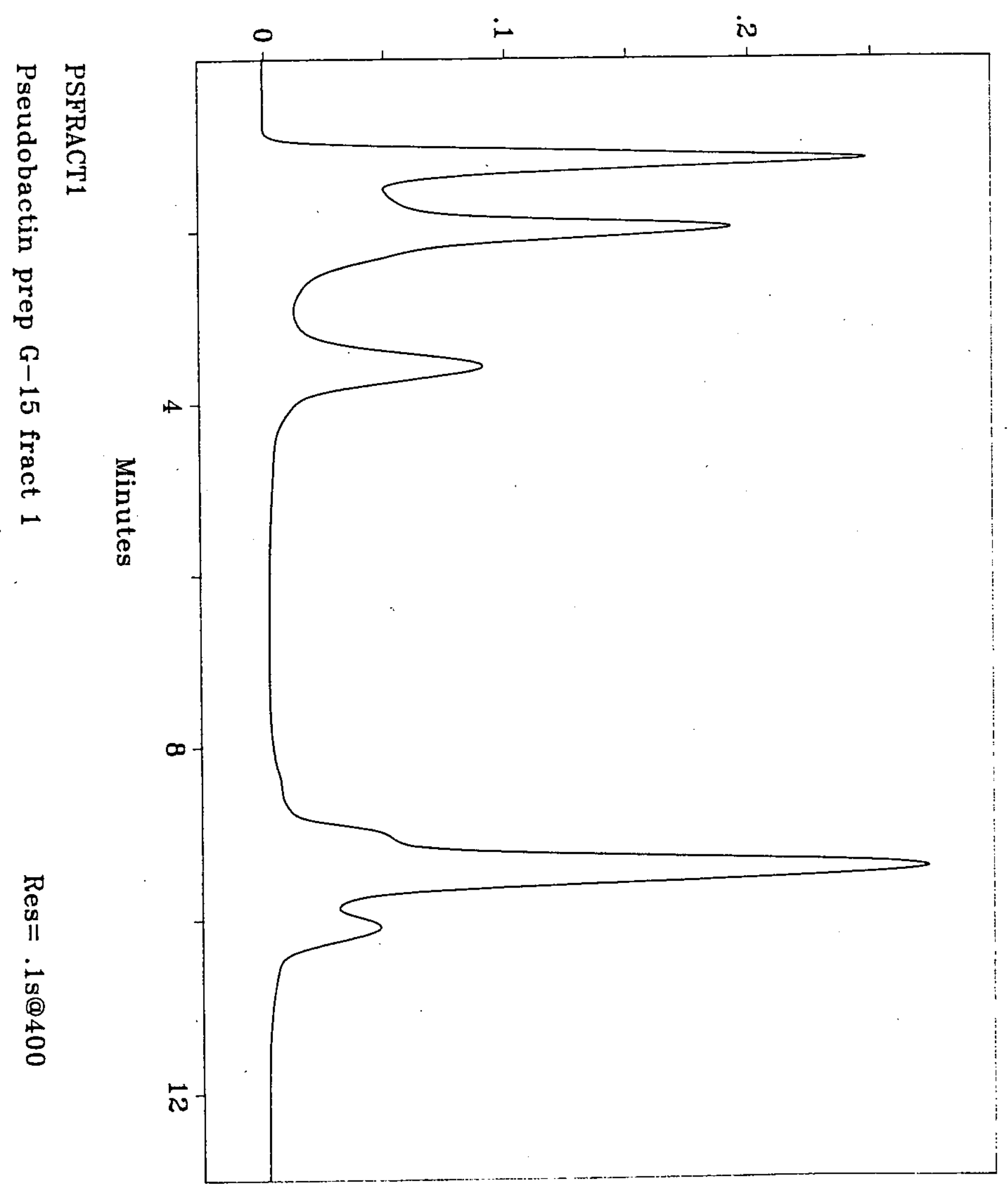
Fig. 4

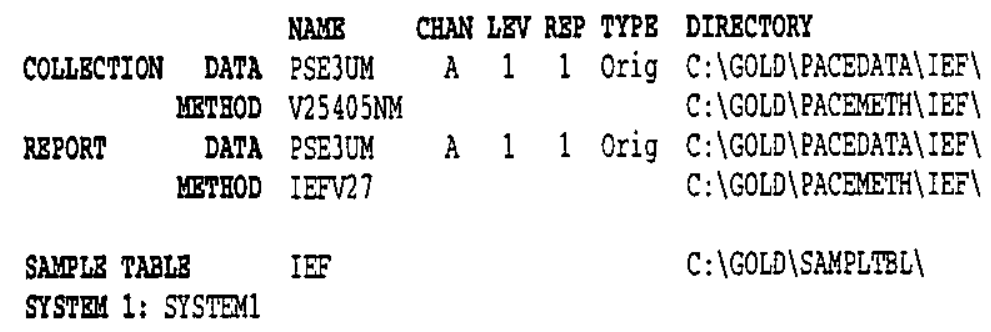

TIMR - DATB

INUBCTION 10:50:15 21 SEP 1993

ANALYSIS 11:00:18 21 SEP 1993

RBPORT 07:31:02 29 JUL 1994

SYSTEI 1: SYSTEM1

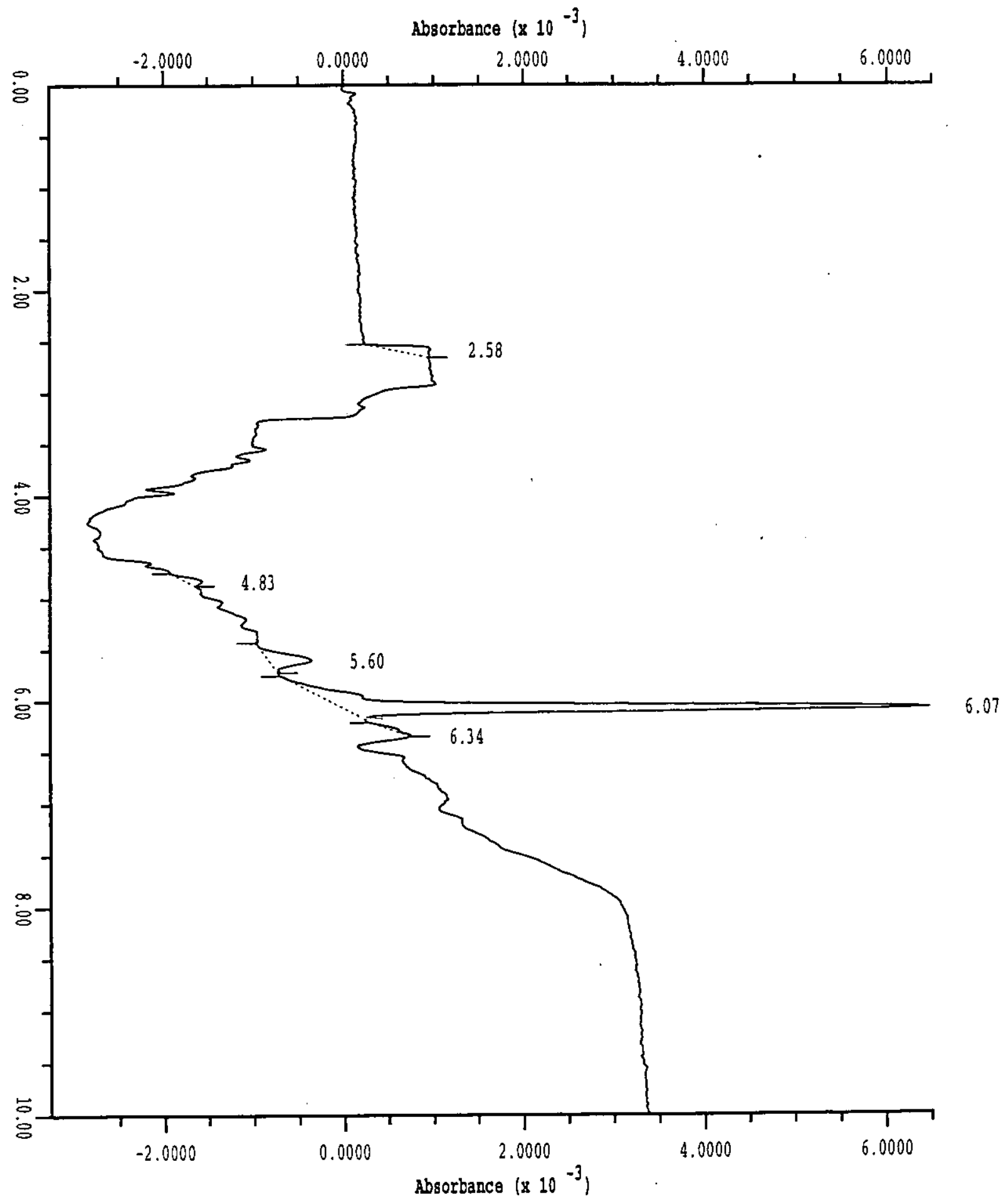


Fig. 5

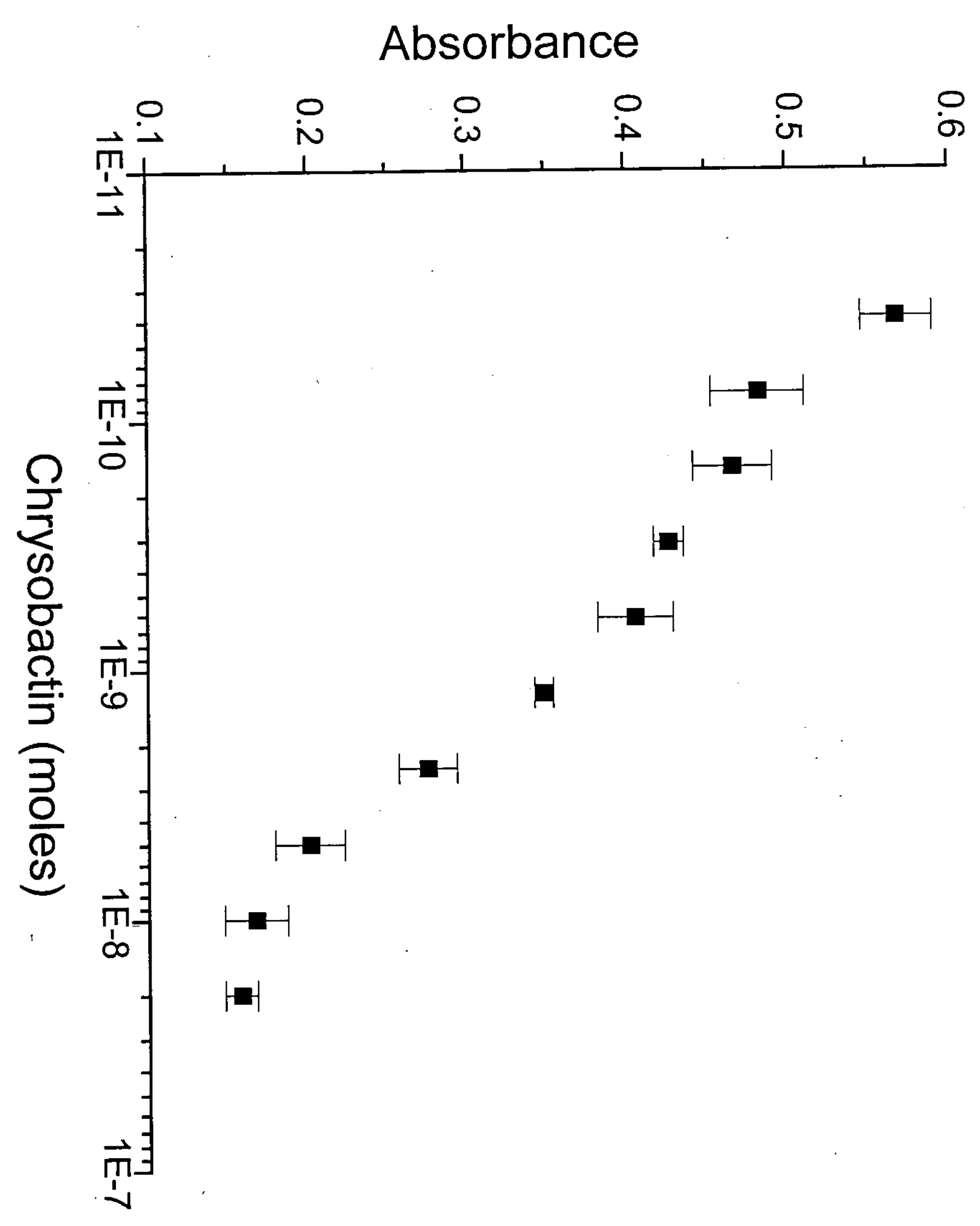


Fig. 6

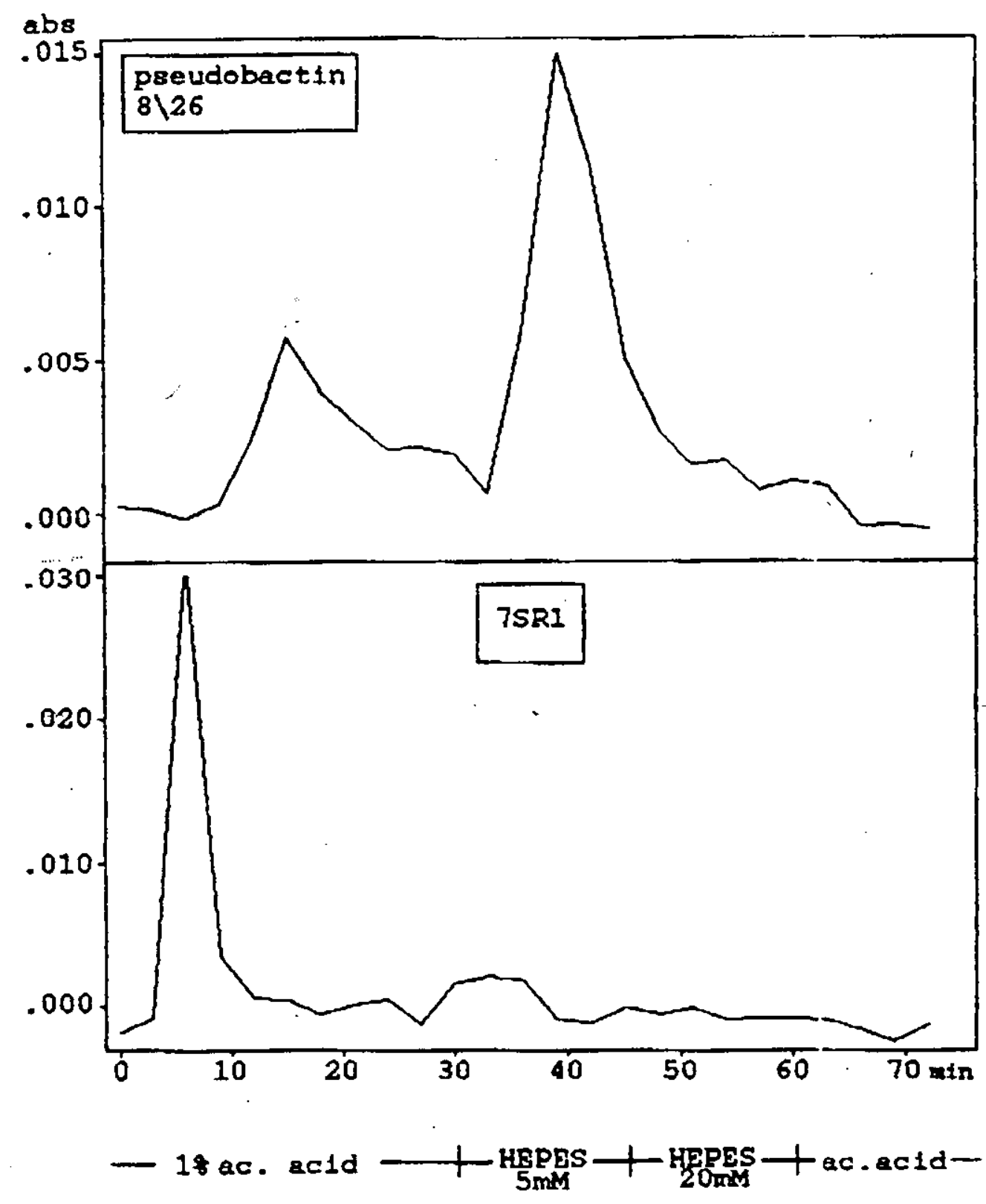




\section{Chemical structure and biological activity of \\ a siderophore produced by Rhizopus arrhizus}

Iron solubility in aerated neutral or basic soils is very low, and as such it often acts as a major growth-limiting factor for all kinds of organisms. As a result, various organisms have developed mechanisms of acquiring Fe from the environment. A mechanism common to many microorganisms is the secretion of low molecular weight ligands exhibiting very high affinity to ferric ions. These ligands, named siderophores, are capable of maintaining high soluble Fe concentrations. Utilization of Fe-siderophores by microorganisms is generally a receptor-dependent process (Matzanke, 1991; Jurkevitch et al., 1992), hence siderophores may serve as Fe sources or as Fe competitors for organisms, depending on the ability of the organisms to acquire Fe from the stable Fe-siderophore complex. Thus, siderophores may play an important role in the competition between microorganisms and may act as growth promoters or as antibiotic-like substances. Since the rhizosphere is heavily populated with siderophore-producing microorganisms, plants may also encounter similar interactions: Fe utilization can be promoted or inhibited. Some studies have indicated that plants do not utilize Fe from microbial siderophores (Becker et al., 1985; Bienfait, 1988), whereas others have found Fe-siderophores to act as Fe source for dicots and monocots (Cline et al., 1984; Crowley et al., 1991). However, relatively high concentrations, 15- to 50-fold higher than those of FeEDDHA, were reported to be necessary to meet plant demands: $19 \mathrm{mg} \mathrm{Fe} / \mathrm{Kg}$ soil as $\mathrm{Fe}$-pseudobactin and $45 \mathrm{mg} \mathrm{Fe} / \mathrm{Kg}$ soil as FOB were equivalent to $1.2 \mathrm{mg} \mathrm{Fe} / \mathrm{Kg}$ soil as FeEDDHA in calcareous soil (Jurkevitch et al., 1988) and $50 \mu \mathrm{M}$ Fe-pseudobactin was equivalent to $1 \mu \mathrm{M}$ FeEDDHA in nutrient culture at pH 6 (Bar-Ness et al., 1991).

Rhizopus arrhizus is a common soilborne fungus, and the ability of members of the genus Rhizopus to produce siderophores has been recently discovered. Helmann et al. (1990) reported on a new siderophore produced by $R$. arrhizus, while Drechsel et al. (1991) 
found siderophore production by R. microsporus. Helmann et al. (1990) stated that the $-=$ sidcrophore produced by $R$. arrhizus does not belong to the hydroxamate or catecholate sidcrophores, and Shenker et al., (1992) found the partially purified compound to be a very efficient Fe source for plants when compared to other microbial siderophores. Drechsel et al. (1991) identified the siderophore from $R$. microsporus by NMR and mass spectrometry to be $\mathrm{N}^{1}, \mathrm{~N}^{4}$-bis(1-oxo-3-hydroxy-3,4-dicarboxybutyl)- diaminobutane and named the compound rhizoferrin.

This study characterized the chemical structure of the siderophore from $R$. arrhizus and determined its specific impact on the growth and iron nutrition of $R$. arrhizus and tomato plants.

\section{MATERIALS AND METHODS}

Siderophore Characterization

Siderophore production and purification: For siderophore production, Rhizopus arrhizus (strain NRRL 1526) was incubated as described previously (Shenker et al., 1992) at $30^{\circ} \mathrm{C}$ in 5-L flasks containing $500 \mathrm{~mL}$ of modified $\mathrm{M}-9$ medium containing $(\mathrm{g} / \mathrm{L}): 10$ glucose; $7 \quad \mathrm{Na}_{2} \mathrm{HPO}_{4} ; 3 \quad \mathrm{KH}_{2} \mathrm{PO}_{4} ; 1 \quad \mathrm{NH}_{4} \mathrm{Cl} ; 0.5 \mathrm{NaCl} ; 0.25 \quad \mathrm{MgSO}_{4} \cdot 7 \mathrm{H}_{2} \mathrm{O} ; 0.015 \quad \mathrm{CaCl}_{2} \cdot 2 \mathrm{H}_{2} \mathrm{O}$; $0.015 \mathrm{ZnCl}_{2}$ and 0.005 thiamine ( $\mathrm{pH}$ 7.2). No iron was added to the medium. All reagents wcre of analytical grade. After an incubation period of 10 to 14 days, the spent medium was scparated by filtration, concentrated by freeze-drying and purified at $4^{\circ} \mathrm{C}$ by a sequence of thrce columns: coarse molecular sieving in a column of Sephadex G-25 eluted by $0.01 \mathrm{M}$ buffer phosphate ( $\mathrm{pH} 7$ ), anion exchange by $\mathrm{DE} 52$ (Whatman) eluted by gradient of 0.08-0.3 $\mathrm{M} \mathrm{NaCl}$ in $0.01 \mathrm{M}$ buffer phosphate ( $\mathrm{pH} 7$ ), and desalting on Sephadex G-10 by distilled 
water. Since the siderophore is colorless, its presence in the collected fractions was identified by both light absorbance (at $240 \mathrm{~nm}$ ) of its Cu complex and by Chrome Azurol S (CAS, Fluka, Switzerland) test (Schwyn and Neilands, 1987) and supported by a specific bioassay described in this work. The CAS test was also used as a means of quantifying the concentration of the siderophore, using EDTA (ethylenediaminetetraacetic acid, Sigma) as a reference. Siderophore-containing fractions were collected and lyophilized.

NMR spectroscopy: ${ }^{1} \mathrm{H}$ and ${ }^{13} \mathrm{C}-\mathrm{NMR}$ spectra were recorded on a Bruker AM 500 instrument. A sample of $R$. arrhizus siderophore $(2.5 \mathrm{mg})$ was lyophilized from a neutral aqueous solution and dissolved in $0.5 \mathrm{~mL}$ of $\mathrm{D}_{2} \mathrm{O}$. ${ }^{1} \mathrm{H}-\mathrm{NMR}$ spectra were obtained at $500.1 \mathrm{MHz}$ using a $30^{\circ}$ pulse, $0.5 \mathrm{~s}$ relaxation delay, $32 \mathrm{~K}$ data points, 1200 scans and a spectral width of 6024 Hz. The HOD signal was used as a reference with a chemical shift of $4.80 \mathrm{ppm}$. The ${ }^{13} \mathrm{C}-\mathrm{NMR}$ spectrum was recorded at $125.7 \mathrm{Mhz}$ using broad-band proton decoupling, a $20^{\circ}$ pulse, $1.5 \mathrm{~s}$ relaxation delay, $16 \mathrm{~K}$ data points, 43,000 scans and a spectral width of 29412 Hz. Chemical shifts are presented in parts per million (ppm) from the standard zero of tetramethylsilane. Single frequency off-resonance proton decoupled (SFORD) ${ }^{13} \mathrm{C}-\mathrm{NMR}$ spectra were obtained using 256 scans and a spectral width of $8771 \mathrm{~Hz}$. ${ }^{1} \mathrm{H}-{ }^{1} \mathrm{H}$ homocorrelated two-dimensional (COSY) and ${ }^{1} \mathrm{H}-{ }^{13} \mathrm{C}$ heterocorrelated spectra were obtained using standard pulse sequence based on the software provided by Bruker, with spectral widths of $1041 \mathrm{~Hz}$ and $8771 \mathrm{~Hz}$ for ${ }^{1} \mathrm{H}$ and ${ }^{13} \mathrm{C}$ domains, respectively. In both cases each dimension had $1 \mathrm{~K}$ data points.

Circular dichroism: Circular dichroism spectra were recorded on a Jasco J-500C spcctropolarimeter equipped with a DP-500N data processor. Studies were executed using a 
$0.1-\mathrm{cm}$ path length quartz cell, a sensitivity of $1 \mathrm{~m} / \mathrm{cm}$, a time constant of $4 \mathrm{~s}$ and a scan $-\cdots$ specd of $50 \mathrm{~nm} / \mathrm{min}$ covering the range from 400 to $200 \mathrm{~nm}$. The spectropolarimeter was calibrated with a solution of d-10-camphorsulphonic acid prior to use. The molar ellipticities $(\Delta \epsilon)$ were calculated using the following relationship:

$$
\Delta \epsilon=\theta / 33 D C
$$

where $C$ is the sample concentration in $\mathrm{mol} / \mathrm{L}, \mathrm{D}$ is the optical path length in $\mathrm{cm}$ and $\Theta$ is the observed ellipticity in degrees.

Analytical HPLC: Because of similarity between NMR and CD spectra of the siderophore from $R$. arrhizus to those described by Dreschel et al. (1991) and Dreschel et al. (1992) for rhizoferrin, our siderophore and rhizoferrin (kindly provided by Prof. Dr. Gunther Winkelmann, University of Tubingen, Germany) were co-analyzed by HPLC (HP 1090 Liquid Chromatograph, Hewlett Packard, Germany) on a Nucleosil $\mathrm{C}_{18}-\mathrm{AB}(5 \mu \mathrm{m})$ column $(250 \times 4$ $\mathrm{mm}$ ) with a precolumn $(11 \times 4 \mathrm{~mm})$ (Macherey-Nagel, Dueren, Germany) using a linear gradient of $0-8 \%$ acetonitrile in water containing $0.1 \%$ trifluoroacetic acid within $25 \mathrm{~min}$, flow rate of $0.8 \mathrm{~mL} / \mathrm{min}$ and detection wavelength of $225 . \mathrm{nm}$.

Mass spectrometry: To elucidate the resemblance of $R$. arrhizus siderophore to rhizoferrin, a sample of the former was send to Prof. Dr. G. Winkelmann for mass spectroscopy. Its ion spray mass spectrum was recorded on a Sciex API III triple-quadropole mass spectrometer with 2400-Da mass range equipped with an ion spray ion source (Sciex, Toronto, Canada), as described by Dreschel et al. (1991).

Based on the results obtained from the analytical techniques described above, we concluded 
that the siderophore produced by $R$. arrhizus was identical to rhizoferrin produced by $R .-\bar{m}$ microsporus.

Growth Stimulation of $R$. arrhizus by Siderophores

A dilution sequence of the tested solutions of rhizoferrin, citrate, pseudobactin (purified from the spent medium of Pseudomonas putida st 3 as described earlier by Jurkevitch et al., 1988), desferri-ferrichrome (isolated as described by Crowley et al., 1988), and desferrioxamine B (DFOB, Desferal, Ciba-Geigy, Switzerland) was performed in 96-well ELISA micro-titration plates. Each well contained $150 \mu \mathrm{L}$ of Fe-free modified M-9 medium containing the above composition, $100 \mathrm{ppm}$ chloramphenicol and a small inoculum of about eight $R$. arrhizus spores. Each plate contained eight replicates of 11 dilution steps of a given tested solution and eight replicates of blank containing the same constituents but without any tested solution. After incubation periods of 40 and $60 \mathrm{~h}$ at $30^{\circ} \mathrm{C}$, fungal development was measured according to its light absorption at $600 \mathrm{~nm}$ (MAXline Microplate Reader, Molecular Devices, Bohannon, CA) against absorption of its blank.

Siderophore Mediated Fe Utilization by Plants

Iron complexation by the siderophore: A solution containing rhizoferrin was shaken for $1 \mathrm{~h}$ with $2.5 \mathrm{mM} \mathrm{FeCl}_{3}$ in $10 \mathrm{mM} \mathrm{HCl}$ at $25^{\circ} \mathrm{C}$, rhizoferrin being in $10 \%$ excess over the $\mathrm{Fe}^{3+}$. The $\mathrm{pH}$ was raised to 7.2 using $10 \mathrm{mM}$ HEPES (N-[2-Hydroxyethyl]piperazine- $\mathrm{N}^{\prime}-[2-$ ethanesulfonic acid], Sigma) buffer solution. The solution was shaken for $24 \mathrm{~h}$ at $25^{\circ} \mathrm{C}$ and centrifuged for $2 \mathrm{~h}$ at $106,000 \mathrm{~g}$ in order to remove Fe-hydroxide.

Preparation of labeled ${ }^{55}$ Fe-chelates: A solution containing unferrated rhizoferrin or EDDHA 
(ethylenediamine di(o-hydroxyphenylacetic acid, Sigma) was stirred for $20 \mathrm{~h}$ with a trace amount of ${ }^{55} \mathrm{FeCl}_{3}(1.1 \mathrm{MBq})$ and with $\mathrm{Fe}\left(\mathrm{NO}_{3}\right)_{3}$ at $25^{\circ} \mathrm{C}$ (yielding specific activity of 23 . $\mathrm{MBq} / \mathrm{mmol} \mathrm{Fe}$ ). The chelate was in a $10 \%$ excess over the Fe. The $\mathrm{pH}$ was maintained at 6.2 using $20 \mathrm{mM}$ MES (2-[N-Morpholino]ethane-sulfonic acid, Sigma) buffer. The solution was filtercd through a $0.2 \mu \mathrm{m}$ filter (Schleicher \& Schuell) to exclude Fe-hydroxide precipitates before being applied to the plants.

Growth of plants: Seeds of tomato (Lycopersicon esculentum Mill, cv. M-82-1-8) were germinated on filter paper presoaked in a saturated $\mathrm{CaSO}_{4}$ solution. Five-day-old seedlings were transferred to an aerated nutrient solution of the following composition $(\mathrm{M}): 7 \times 10^{-4}$ $\mathrm{K}_{2} \mathrm{SO}_{4}, \quad 10^{-4} \mathrm{KCl}, 2 \times 10^{-3} \mathrm{Ca}\left(\mathrm{NO}_{3}\right)_{2}, \quad 5 \times 10^{-4} \mathrm{MgSO}_{4}, \quad 10^{-4} \mathrm{KH}_{2} \mathrm{PO}_{4}, \quad 10^{-5} \mathrm{H}_{3} \mathrm{BO}_{3}, \quad 5 \times 10^{-7}$ $\mathrm{MnSO}_{4}, 5 \times 10^{-7} \mathrm{ZnSO}_{4}, 2 \times 10^{-7} \mathrm{CuSO}_{4}$, and $10^{-8} \quad\left(\mathrm{NH}_{4}\right)_{6} \mathrm{Mo}_{7} \mathrm{O}_{24}$.

Iron was supplied to the nutrient solution as $5 \mu \mathrm{M}$ FeEDDHA (Sequestrene $138 \mathrm{Fe}$, Ciba-Geigy) during the early stages of seedling growth (10 to 14 days). In this early stage containers of $5 \mathrm{~L}$ were used for each dozen of seedlings. Plants were then transferred separately to $0.5 \mathrm{~L}$ pots and the following pretreatments were applied for an additional 7 days in $\mathrm{CaCO}_{3}$-buffered solutions ( $\mathrm{pH}$ 7.3) to induce Fe-deficient, Fe-stressed and Fe-sufficient plants, respectively: (i) Fe was excluded from the nutrient solution; (ii) Fe was supplied as $1 \mu \mathrm{M}$ FeEDDHA; and (iii) Fe was supplied as $5 \mu \mathrm{M}$ FeEDDHA. Growth chamber climate conditions were: day/night period, $16 / 8 \mathrm{~h}$; day/night temperature, $28 / 25 \pm 1.5^{\circ} \mathrm{C}$; light intensity, $26 \mathrm{~W} / \mathrm{m}^{2}$ (fluorescent tubes, Osram L 40W/20 S, cool white $3000 \mathrm{~lm}$ ). 
Correction of Fe deficiency ( 2 weeks of growth): Fe-stressed plants prepared as described above were transferred to fresh solutions containing the following Fe treatments: (I) $5 \mu \mathrm{M}$ FeEDDHA; (II) $5 \mu \mathrm{M}$ Fe-rhizoferrin; (III) $10 \mu \mathrm{M}$ Fe-rhizoferrin; and (IV) control without $\mathrm{Fe}(-\mathrm{Fe})$. Concentrated nutrient solution (10 fold) without $\mathrm{Fe}$ was added periodically to maintain fixed electrical conductivity of the nutrient solutions to help maintain uniform nutritional status throughout the 14 days. Acidity was buffered to $\mathrm{pH} 7.3$ by $\mathrm{CaCO}_{3}$.

Leaf chlorophyll concentration was measured periodically in the youngest fully-expanded leaves using a SPAD-502 chlorophyll meter (Minolta Camera Co., Osaka, Japan). These measurements were performed every 2 to 3 days. Transformation of SPAD readings to chlorophyll content was performed as described previously (Chen et al., 1991; Shenker et al., 1992).

At the end of the experiment, root system length and root and shoot fresh weights were recorded.

Short-term uptake experiment ( $10 \mathrm{~h}$ of growth): Precultured Fe-deficient or Fe-sufficient plants, prepared as described above, were transferred to $180 \mathrm{~mL}$ of aerated nutrient solution containing 5, 10 or $15 \mu \mathrm{M}{ }^{55} \mathrm{Fe}$-rhizoferrin or $5 \mu \mathrm{M}{ }^{55} \mathrm{Fe}$-EDDHA buffered with $5 \mathrm{mM}$ MES at $\mathrm{pH}$ 6.2. After $10 \mathrm{~h}$, the plants were transferred for $10 \mathrm{~min}$ to $180 \mathrm{~mL}$ of $1.5 \mathrm{mM}$ 2,2'-dipyridyl (Sigma) in saturated $\mathrm{CaSO}_{4} \cdot \quad \mathrm{Na}_{2} \mathrm{~S}_{2} \mathrm{O}_{4}(0.5 \mathrm{~g})$ was added and $\mathrm{N}_{2}$ was bubbled to remove free-space Fe from the roots. Shoots and roots were separated, oven-dried at $65^{\circ} \mathrm{C}$, weighed and ashed at $500^{\circ} \mathrm{C}$. The ash was dissolved in $\mathrm{HCl} 0.27 \mathrm{M}$, and the concentration of ${ }^{55} \mathrm{Fe}$ was measured by liquid scintillation. 


\section{RESULTS AND DISCUSSION}

Partially purified siderophore from $R$. arrhizus was found earlier to be an extremely efficient Fe source for plants when compared to other microbial siderophores (Shenker et al., 1992). Therefore, an effort was done to purify the siderophore and to study its chemical structure and its biological activity. Our production and purification method yielded 50-100 $\mathrm{mg}$ of pure siderophore, as a tetrasodium salt, per liter of culture. The pure siderophore appeared as a white fluffy compound completely soluble in water.

\section{Siderophore Characterization}

The ${ }^{1} \mathrm{H}$-NMR spectrum at $500.1 \mathrm{MHz}$ of the purified siderophore in $\mathrm{D}_{2} \mathrm{O}$ showed three sets of resonances at $1.48 \mathrm{ppm}, 2.4$ to $2.7 \mathrm{ppm}$ and $3.16 \mathrm{ppm}$ (Fig. 1-A) with a relative integration of $1: 2: 1$, respectively. The set of resonances between 2.4 and 2.8 ppm collapses to a set of two well defined doublet of doublets upon acidification of the sample (Fig. 1-B). In both cases the pattern is characteristic of an $\mathrm{AA}^{\prime} \mathrm{BB}^{\prime}$ spin system, such as a $\mathrm{CH}_{2}-\mathrm{X}-\mathrm{CH}_{2}$ moiety in which the protons on each methylene group are diastereotopic. The resonances which appear at 1.48 and $3.16 \mathrm{ppm}$ are broad multiplets, and the broadening is probably due to the quadrupole moment of an adjacent nitrogen nucleus. The simplicity of the ${ }^{1} \mathrm{H}-\mathrm{NMR}$ spectrum is suggestive of a compound having high symmetry, and the relative integration of the set of four peaks supports the presence of four methylene groups. The COSY spectrum (data not shown) further demonstrated a connectivity between the resonances at 1.48 and 3.16 ppm, data consistent with the presence of a $\mathrm{CH}_{2}-\mathrm{CH}_{2}$ group. Based on the data presented, the compound is proposed to contain $\mathrm{CH}_{2}-\mathrm{X}-\mathrm{CH}_{2}$ and $\mathrm{CH}_{2}-\mathrm{CH}_{2}-\mathrm{N}$ structural moieties. The ${ }^{13} \mathrm{C}$ NMR spectrum (Fig. 2) shows eight resonances. The three resonances at $172.47,178.47$ and 
$180.21 \mathrm{ppm}$ indicate the presence of three distinct carboxylate or amidic carbonyl functionalities. SFORD experiments (data not shown) showed the presence of four methylene carbon atoms at $25.70,38.92,44.48$ and $45.20 \mathrm{ppm}$, in agreement with the ${ }^{1} \mathrm{H}$-NMR data. Further, the SFORD experiments demonstrate that the resonance at $74.94 \mathrm{ppm}$ arises from a quaternary carbon atom bearing no ${ }^{1} \mathrm{H}$ substituents. The ${ }^{1} \mathrm{H}-{ }^{13} \mathrm{C}$ correlated spectrum (data not shown) linked the two outer doublets of the ${ }^{1} \mathrm{H}$ resonances between 2.5 and $2.8 \mathrm{ppm}$ to the ${ }^{13} \mathrm{C}$ resonance at $45.20 \mathrm{ppm}$, and the set of two inner doublets correspond to the carbon atom at $44.48 \mathrm{ppm}$. Similarly, the multiplets at 1.48 and $3.16 \mathrm{ppm}$ correspond to the carbon resonances at 25.70 and $38.92 \mathrm{ppm}$, respectively. The ${ }^{13} \mathrm{C}-\mathrm{NMR}$ spectrum is thus consistent with the proposed $\mathrm{CH}_{2}-\mathrm{X}-\mathrm{CH}_{2}$ and $\mathrm{CH}_{2}-\mathrm{CH}_{2}-\mathrm{N}$ moieties. Furthermore, the group $\mathrm{X}$ is proposed to be the quaternary carbon atom bearing four different substituents.

The ${ }^{1} \mathrm{H}-\mathrm{NMR}$ chemical shift data is consistent with the presence of a $\mathrm{CO}-\mathrm{CH}_{2}-\mathrm{C}-\mathrm{CH}_{2}-\mathrm{CO}$ group, accounting for two of the carbonyl groups observed by ${ }^{13} \mathrm{C}-\mathrm{NMR}$. Addition of trifluoroacetic acid to the sample, leading to an uncorrected $\mathrm{pD}$ of 1.0 , led to dramatic changes in the 'H-NMR spectrum, as noted in Figure 1-B. The peaks characterizing the $\mathrm{CO}-\mathrm{CH}_{2}-\mathrm{C}-\mathrm{CH}_{2}-\mathrm{CO}$ group shift downfield and simplify to a doublet of doublets. The pattern of resonances in the spectrum is reminiscent of the spectrum reported previously for rhizoferrin (Drechsel et al., 1991). The complete NMR data is consistent with the structure shown in Fig. 3, and it would appear that the siderophore from $R$. arrhizus is chemically identical to rhizoferrin. Indeed, both HPLC and mass spectral measurements for the two siderophores point to their chemical identity: retention time of $15.1 \mathrm{~min}$. for both siderophores by the described HPLC method, and mass spectrum identical to the mass spectrum reported for rhizoferrin (Fig. 5-B in Drechsel et al., 1991). Table 1 summarizes the NMR data and peak assignments based on the combination of the 1-D and 2-D spectra measured. It is 
interesting to point out that the ${ }^{1} \mathrm{H}-\mathrm{NMR}$ spectrum shows a $\mathrm{pH}$ dependence, possibly $-=$ reflecting the ionization of the carboxylic acid groups. A similar dependence has been reported for staphyloferrin A, a siderophore with a similar structure (Konetschny-Rapp et al., 1990).

The electronic absorption spectra as well as the circular dichroism spectra of thizoferrin and the ferric complex obtained in this study are similar to those reported previously for rhizoferrin (Dreschel et al., 1992). These spectra indicates that the siderophore from $R$. arrhizus is not only chemically identical to rhizoferrin but it has the same R,R configuration and it complex $\mathrm{Fe}^{3+}$ in a similar chiral manner (i.e. $\Lambda$ complex).

Growth Stimulation of $R$. arrhizus by Siderophores

Cultures treated with rhizoferrin exhibited a pronounced growth promotion effect during the first 40-60 h after incubation, when the rhizoferrin was applied to a small inoculum of $R$. arrhizus in a medium with no added Fe (Fig. 4). The stimulatory effect was diminished at higher inoculum levels and longer incubation periods (5-8 days) (data not shown), probably due to in situ production of rhizoferrin. Growth stimulation by rhizoferrin may be explained by mobilization of the minute amounts of Fe present as contaminants in the chemicals and glassware. Other Fe-binding compounds had little effect during the first $40 \mathrm{~h}$. Citrate and DFOB promoted fungal growth, but only at concentrations 10 times higher than that of rhizoferrin (data not shown). Drechsel et al. (1991) found DFOB to be almost as efficient as rhizoferrin as an Fe-transport agent for R. microsporus, and they concluded that a common transport system for ferrioxamines and rhizoferrin exists due to the resemblance in the diamine portion of the molecule. In contrast, pseudobactin and ferrichrome did not 
promote fungal growth in the first $40 \mathrm{~h}$, suggesting that $R$. arrhizus does not have a specific $-\overline{\text {. }}$ receptor for these siderophores. However, after an additional $20 \mathrm{~h}$ (total of $60 \mathrm{~h}$, Fig. 4) there was a dramatic change: Pseudobactin and ferrichrome exhibited a pronounced promotion effect on $R$. arrhizus growth, that equaled or exceeded, respectively, that of rhizoferrin, at equivalently low concentrations. This could be a result of ligand exchange after de novo synthesis of rhizoferrin by the newly developed fungus. The elapsed time for de novo synthesis of rhizoferrin indicates it to be a secondary, rather then primary product of the fungus. The specific early $(40 \mathrm{~h})$ response of $R$. arrhizus to rhizoferrin under the described method in the concentration range of $10^{-6}$ to $10^{-5} \mathrm{M}$ was used as a bioassay for detection of rhizoferrin.

Siderophore Mediated Fe Utilization by Plants

Correction of Fe deficiency: Purified Fe-rhizoferrin at a concentration of $5 \mu \mathrm{M}$ was found to alleviate Fe deficiency as effectively as $5 \mu \mathrm{M}$ FeEDDHA when applied to Fe-stressed tomato plants in solutions buffered to $\mathrm{pH} 7.3$ with $\mathrm{CaCO}_{3}$ (Fig. 5). When applied at $10 \mu \mathrm{M}$, Fe-rhizoferrin was slightly more effective. Control plants grown without $\mathrm{Fe}(-\mathrm{Fe})$ became highly chlorotic within 6 days. Shoot weight at the end of the experiment gave similar results: Fe-rhizoferrin at concentrations of $5 \mu \mathrm{M}$ or $10 \mu \mathrm{M}$ was as effective as $5 \mu \mathrm{M}$ FeEDDHA in supporting normal growth in nutrient solutions. Whereas shoots seemed to be similar among these Fe treatments, the root systems of the Fe-rhizoferrin treated plants were heavier than that of the FeEDDHA plants and the -Fe plants. On the other hand, the root systems appeared more condensed in the rhizoferrin and -Fe treatments as compared to the FeEDDHA treated plants. This is demonstrated by the root fresh weight to root length ratio (Table 2). The described morphological effect of rhizoferrin and its significance should be further studied. 
Short-term uptake experiment: Uptake levels of ${ }^{s s} \mathrm{Fe}$ by Fe-sufficient or Fe-deficient tomato plants from nutrient solutions containing 5, 10 or $15 \mu \mathrm{M}{ }^{55} \mathrm{Fe}$-rhizoferrin at $\mathrm{pH} 6.2$ were higher than those from solutions containing ${ }^{55}$ FeEDDHA (Table 3). Iron translocation (calculated as total shoot Fe per gram root dry weight) to the shoots of Fe-deficient plants was higher from ${ }^{55} \mathrm{Fe}$-rhizoferrin as compared to ${ }^{55} \mathrm{FeEDDHA}$. The translocation data are in agreement with the positive long-term response to Fe-rhizoferrin and we, therefore, concluded that Fe-rhizoferrin is an efficient $\mathrm{Fe}$ source for tomato plants. Translocation rates from Fe-rhizoferrin were significantly higher than those reported for other microbial siderophores (Crowley et al., 1992; Bar-Ness et al., 1992a; Bar-Ness et al., 1992b).

\section{CONCLUSIONS}

A siderophore produced by the fungus $R$. arrhizus under Fe deficiency acts as a specific growth stimulant for the fungus in the early stages of incubation when grown from a small inoculum under $\mathrm{Fe}$ stress. This effect is much more pronounced than that of other siderophores and could be used as a bioassay for the detection of the siderophore.

The siderophore produced by $R$. arrhizus, which was reported earlier by our group (Helmann et al., 1990), was found to be chemically identical to rhizoferrin, a siderophore produced by $R$. microsporus (Drechsel et al., 1991). NMR and circular dichroism data, supported by HPLC and mass spectrometry confirmed its identity as rhizoferrin.

Rhizoferrin has an outstanding capacity to act as a Fe carrier for tomato plants grown in nutrient solution. Its high efficiency as a Fe mediator for plants as compared to other microbial siderophores, and the high abundance of its producer in the rhizosphere, may suggest an important role for rhizoferrin in the Fe supply to higher plants in nature. 


\section{REFERENCES}

Bar-Ness, E., Y. Chen, Y. Hadar, H. Marschner and V. Romheld. 1991. Siderophores of Pseudomonas putida as an iron source for dicot and monocot plants. pp. 271-281. In: Y. Chen and X. Hadar (eds.), Iron Nutrition and Interactions in Plants. Kluwer Academic - Publishers, London.

Bar-Ness, E., Y. Hadar, Y. Chen, A. Shanzer and J. Libman. 1992a. Iron uptake by plants from microbial siderophores. Plant Physiol. 99:1329-1335.

Bar-Ness, E., Y. Hadar, Y. Chen, V. Romheld and H. Marschner. 1992b. Short-term effect of rhizosphere microorganisms on Fe uptake from microbial siderophores by maize and oat. Plant Physiol. 100:451-456.

Becker, J.O., R.W. Hedges and E. Messens. 1985. Inhibitory effect of pseudobactin on the uptake of iron by higher plants. App. Environ. Microbiol. 49:1090-1093.

Bienfait, H.F. 1988. Mechanisms in Fe-efficiency reactions of higher plants. J. Plant Nutr. $11: 605-629$.

Chen, Y., R.L. Chaney and P. Bell. 1991. Determination of $\mathrm{Fe}^{2+}$ requirements of plants using ferrozine-buffered nutrient solution. Abstract presented at the VI International Iron Symposium, July 14-19, 1991. Utah State University, Logan, Utah, U.S.A.

Cline, G.R., C.P.P. Reid and P.J. Szanizlo. 1984. Effects of a hydroxamate siderophore on iron absorption by sunflower and sorghum. Plant Physiol. 76: 36-39.

Crowley, D.E., C.P.P. Reid and P.J. Szanizlo. 1988. Utilization of microbial siderophores in iron acquisition by oat. Plant Physiol. 87:680-685.

Crowley, D.E., V. Romheld, H. Marschner and P.J. Szanizlo. 1992. Root-microbial effects on plant iron uptake from siderophores and phytosiderophores. Plant and Soil 142:1-7. 
Crowley, D.E., Y.C. Wang, C.P.P. Reid and P.J. Szanizlo. 1991. Mechanisms of iron acquisition from siderophores by microorganisms and plants. pp. 213-232. In: Y. Chen and Y. Hadar (eds.), Iron Nutrition and Interactions in Plants. Kluwer Academic Publishers, London.

Drechsel, H., G. Jung and G. Winkelmann. 1992. Stereochemical characterization of rhizoferrin and identification of its dehydration products. BioMetals 5:141-148.

Drechsel, H., J. Metzger, S. Freund, G. Jung, J.R. Boelaert and G. Winkelmann. 1991. Rhizoferrin - a novel siderophore from the fungus Rhizopus microsporus var. rhizopodiformis. Biol. Metals 4:238-243.

Helmann, M., T. Sery, Y. Chen, E. Bar-Ness, S. Gilan and Y. Hadar. 1990. A novel siderophore from Rhizopus arrhizus and the utilization of its iron complex by plants. Abstract presented at the International Symposium on Iron Transport, Storage and Metabolism II. July 20-22, 1990. The University of Texas, Austin, TX, U.S.A.

Jurkevitch, E., Y. Hadar and Y. Chen. 1988. Involvement of bacterial siderophores in the remedy of lime-induced chlorosis in peanut. Soil Sci. Soc. Am. J. 52:1032-1037.

Jurkevitch, E., Y. Hadar, Y. Chen, J. Libman and A. Shanzer. 1992. Iron uptake and molecular recognition in Pseudomonas putida: receptor mapping with ferrichrome and its biomimetic analogs. J. Bacteriol. 174:78-83.

Konetschny-Rapp, S., G. Jung, J. Meiwes and H. Zahner. 1990. Staphyloferrin A: a structurally new siderophore from staphylococci. Eur. J. Biochem. 191:65-74.

Matzanke, B.F. 1991. Structure, coordination chemistry and functions of microbial iron chelates. pp. 15-64. In: G. Winkelmann (ed.), CRC Handbook of Microbial Iron Chelates. CRC Press, London. 
Schwyn, B. and J.B. Neilands. 1987. Universal chemical assay for the detection and determination of siderophores. Anal. Biochem. 160:47-56.

Shenker, M., I. Oliver, M. Helmann, Y. Hadar and Y. Chen. 1992. Utilization by tomatoes of iron mediated by a siderophore produced by Rhizopus arrhizus. J. Plant Nut. $15: 2173-2182$. 


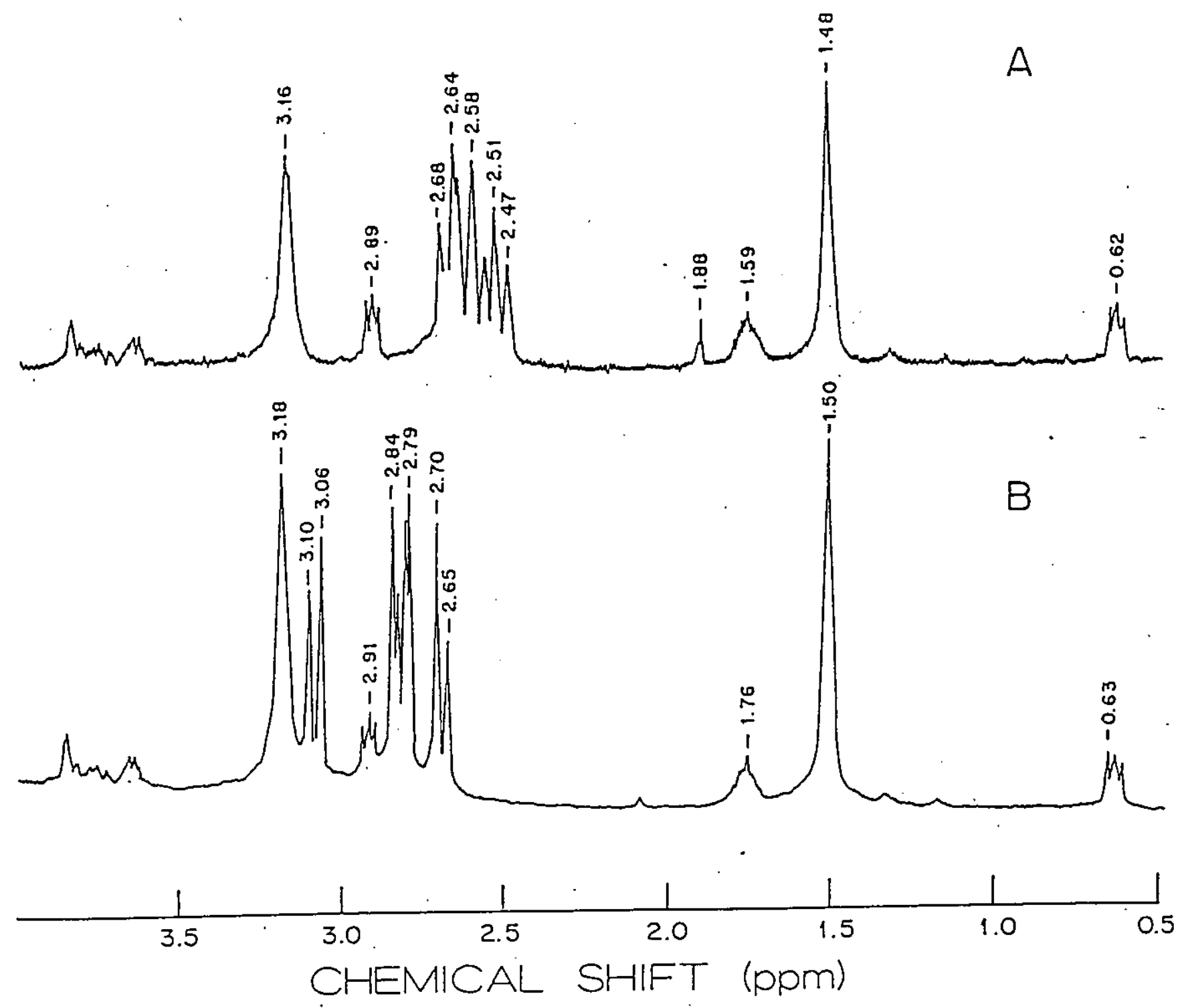

Fig. 1. ${ }^{1} \mathrm{H}$ NMR spectrum of a siderophore (rhizoferrin) produced by $R$. arrhizus in $\mathrm{D}_{2} \mathrm{O}$ (A) and in trifluoroacetic acid $+\mathrm{D}_{2} \mathrm{O}(\mathrm{pD}$ of 1.0$)(\mathrm{B})$. 


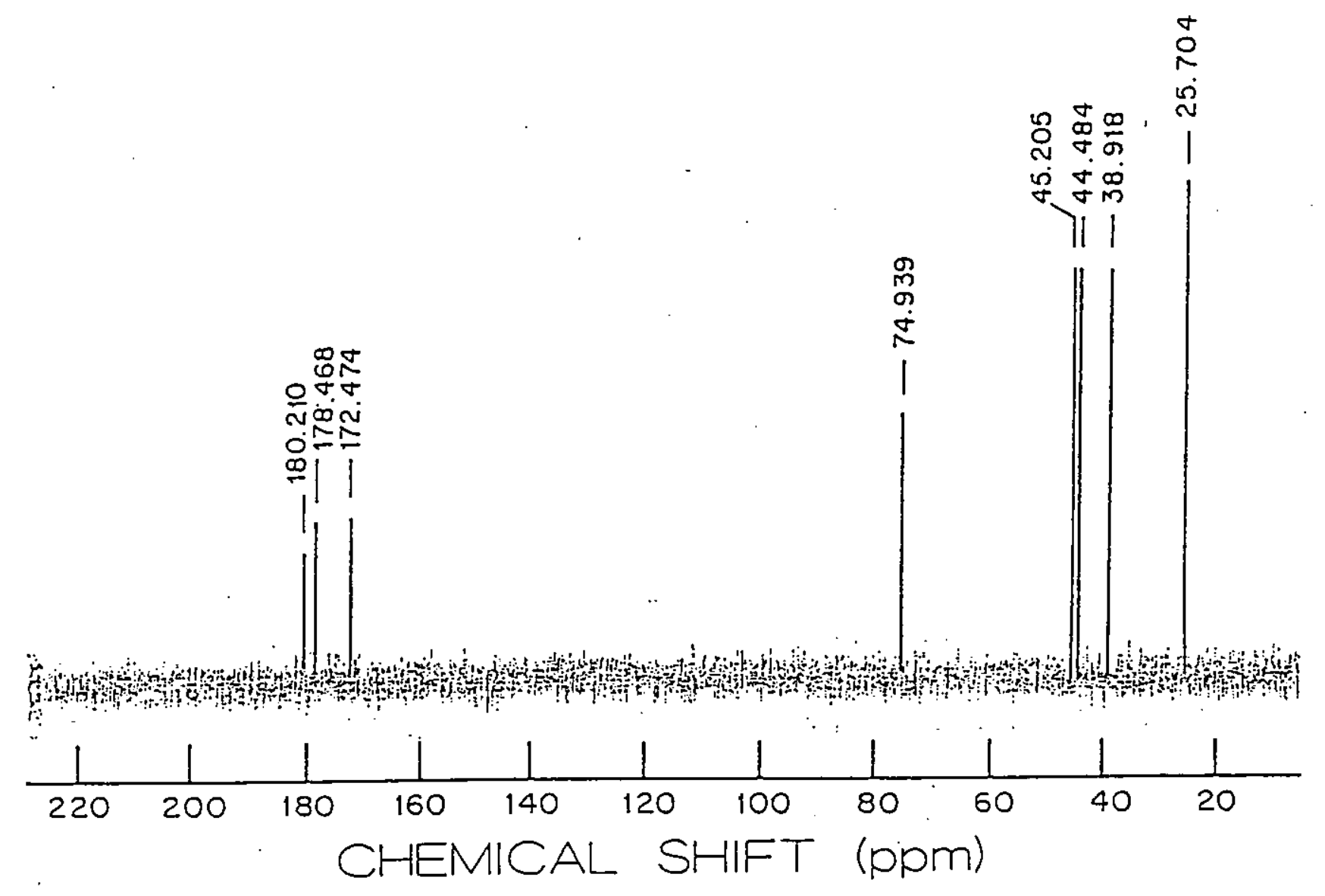

Fig. $2 .{ }^{13} \mathrm{C}$ NMR spectrum of a siderophore (rhizoferrin) produced by $R$. arrhizus in $\mathrm{D}_{2} \mathrm{O}$. 


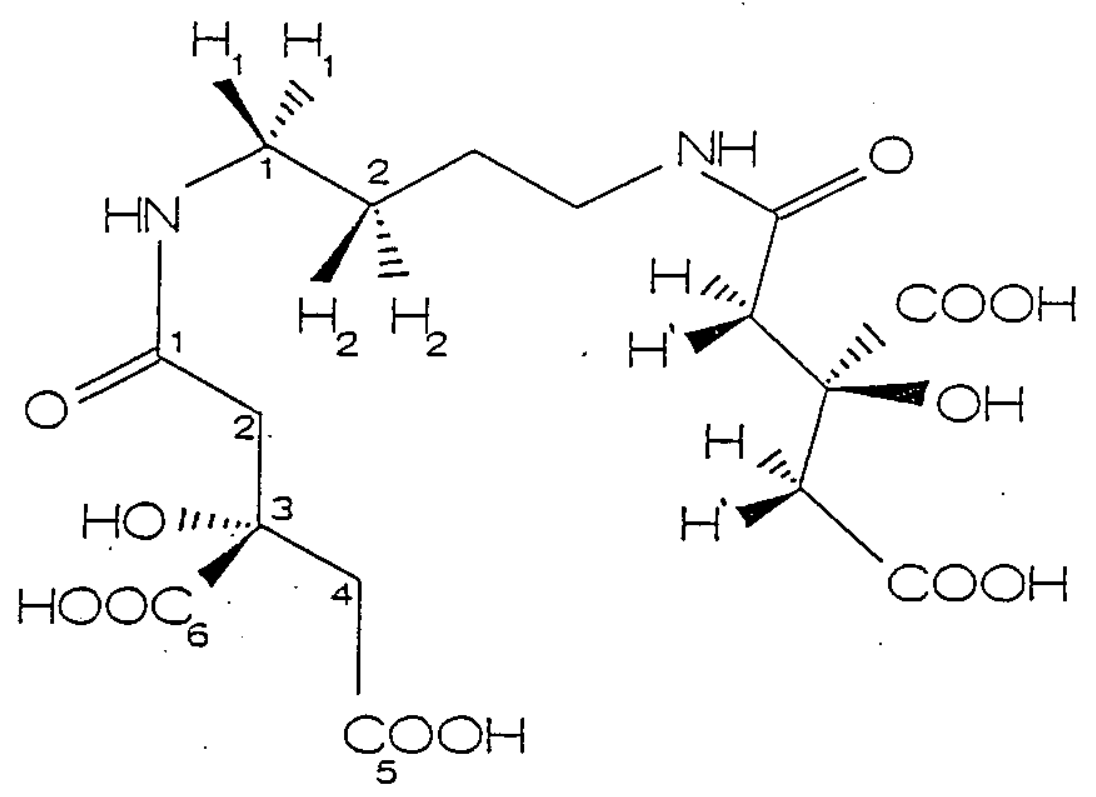

Fig. 3. Structure of a siderophore (rhizoferrin) produced by R. arrhizus. Marking of $\mathrm{C}$ and $\mathrm{H}$ atoms refers to Table 1. 

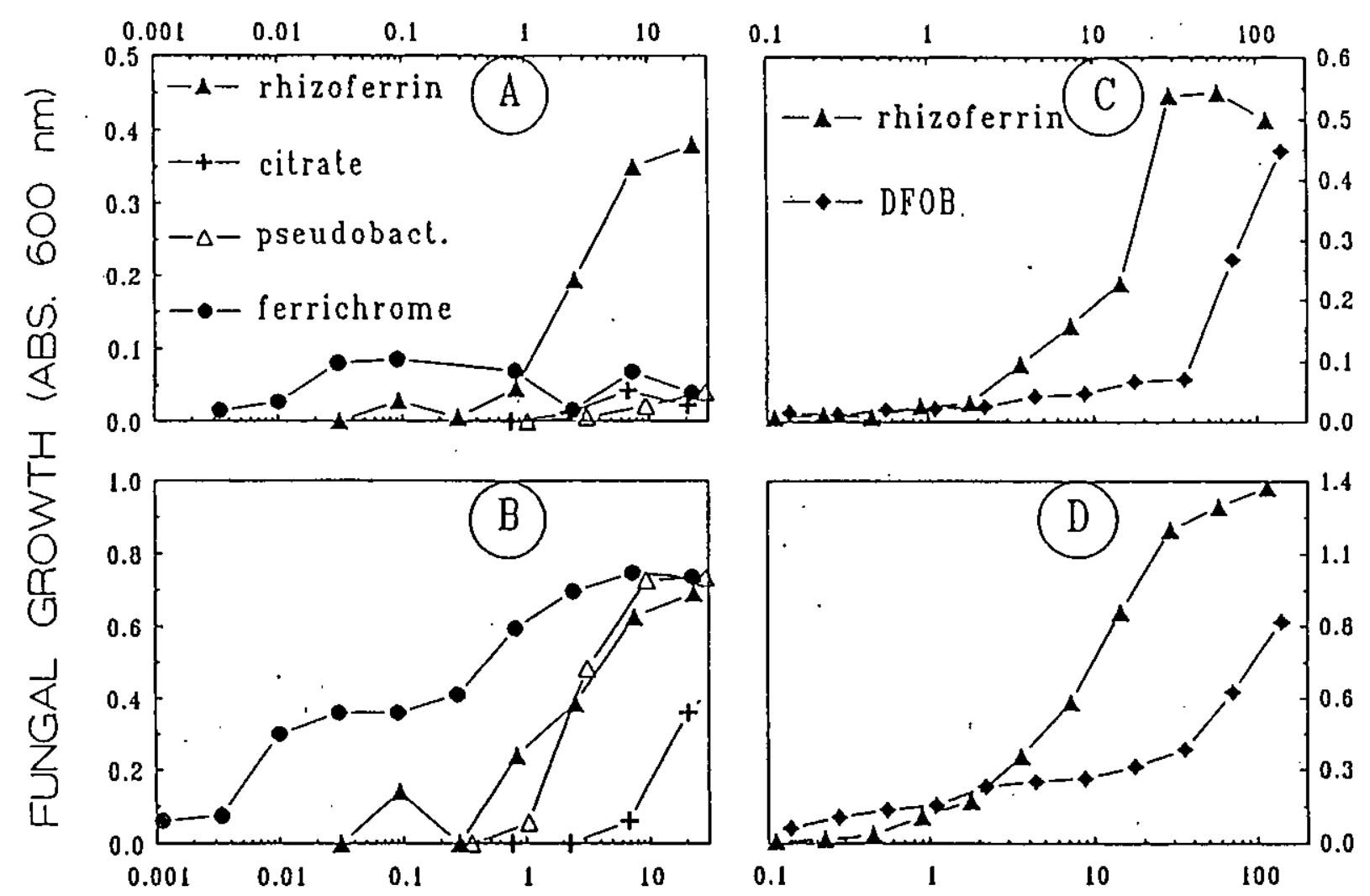

CHELATOR CONCENTRATION (MM)

Fig. 4. Rhizopus arrhizus growth in presence of increasing concentrations of rhizoferrin, citrate, pseudobactin, desferri-ferricrome (A and B), and rhizoferrin and DFOB (C and D), after incubation times of $40 \mathrm{~h}$ ( $A$ and $C$ ) and $60 \mathrm{~h}$ (B and D). Each point is an average of 8 replicates. 


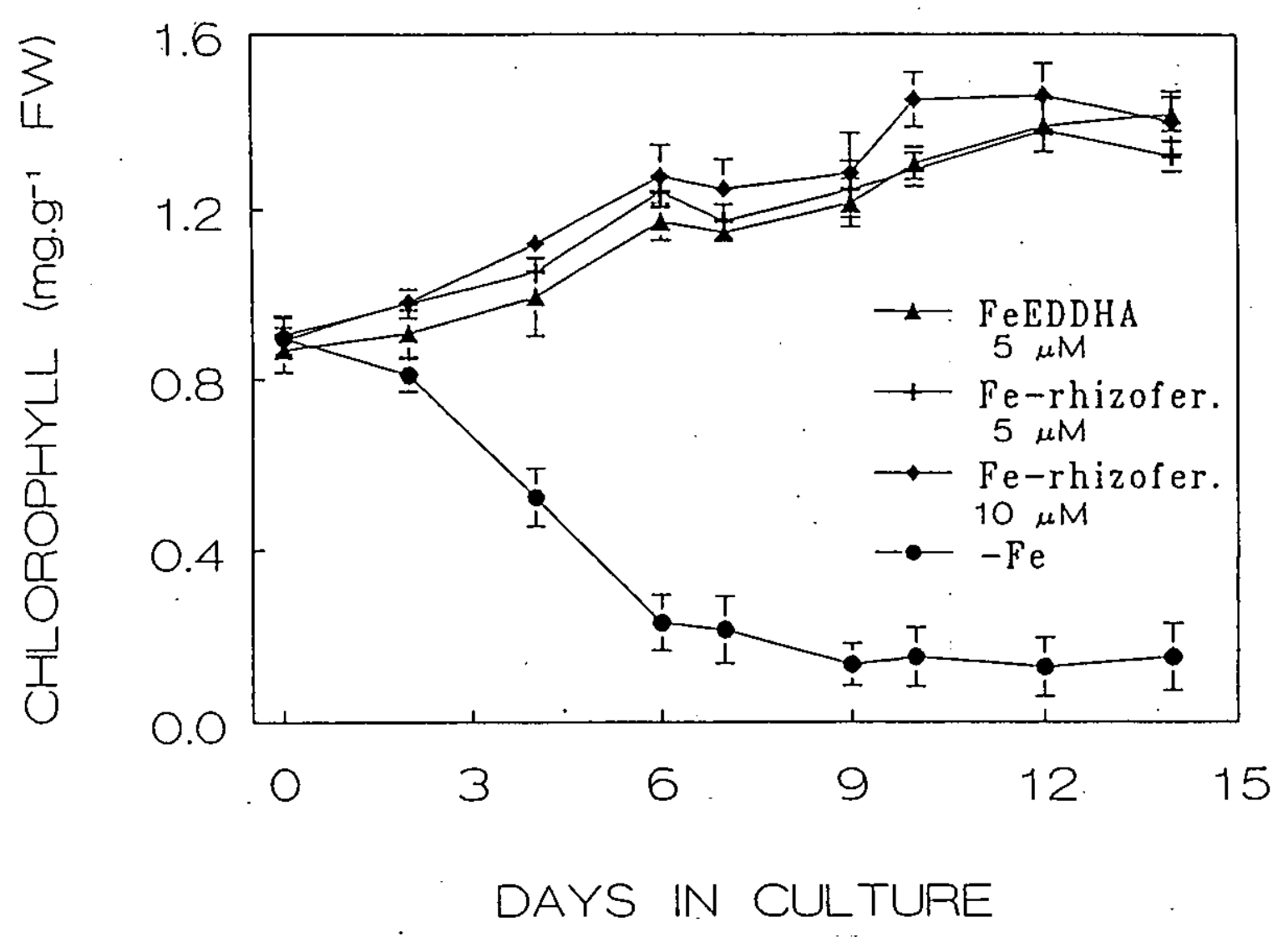

Fig. 5. Chlorophyll concentration during 14 days of growth of tomato plants supplied with various $\mathrm{Fe}$ treatments in nutrient solutions buffered to $\mathrm{pH} 7.3$ with $\mathrm{CaCO}_{3}$. Each value is a mean of 5 replicates. Bars indicate standard deviations. 
Table $1 .{ }^{1} \mathrm{H}$ and ${ }^{13} \mathrm{C}-\mathrm{NMR}$ data of a siderophore (rhizoferrin) produced by $R$. arrhizus, based $--\overline{-}$ on $1-D$ and $2-D$ experiments.

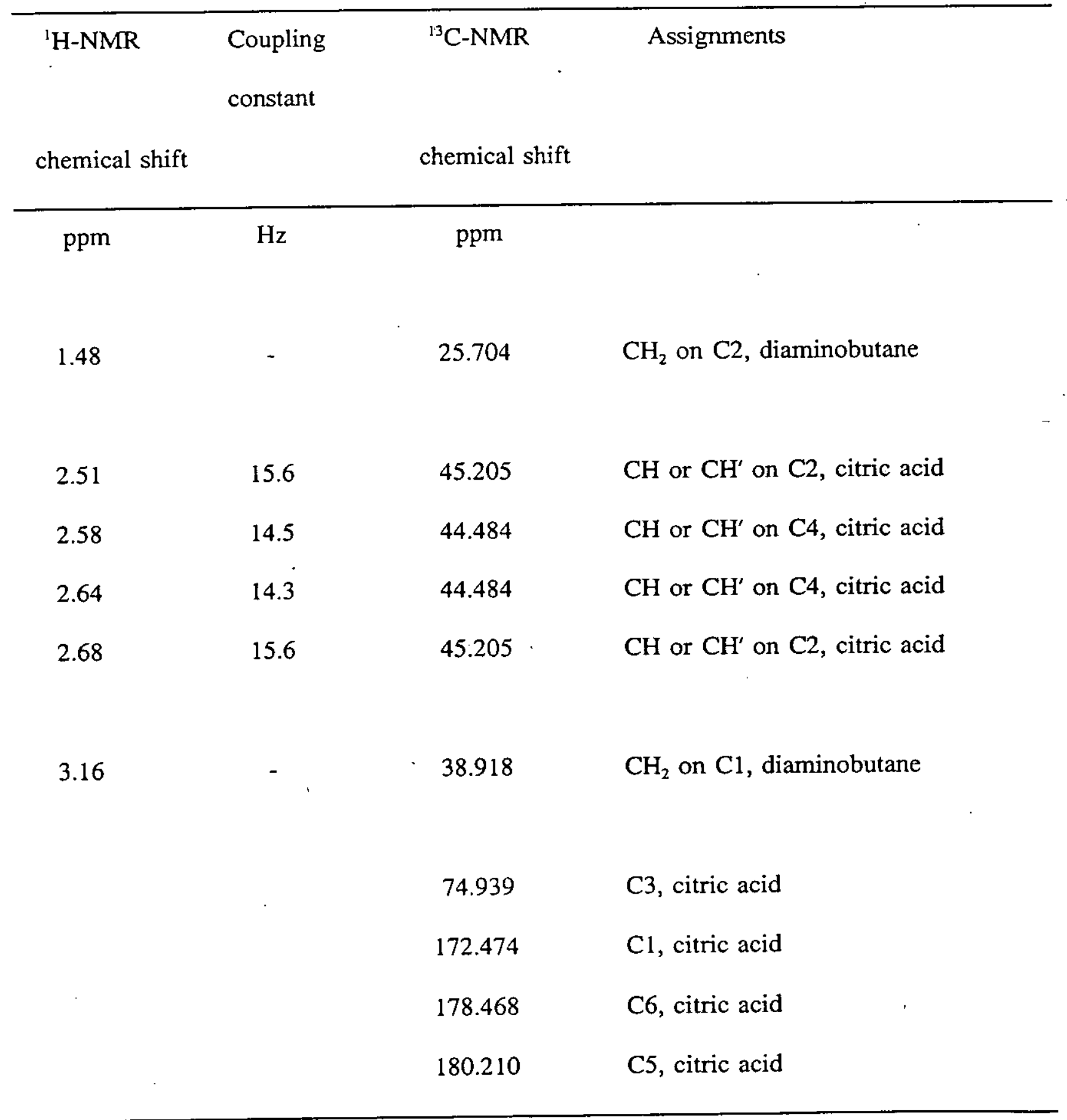


Table 2. The effect of Fe supplied as FeEDDHA or Fe-rhizoferrin on tomato plants grown for 14 days in nutrient solutions buffered to $\mathrm{pH} 7.3$ with $\mathrm{CaCO}$. Each value is a mean of 5 replicates \pm standard deviation.

\begin{tabular}{|c|c|c|c|c|c|}
\hline \multirow[t]{2}{*}{$\begin{array}{c}\mathrm{Fe} \\
\text { treatment }\end{array}$} & \multicolumn{2}{|c|}{ Fresh weight } & \multirow[t]{2}{*}{$\begin{array}{l}\text { Shoot-root } \\
\text { ratio }\end{array}$} & \multirow[t]{2}{*}{ Root length } & \multirow{2}{*}{$\begin{array}{l}\text { Ratio of root } \\
\text { fresh weight } \\
\text { to length }\end{array}$} \\
\hline & Shoot & Root & & & \\
\hline & $\mathrm{g}$ & $\mathrm{g}$ & $\mathrm{g} / \mathrm{g}$ & $\mathrm{cm}$ & $\mathrm{mg} / \mathrm{cm}$ \\
\hline $\begin{array}{c}\text { FeEDDHA } \\
5 \mu \mathrm{M}\end{array}$ & $21.9 \pm 1.0$ & $10.5 \pm 1.0$ & $2.1 \pm 0.2$ & $53.8 \pm 12.7$ & $209 \pm 67$ \\
\hline $\begin{array}{l}\text { Fe-rhizoferrin } \\
\quad 5 \mu \mathrm{M}\end{array}$ & $21.5 \pm 0.9$ & $16.0 \pm 1.3$ & $1.3 \pm 0.1$ & $41.9 \pm 5.6$ & $387 \pm 45$ \\
\hline $\begin{array}{l}\text { Fe-rhizoferrin } \\
10 \mu \mathrm{M}\end{array}$ & $21.0 \pm 1.4$ & $16.7 \pm 1.8$ & $1.3 \pm 0.1$ & $41.3 \pm 10.1$ & $429 \pm 102$ \\
\hline No added Fe & $14.4 \pm 1.8$ & $10.7 \pm 2.5$ & $1.4 \pm 0.3$ & $29.3 \pm 7.3$ & $376 \pm 87$ \\
\hline
\end{tabular}


Table 3. Uptake and translocation of ${ }^{55} \mathrm{Fe}$ from ${ }^{55} \mathrm{Fe}$-rhizoferrin and ${ }^{55} \mathrm{FeEDDHA}$ by $-\ldots$. Fe-sufficient and Fe-deficient tomato plants during a $10 \mathrm{~h}$ period at $\mathrm{pH} 6.2$. Each value is a mean of 4 replicates \pm standard deviation.

\begin{tabular}{|c|c|c|c|c|c|}
\hline \multirow{3}{*}{$\begin{array}{c}{ }^{55} \mathrm{Fe} \text { source } \\
{ }^{55} \mathrm{Fe} \text {-rhizoferrin }\end{array}$} & \multirow{3}{*}{$\begin{array}{c}\text { Fe preculture } \\
\\
\\
- \\
+\end{array}$} & \multicolumn{2}{|c|}{ Uptake } & \multicolumn{2}{|c|}{ Translocation } \\
\hline & & \multicolumn{2}{|c|}{ nmole ${ }^{55} \mathrm{Fe} / \mathrm{g}$ root } & \multicolumn{2}{|c|}{ dry weight } \\
\hline & & $2579 \pm$ & 184 & $1.3 \pm$ & 0.9 \\
\hline $5 \mu \mathrm{M}$ & - & $2271 \pm$ & 316 & $125.0 \pm$ & 51.7 \\
\hline${ }^{55} \mathrm{Fe}$-rhizoferrin & + & $4645 \pm$ & 1370 & $16.0 \pm$ & 7.7 \\
\hline $10 \mu \mathrm{M}$ & - & $4530 \pm$ & 1165 & $91.5 \pm$ & 103.3 \\
\hline${ }^{55} \mathrm{Fe}$-rhizoferrin & + & $8141 \pm$ & 1029 & $3.3 \pm$ & 0.4 \\
\hline $15 \mu \mathrm{M}$ & - & $7945 \pm$ & 1346 & $744.3 \pm$ & 381.7 \\
\hline${ }^{s 5} \mathrm{FeEDDHA}$ & + & $27 \pm$ & 12 & $3.3 \pm$ & 3.2 \\
\hline $5 \mu \mathrm{M}$ & - & $152 \pm$ & 65 & $10.6 \pm$ & 5.6 \\
\hline
\end{tabular}


UTILIZATION BY TOMATOES OF IRON MEDIATED BY A SIDEROPHORE PRODUCED BY RHIZOPUS ARRHIZUS

\section{ABSTRACT}

Rhizopus arrhizus was found to produce a novel siderophore named raphorin ( $R a$ ) when grown under Fe deficiency. Partially purified Fe-Ra was found to alleviate Fe deficiency when applied to tomato plants grown in nutrient solutions buffered by either $\mathrm{CaCO}_{3}$ $(\mathrm{pH} 7.3)$ or HEPES ( $\mathrm{pH} 7) .{ }^{55} \mathrm{Fe}$ uptake rate by $\mathrm{plants}$ mediated by $\mathrm{Ra}$, and translocation rate to the shoot, was almost as high as from ${ }^{55} \mathrm{FeEDDHA}$. It has been concluded the $\mathrm{Fe}-\mathrm{Ra}$ is a most efficient $\mathrm{Fe}$ source for plants when compared to other microbial siderophores.

\section{INTRODUCTION}

Siderophores are produced by microbes under fe deficient conditions as a means to acquire $\mathrm{Fe}$ in such environments. Since their discovery, researchers have argued whether siderophores can serve as Fe carriers to plants. Bienfait (1988) argued that due to their redox potential, microbial siderophores such as FOB are not 
reduced at appreciable rates by dicots and therefore these biomolecules do not have a significant role in the fe nutrition of plants. Later, Bienfait (1989) proposed a "third" strategy that plants use to facilitate $\mathrm{Fe}$ uptake mediated by microbial siderophores. Becker et al. (1985) performed nutrient solution studies and concluded that pseudobactin (PSB) inhibits plant growth and does not carry Fe to plants. It seems that in the experiments conducted by Becker and his collaborators, excessive PSB as compared to $\mathrm{Fe}$, has caused a decrease in the free Fe concentration and thereby impaired $\mathrm{Fe}$ uptake. Extensive studies on various microbial siderophores, especially FOB, and their role in the Fe acquisition in plants, were conducted by Szaniszlo, Reed, Crowley and their collaborators. Their results indicate that the microbial siderophore uptake mechanism in oats is induced by $\mathrm{Fe}$ deficiency, dependent on metabolic energy, saturable, and functions within physiological concentrations produced by microbes (Crowley et al., 1987; Crowley et a1., 1988; Crowley et a1., 1991).

Studies by Jurkevitch et a]. (1986, 1988) conducted with peanut plants grown on a calcareous soil clearly demonstrated that both FePSB and FeFOB act as Fe source to plants although concentrations required to achieve a complete remedy to $\mathrm{Fe}$ deficiency symptoms were 10 or 30-fold, respectively, higher than those required for FeEDDHA. Tests conducted in nutrient solutions indicate that both FeFOB and FePSB act as moderately effective Fe source to both dicots and monocots (Bar-Ness et al., 1991).

Redox potentials for FeFOB and FePSB were measured and found to be $-470 \mathrm{mV}$ and $-482 \mathrm{mV}$ as compared to $-230 \mathrm{mV}$ for FeEDDHA (BarNess et a1., 1991). This suggests that reduction of $\mathrm{Fe}^{3+}$ by root reductases is more difficult to achieve in the case of both FeFOB and FePSB although non-equilibrium and kinetic consideration can not be 
made based on these numbers. Iron uptake studies performed by BarNess et a1. (1991) suggested a 5 to 10-fold lower Fe uptake from these microbial siderophores as compared to FeEDDHA, based on equivalent concentrations.

Since these results obtained by our group demonstrate that microbial siderophores have the potential to play a role in the $\mathrm{Fe}$ nutrition of plants, we continued the search for siderophores originating from rhizosphere microorganisms. Rhizopus is a common rhizosphere fungus and was selected as a target organism. Although Winkelmann (early 1991) reported that members of this genus are not known to produce any siderophores, Drechsel et al. (1991) reported on a siderophore biosynthesized by Rhizopus microsporus.

In 1990, our group firstly reported on a siderophore produced by Rhizopus arrhizus, one of the most common organisms of this genus (Helmann et al., 1990), and named it "raphorin" (Ra). The produced siderophore was shown, in preliminary experiments, to be an effective carrier to cotton and corn plants. The aim of this study was to investigate the effects of $\mathrm{Ra}$ on regreening of tomato $\mathrm{plants}$ grown in nutrient solutions in the absence of $\mathrm{Fe}$ and on uptake to roots and translocation to shoots of ${ }^{55} \mathrm{Fe}$ mediated by $\mathrm{Ra}$.

\section{MATERIALS AND METHODS}

\section{Preparation of Chelates and Nutrient Solutions}

Siderophore Production: To study raphorin production, Rhizopus arrhizus was incubated at $30^{\circ} \mathrm{C}$ in $50 \mathrm{~mL}$ of medium containing $(\mathrm{g} / \mathrm{L})$ : 10-glucose, $7-\mathrm{Na}_{2} \mathrm{HPO}_{4}, 3-\mathrm{KH}_{2} \mathrm{PO}_{4}, 1-\mathrm{NH}_{4} \mathrm{Cl}, 0.5-\mathrm{NaCl}, 0.25-\mathrm{MgSO}_{4} .7 \mathrm{H}_{2} \mathrm{O}$, $0.015-\mathrm{CaCl}_{2} .2 \mathrm{H}_{2} \mathrm{O}, 0.015-\mathrm{ZnCl}_{2}$ and 0.005 -thiamine in $500 \mathrm{~mL}$ flasks at $\mathrm{pH} 7.2$.

After stationary incubation periods of $3,5,7,9,11,13$ or 15 
days, the spent medium of two flasks was separated from the fungal mat. The concentration of siderophores in the solutions of the two replicates of each incubation period was tested by the Chrome Azurol $S$ (CAS) method (Schwyn and Neilands, 1987). The fungal biomass was measured by drying the fungal mat at $60^{\circ} \mathrm{C}$.

For siderophore production and collection, the same growing method was used on a larger scale. Incubation time was 10 days after which the spent supernatant was filtered and concentrated by rotavapor. Partial purification was conducted by molecular sieving in a column of Sephadex G25. Detection of the siderophore fractions was achieved by measuring the light absorbance of its Cu-complex and by the CAS test.

Iron Complexation to the Siderophore: A solution containing partially purified $\mathrm{Ra}$ at a $10 \%$ excess over the $\mathrm{Fe}$ was shaken for $1 \mathrm{~h}$ with 2.5 $\mathrm{mM} \mathrm{FeCl}{ }_{3}$ in $10 \mathrm{mM} \mathrm{HCl}$ at $25^{\circ} \mathrm{C}$. The $\mathrm{pH}$ was raised to 7.2 using $100 \mathrm{mM}$ HEPES buffer solution. The solution was shaken for $24 \mathrm{~h}$ at $25^{\circ} \mathrm{C}$. To exclude Fe-hydroxide precipitates the solution was filtered through a $0.2 \mu \mathrm{m}$ Millipore filter.

Labeling and Preparation of $55 \mathrm{Fe}$-raphorin: A solution containing partially purified raphorin or EDTA was stirred for $20 \mathrm{~h}$ with a trace of ${ }^{55} \mathrm{FeCl}_{3}(0.01 \mathrm{mCi})$ and with $\mathrm{Fe}\left(\mathrm{NO}_{3}\right)_{3}$ at $25^{\circ} \mathrm{C}$. The Ra concentration was in $10 \%$ excess over the $\mathrm{Fe}$. A pH of 6.0 has been maintained using $4 \mathrm{mM}$ MES buffer. The solution was filtered through a $0.2 \mu \mathrm{m} \mathrm{Millipore}$ filter before application to the nutrient solutions in which plants were grown. This precaution was taken to avoid Fe-hydroxide precipitates.

Utilization of Fe-raphorin by $\mathrm{Plants}$

Growth of Plants: Plants of tomato (Lycopersicon esculentum Mill, cv. M-82-1-8) were cultured in an aerated nutrient solution of the following composition(M): $7 \times 10^{-4} \mathrm{~K}_{2} \mathrm{SO}_{4}, 10^{-4} \mathrm{KCl}, 2 \times 10^{-3} \mathrm{Ca}\left(\mathrm{NO}_{3}\right)_{2}, 5 \times 10^{-}$ 
$\mathrm{MgSO}_{4}, 10^{-4} \mathrm{KH}_{2} \mathrm{PO}_{4}, 10^{-5} \mathrm{H}_{3} \mathrm{BO}_{3}, 5 \times 10^{-7} \mathrm{MnSO}_{4}, 5 \times 10^{-7} \mathrm{ZnSO}_{4}, 2 \times 10^{-7} \mathrm{CuSO}_{4}$, and $10^{-8}\left(\mathrm{NH}_{4}\right)_{6} \mathrm{Mo}_{7} \mathrm{O}_{24}$.

Iron was supplied to the nutrient solution as $5 \mu \mathrm{M}$ FeEDDHA during the early stages of seedling growth (10 to 14 days). The following pretreatments were then applied for 7 days of growth in $\mathrm{CaCO}_{3}$ buffered solutions ( $\mathrm{pH} 7.3$ ) to induce $\mathrm{Fe}$-deficient, Fe-stressed and $\mathrm{Fe}$-sufficient $\mathrm{plants,}$ respectively: (i) Fe was totally excluded from the nutrient solution; ( $i i)$ Fe was supplied as $1 \mu \mathrm{M}$ FeEDDHA; and (iii) Fe was supplied as $5 \mu \mathrm{M}$ FeEDDHA.

Long-term Experiment (2 weeks of growth): Plants from the various pretreatments were transferred to fresh fe treatment solutions as indicated later. The chlorophyll concentration of the leaves was measured periodically in the youngest mature leaf using a SPAD-502 Chlorophyll Meter (Minolta Camera Co.). These measurements were performed every 2 to 3 days to facilitate a continuous measurement of the plant response. Spad reading of 10 or less indicates very chlorotic leaves whereas Spad reading of 45 or more indicates heal thy green plants. The curve used to correlate Spad reading vs. chlorophyll concentration for tomato $\mathrm{plants}$ was: Spad reading = chlorophyll (mg/g FW) $\times 27.3+6.6$ (Chen et a1., 1991).

Short-term Experiment ( $10 \mathrm{~h}$ of growth): Precultured Fe-deficient or $\mathrm{Fe}$-adequate $\mathrm{plants}$ were transferred to an aerated $200 \mathrm{~mL}$ nutrient solution containing $0.5 \mu \mathrm{M}{ }^{55} \mathrm{Fe}-\mathrm{Ra}$ or $5 \mu \mathrm{M}{ }^{55} \mathrm{FeEDTA}$. The $\mathrm{pH}$ was buffered to 6.0 using a $5 \mathrm{mM}$ MES solution. After $10 \mathrm{~h}$, the plants were transferred for $10 \mathrm{~min}$ to $200 \mathrm{~mL} 1.5 \mathrm{mM} \mathrm{2,2-dipyridyl} \mathrm{in}$ saturated $\mathrm{CaSO}_{4}$. Half a $\mathrm{g} \mathrm{Na}_{2} \mathrm{~S}_{2} \mathrm{O}_{4} \cdot 5 \mathrm{H}_{2} \mathrm{O}$ was added and $\mathrm{N}_{2}$ was bubbled through the solution to remove free-space-Fe from the roots. Shoots and roots were separated, oven-dried at $65^{\circ} \mathrm{C}$, weighed and ashed at $500^{\circ} \mathrm{C}$. The ash was dissolved in $1 \% \mathrm{HCl}$ and ${ }^{55} \mathrm{Fe}$ concentration was measured by liquid scintillation. 


\section{RESULTS AND DISCUSSION}

Raphorin Production: Raphorin production and fungal biomass accumulation were tested as a function of incubation time (Fig. 1). While the fungal biomass reached a maximum after 7 days, and was then followed by autolysis, Ra (measured by the CAS test and expressed as FOB equivalents) was produced and had been accumulated in the medium solution during the entire incubation period of 15 days. The rate of accumulation was high. in the first few days and tended to leveloff after about 10 days. Accordingly, the standard time for Ra collection was set at the 10th day.

Long-term Plant Growth Experiment: Partially purified Fe-Ra was found to alleviate Fe deficiency when applied to Fe-stressed plants grown in solutions buffered by $\mathrm{CaCO}_{3}$ (Fig. 2). The remedy of the deficiency fell only slightly short to that achieved by the same concentration $(5 \mu \mathrm{M})$ of FeEDDHA. The desferri-Ra treatment did not result in any plant response. Within 14 days, the plants became as chlorotic as the control plants grown without $\mathrm{Fe}(-\mathrm{Fe})$. The remedy of chiorosis has been attributed to $\mathrm{Fe}$ uptake mediated by Ra.

When grown in nutrient solution buffered to $\mathrm{pH} 7.0$ with a $5 \mathrm{mM}$ HEPES, the remedy of chlorosis of Fe-stressed plants achieved completion in treatments with $5 \mu \mathrm{M} \mathrm{Fe-Ra.} \mathrm{A} \mathrm{similar} \mathrm{response} \mathrm{was}$ obtained when the plants were treated with $10 \mu \mathrm{M} \mathrm{Fe-Ra} \mathrm{or} \mathrm{with} 5 \mu \mathrm{M}$ FeEDDHA. Control plants $(-\mathrm{Fe})$ turned very chlorotic within a few days (Fig. 3).

In a similar experiment that was conducted in nutrient solutions buffered with $\mathrm{CaCO}_{3}, \mathrm{Fe}$-sufficient plants maintained their healthy appearance and sufficient concentration of chlorophyll for 15 days after being transferred to a nutrient solution containing 5 $\mu \mathrm{MFe}-\mathrm{Ra}$. The chlorophyll concentrations were identical to those of 
plants supplied with 5 HM FeEDDHA. Fe-deficient plants were completely cured within 6 days after being transferred to a nutrient solution containing $5 \mu \mathrm{M} \mathrm{Fe}$-Ra whereas control plants (-Fe) became very chlorotic (Fig. 4).

Short-term Experiment: Uptake and transiocation levels of ${ }^{55} \mathrm{Fe}$ by Fe-sufficient or Fe-deficient plants from a solution containing $0.5 \mu \mathrm{M}$ ${ }^{55} \mathrm{Fe}-\mathrm{Ra}$ resembled the uptake and translocation rates by plants precultured in the same treatments but supplied with a 10-fold higher concentration of ${ }^{55} \mathrm{FeEDTA}$. This relatively high uptake rate indicates that $\mathrm{Fe}-\mathrm{Ra}$ is a very efficient $\mathrm{Fe}$ source for tomato plants (Table 1).

\section{SUMMARY AND CONCLUSIONS}

Microbial siderophores can act as mediators in Fe uptake processes by dicotyledonous plants. As for synthetic chelates, the efficiency of the siderophores as Fe carriers varies. Literature data show that FOB exhibits relatively low efficiency whereas PSB exhibits somewhat higher efficiency al though lower than that of EDDHA by a factor of 5 to 10 (Bar-Ness et al., 1991). Results reported by Becker et al. (1985) showing inhibition of Fe uptake by PSB were not confirmed by other studies. It seems that the inhibition was obtained due to two main reasons: (i) $\mathrm{FeCl}_{3}$ was added to their nutrient solution separately from PSB. Iron could have precipitated as hydroxide and the free PSB ligand would then act as a competitor to the plant. Usually complexes, not free ligands, are added; (ii) The containers used by these investigators were extremely small (40 $\mathrm{mL}$ ) and other stresses could have developed. In addition, very small plant seedlings were studied.

In the present study, we show that a novel fungal siderophore 
produced by Rhizopus arrhizus named raphorin can act as a Fe carrier to plants growing in nutrient solutions at $\mathrm{pH} 6.0,7.0$ and 7.3 at least as well as EDDHA does. Uptake rates of ${ }^{55} \mathrm{Fe}$ mediated by $0.5 \mu \mathrm{M}$ Fe-Ra solution at $\mathrm{pH} 6.0$ were almost as high as those from a ${ }^{55}$ FeEDTA solution that contained 10-fold higher concentration of the $\mathrm{Fe}$ chelate. Fe-Ra is the most efficient microbial siderophore reported todate in relation to the supply of Fe to plants.

\section{ACKNOWLEDGMENTS}

This research was supported by the U.S.-Israel Binational Agricultural Research and Development Fund (BARD).

\section{REFERENCES}

Bar-Ness, E., Y. Chen, Y. Hadar, H. Marschner, and V. Romheld. 1991. Siderophores of Pseudomonas putida as an iron source for dicot and monocot plants. pp. 271-281. IN: Y. Chen and Y. Hadar (eds.): Iron Nutrition and Interactions in Plants. Kluwer Academic Publisher, London, Great Britain.

Becker, J.0., R.W. Hedges, and E. Messens. 1985. Inhibitory effect of pseudobactin on the uptake of iron by higher plants. Applied and Environmental Microbiology 49:1090-1093.

Bienfait, H.F. 1988. Mechanisms in Fe-efficiency reactions of higher plants. J. Plant Nutr. 11:605-629.

Bienfait, H.F. 1989. Prevention of stress in iron metabolism of plants. Acta Bot. Neerl. 38(2):105-129.

Chen, Y., R.L. Chaney, and P. Bel1. 1991. Determination of $\mathrm{Fe}^{2+}$ requirements of plants using ferrozine-buffered nutrient solution. Abstract presented at the VI International Iron Symposium, July 14-19, 1991. Utah State University, Logan, Utah, U.S.A. 
Crowley, D.E., C.P.P. Reid, and P.J. Szaniszlo. 1987. Microbial siderophores as iron sources for plants. pp. 370-386. IN: Winkelmann, G., D. Van der Helm and J.B. Neilands (eds.) Iron Transport in Animals, Plants, and Microorganisms. VCH Chemie, Weinheim, FRG.

Crowley, D.E., C.P.P. Reid, and P.J. Szanisz10. 1988. Utilization of microbial siderophores in iron acquisition by oats. Plant Physiol. 87:680-685.

Crowley, D.E., Y.C. Wang, C.P.P. Reid, and P.J. Szaniszlo. 1991. Mechanisms of iron acquisition from siderophores by microorganisms and plants. pp. 213-232. IN: Chen, $Y$. and $Y$. Hadar (eds.) Iron Nutrition and Interactions in Plants. Kluwer Academic Publishers, London, Great Britain.

Domsch, K.H., W. Gams, and T.H. Anderson. 1980. Compendium of Soil Fungi. Academic Press, London.

Drechsel, H., J. Metzger, S. Freund, G. Jung, S.R. Boelaert, and G. Winkelmann. 1991. Rhizoferrin - a novel siderophore from the fungus Rhizopus microsporus var. rhizopodiformis. Biology of Metals $4: 238-243$.

Helmann, M., T. Sery, Y. Chen, E. Bar-Ness, S. Gilan, and Y. Hadar. 1990. A novel siderophore from Rhizopus arrhizus and the utilization of its iron complex by plants. Abstract presented in the International Symposium on Iron Transport, Storage and Metabolism II. July 20-22, 1990. The University of Texas, Austin, TX, U.S.A.

Jurkevitch, E.; Y. Hadar, and Y. Chen. 1986. The remedy of limeinduced chlorosis in peanuts by Pseudomonas sp. siderophores. J. Plant Nutr. 9:535-545.

Jurkevitch, E., Y. Hadar, and Y. Chen. 1988. Involvement of bacterial siderophores in the remedy of 1 ime-induced chlorosis in peanut. Soil Sci. Soc. Am. J. 52:1032-1037.

Schwyn, B., and J.B. Neilands. 1987. Universal chemical assay for the detection and determination of siderophores. Analytical Biochemistry 160:47-56. 
Winkelmann, G. 1991. Recent advances in uptake and storage of irun in fungi. pp. 233-238. IN: Y. Chen and Y. Hadar (eds.): Iron Nutrition and Interactions in Plants. Kluwer Academic Publisher, London, Great Britain. 
TABLE 1. ${ }^{55} \mathrm{Fe}$ Uptake and Translocation from $0.5 \mu \mathrm{M}{ }^{55} \mathrm{Fe}-\mathrm{Ra}$ and from $5 \mu M$ FeEDTA by Fe-sufficient and Fe-Deficient Tomato PTants (10 hrs uptake at $\mathrm{pH} 6.0)$.

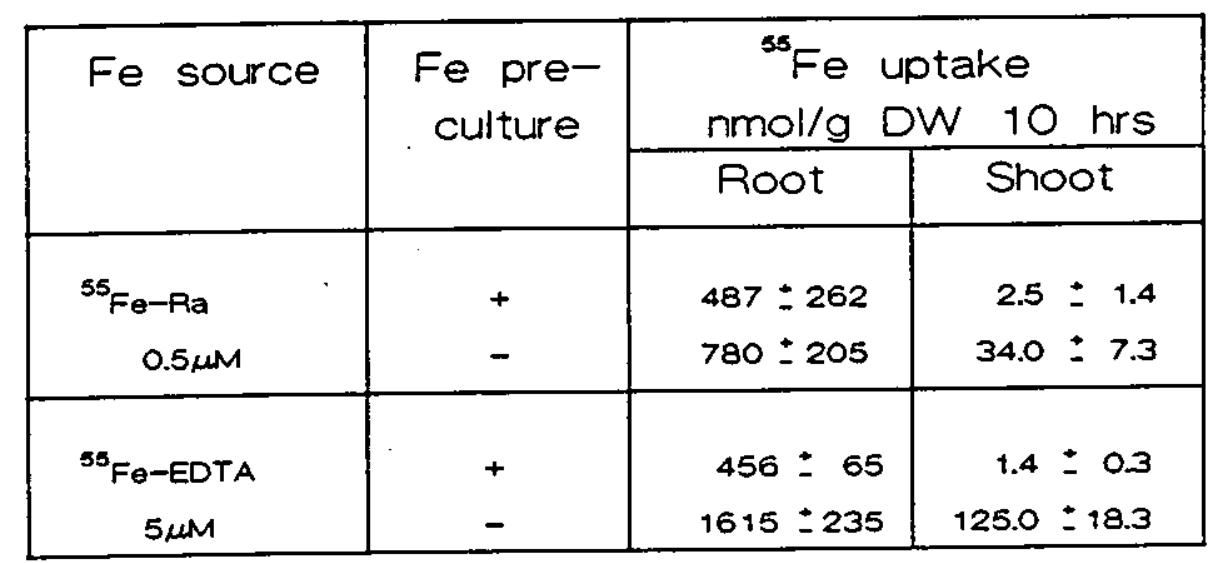


TABLE 1. ${ }^{55} \mathrm{Fe}$ Uptake and Translocation from $0.5 \mu \mathrm{M}{ }^{55} \mathrm{Fe}-\mathrm{Ra}$ and from $5 \mu M$ FeEDTA by Fe-sufficient and Fe-Deficient Tomato Plants (10 hrs uptake at $\mathrm{pH} 6.0)$.

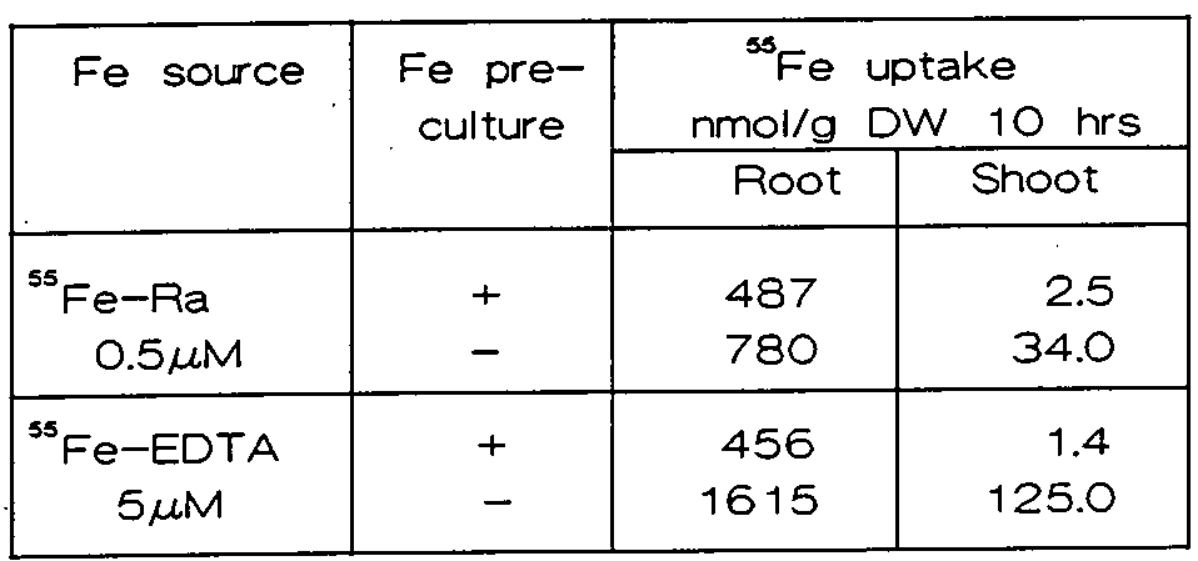




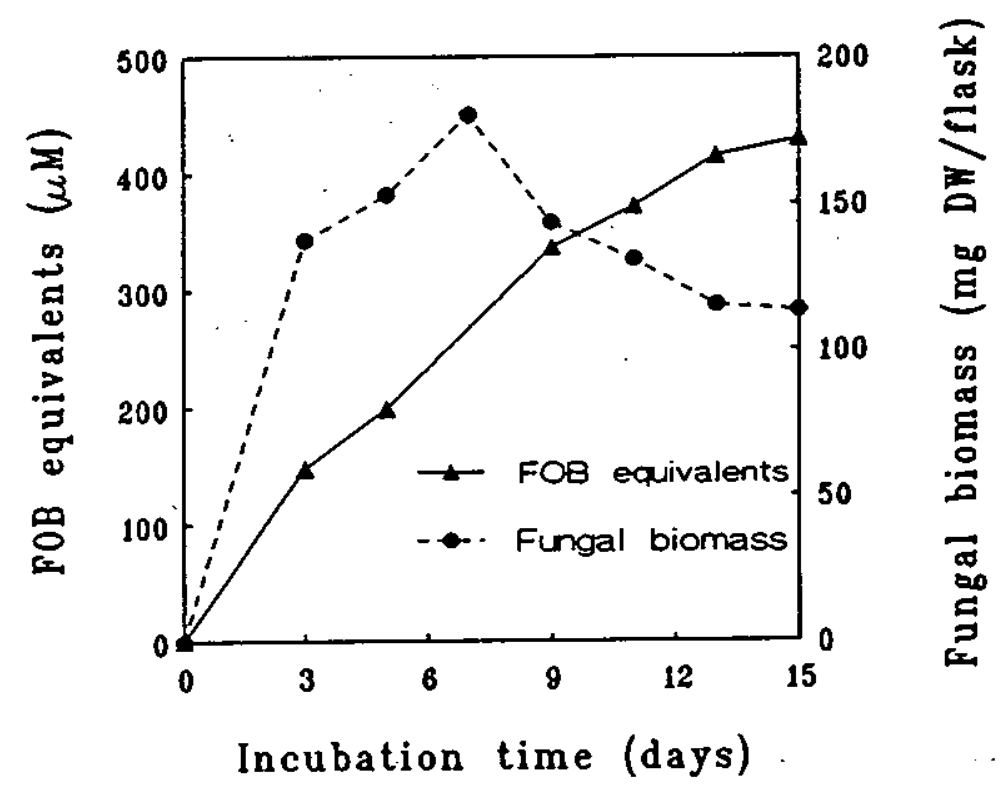

FIGURE 1. Raphorin Accumulation in the Medium and Fungal Biomass Growth During 15 Days of Incubation. 


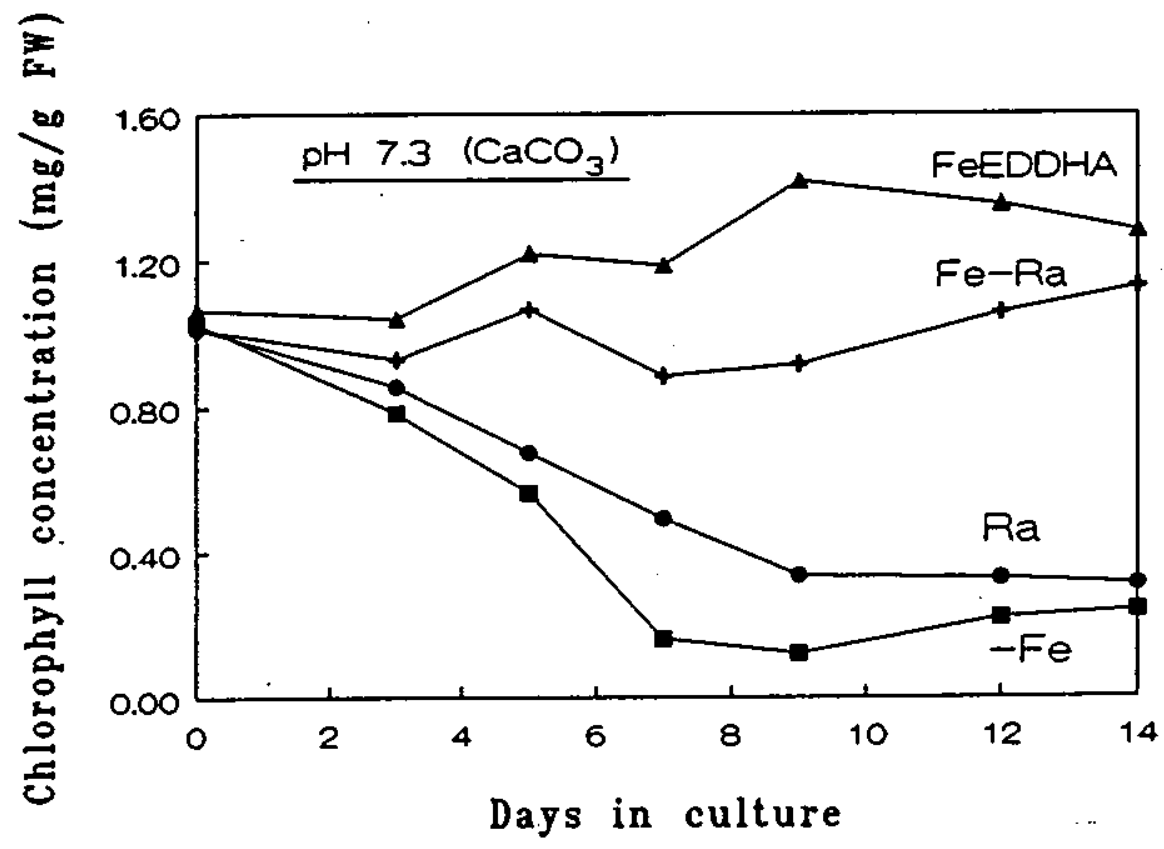

FIGURE 2. Chlorophyll Concentration (mg/g FW) Changes During 14 Days of Growth of Tomato Plants Supplied with Various Fe Treatments in Nutrient Solutions Buffered to $\mathrm{pH} 7.3$ with $\mathrm{CaCO}_{3}$. 


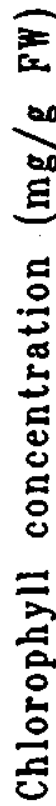

FIGURE 3. Chlorophyll Concentration (mg/g FW) Changes During 13 Days of Growth of Tomato Plants Supplied with Various Fe Treatments in Nutrient Solutions Buffered to $\mathrm{pH} 7.0$ with $5 \mu M$ HEPES Solution. The Bars Indicate the Standard Error of 6 Replicates. 


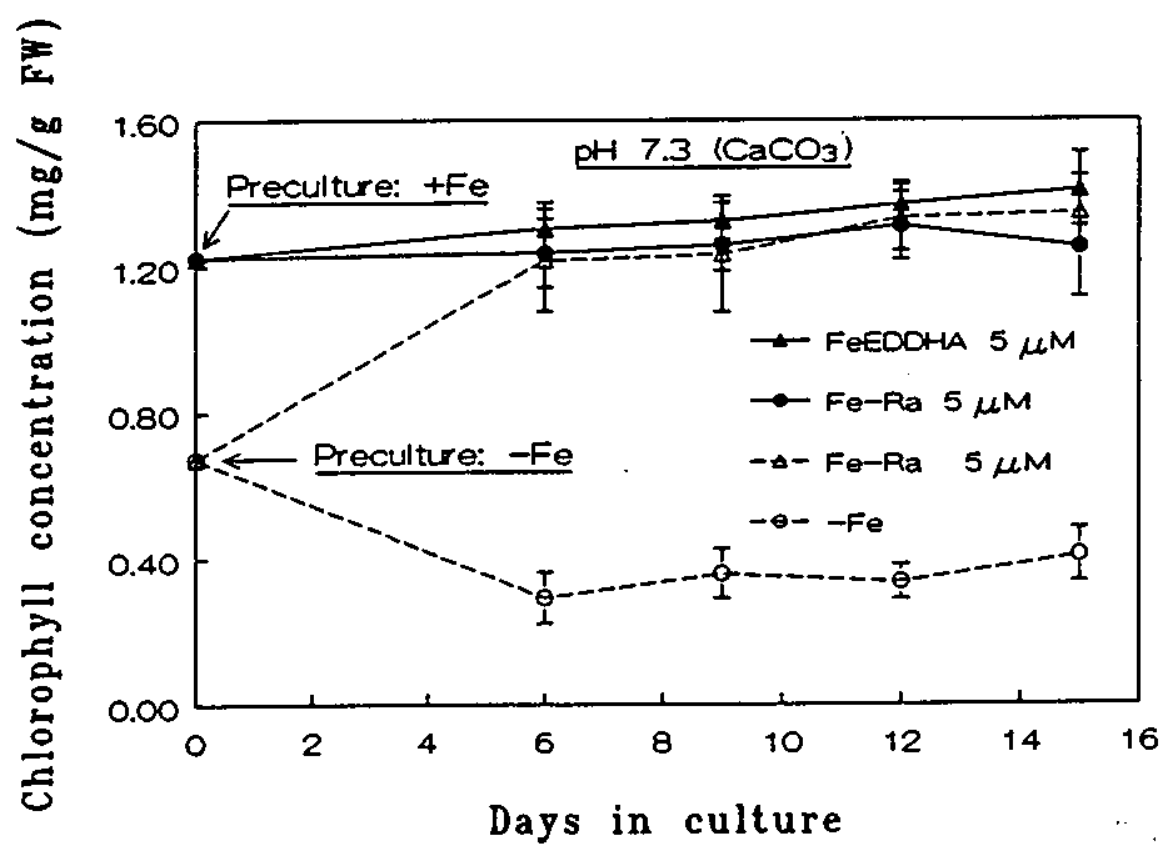

FIGURE 4. Chlorophyll Concentrations (mg/g FW) Changes During 15 Days of Growth of Tomato Plants Supplied with Various Fe Treatments and Pretreatments in Nutrient Solutions. The Solutions were Buffered to $\mathrm{pH} 7.3$ using $\mathrm{CaCO}_{3}$. The Bars Indicate the Standard Error of 6 Replicates. 
TABLE 1. $\quad{ }^{55} \mathrm{Fe}$ Uptake and Translocation from $0.5 \mu \mathrm{M}{ }^{55} \mathrm{Fe}-\mathrm{Ra}$ and from $5 \mu \mathrm{M}$ FeEDTA by Fe-sufficient and Fe-Deficient Tomato Plants (10 hrs uptake at $\mathrm{pH} 6.0)$.

\begin{tabular}{|c|c|c|c|}
\hline \multirow{2}{*}{ Fe source } & \multirow[t]{2}{*}{$\begin{array}{l}\text { Fe pre- } \\
\text { culture }\end{array}$} & \multicolumn{2}{|c|}{$\begin{array}{l}{ }^{53} \mathrm{Fe} \text { uptake } \\
\mathrm{nmol} / \mathrm{g} \text { DW } 10 \text { hrs }\end{array}$} \\
\hline & & Root & Shoot \\
\hline${ }^{55} \mathrm{Fe}-\mathrm{Ra}$ & + & $487 \pm 262$ & $2.5 \div 1.4$ \\
\hline $0.5 \mu \mathrm{M}$ & - & $780 \div 205$ & $34.0 \div 7.3$ \\
\hline${ }^{55} \mathrm{Fe}$-EDTA & + & $456 \div 65$ & $1.4: 0.3$ \\
\hline $5 \mu \mathrm{M}$ & - & $1615 \div 235$ & $125.0 \div 18.3$ \\
\hline
\end{tabular}




\section{Potentiometric and fluorescent spectroscopic deter-minations of stability constants of the siderophorepseudobactin complexes with transition metals.}

Siderophores are low molecular weight ligands produced by most aerobic microorganisms under iron stress conditions. Siderophores were found to be active as Fe carriers to microbial cells (Neilands, 1981). Ferric iron is strongly and specifically complexed by siderophores. Binding constants of up to $10^{52}$ have been reported (Hider, 1984).

Fluorescent pseudomonads excrete yellow-green fluorescent siderophores usually called pseudobactins (PSB) or pyoverdin. These compounds are chromopeptides possessing a peptide chain of 6 to 10 amino acids bound to a chromophore derived from 2,3-diamino-6,7-dihydroxyquinoline (Demange et al., 1987). Three ligand groups are present in all pseudobactins: One catechol and two hydroxamates or one catechol, one hydroxamate and one hydroxy acid (Demange et al., 1987). Pseudobactin type siderophores exhibit high affinity for $\mathrm{Fe}^{3+}$, as shown by their stability constants of about $10^{25}$ at neutral $\mathrm{pH}$ values (Meyer and Abdallah, 1978, Philson and Llinas, 1982, Persmark et al., 1990). The visible spectrum of all PSBs exhibit an absorbance peak at $400 \mathrm{~nm}$ at neutral $\mathrm{pH}$. Upon complexation of $\mathrm{Fe}^{3+}$ a shoulder is formed at $450 \mathrm{~nm}$ (Meyer and Abdallah, 1978). In addition, the yellow-green PSBs fluoresce at $470 \mathrm{~nm}$ when irradiated with visible (VIS) light at $400 \mathrm{~nm}$ (Meyer and Abdallah, 1978). Metal binding of some metal ions results in proportional fluorescence quenching (Frimmel and Hopp, 1984). The stability constants of the $\mathrm{Fe}^{3+} \mathrm{PSB}$ can be calculated from the decrease in absorbance at $450 \mathrm{~nm}$ with increasing concentrations of a competing ligand (L) of a known stability constant as follows (Rossotti and Rossotti, 1961):

$$
\mathrm{Fe}^{3+}+\mathrm{PSB}--->\text { FePSB } ; \quad \mathrm{K}_{1}=\frac{[\mathrm{FePSB}]}{\left[\mathrm{Fe}^{3+}\right][\mathrm{PSB}]}
$$


$\mathrm{Fe}^{3+}+\mathrm{L} \cdots \mathrm{FeL} \quad ; \quad \mathrm{K}_{2}=\frac{[\mathrm{FeL}]}{\left[\mathrm{Fe}^{3+}\right][\mathrm{L}]}$

$\mathrm{PSB}+\mathrm{FeL} \ldots-\mathrm{FePSB}+\mathrm{L} \quad ; \quad \mathrm{K}_{3}=\frac{[\mathrm{FePSB}][\mathrm{L}]}{[\mathrm{FeL}][\mathrm{PSB}]}$

Eq. (3) describes the exchange of $\mathrm{Fe}^{3+}$ between the ligands (PSB and L). Therefore, the stability constant, $\mathrm{K}_{3}$, can be calculated from Eq. (1) and (2) according to Eq. (4).

$$
\mathrm{K}_{3}=\mathrm{K}_{1} / \mathrm{K}_{2}
$$

Since $[\mathrm{PSB}]_{\text {total }}=[\mathrm{FePSB}]+[\mathrm{PSB}]$, and $[\mathrm{L}]_{\text {total }}=[\mathrm{FeL}]+[\mathrm{L}]$, and assuming that the concentration of $\left[\mathrm{Fe}^{3+}\right]$ is negligible, then at equilibrium of each point of the titration $[\mathrm{FeL}]=$ [PSB].

The stability constant of the competing chelate $\left(\mathrm{K}_{2}\right)$ is known for all $\mathrm{pH}$ values. Since the formation of the $\mathrm{Fe}^{3+} \mathrm{PSB}$ complex can be monitored at $450 \mathrm{~nm}$, the concentrations of the various components of Eq. (3) can be derived, assuming equilibrium is reached. The stability constant of the $\mathrm{Fe}^{3+}$ PSB complex can then be calculated, based on Eq. (4).

Complexes of metals other than Fe with PSB do not exhibit large changes in their UV-VIS spectra upon complexation or release of the metal. The determination of their stability constant is, therefore, more difficult to achieve. Moreover, the use of competing chelates is limited to compounds exhibiting no absorbance at the wavelength used for the measurements.

Fluorescence spectroscopy is often strongly affected by metal binding. Therefore, it facilitates detection of metal binding at very low concentrations. Fluorescence quenching has 
already been used by some researchers for the determination of binding constants of metals to humic substances (Ryan and Weber, 1982, Frimmel and Hopp, 1984). However, the fluorescence of PSB has not yet been used to study its metal complexes.

Microbial siderophores in general and PSB in particular have been shown to act as Fe carriers to Fe deficient plants (Jurkevitch et al., 1988; Bar-Ness et al., 1990). These compounds were also shown to be important in the competition for Fe between soilborne plant pathogens and rhizosphere pseudomonads.

Microbial siderophores are usually evaluated as $\mathrm{Fe}^{3+}$ chelating agents only. An assessment of their ecological significance in the rhizosphere must include considerations of their affinity for other metals commonly found in soil solutions, mainly those present at a concentration several orders of magnitude higher than that of $\mathrm{Fe}^{3+}$. The determination of the stability constants of such metals with PSB is a prerequisite for any analysis of their speciation in solution. These analyses are often performed using computer modelling programs such as GEOCHEM (Sposito and Mattigod, 1980).

In this research, we propose a method for the determination of stability constants of transition metal complexes with $\mathrm{PSB}_{3}$ using the fluorescent properties of this ligand. Measuring the changes in fluorescence intensity of the $\mathrm{PSB}_{3}$ and its complexes with several metals in the presence of competing chelates facilitates calculation of the stability constants of PSB with these metals. Protonation constants and overall stability constants are calculated from potentiometric measurements. 


\section{MATERIALS AND METHODS}

Strains and media: A Pseudomonas putida (strain St3) isolated from roots of peanuts (Arachis hypogaea cv. "Shulamit") (Jurkevitch et al., 1988) was used as the source of pseudobactin referred to as $\mathrm{PSB}_{3}$ in all experiments. The bacterium was grown in standard succinate medium (Meyer and Abdallah, 1978) in $250 \mathrm{~mL}$ erlenmeyer flasks at $28^{\circ} \mathrm{C}$. For comparison in one set of measurements, $\mathrm{PSB}_{3}$ was produced in a $20 \mathrm{~L}$ fermentor (New Brunswick, U.S.A., $14 \mathrm{~L}$ working volume) for $40 \mathrm{~h}$. The $\mathrm{pH}$ was maintained between 7 and 8 by addition of $\mathrm{HCl}$.

Purification procedure: The pigment (ligand solution) containing $\mathrm{PSB}_{3}$ was purified by column chromotography according to the method developed by Meyer and Abdallah (1978) as previously described (Jurkevitch et al., 1988). Purity was checked by thin layer chromatography with 70:30 ethanol: $\mathrm{H}_{2} \mathrm{O}$ and 70:30 methanol: $\mathrm{H}_{2} \mathrm{O}$ solutions (Teintze and Leong 1981; Philson and Llinas, 1982). The main two bands ( $\mathrm{PSB}_{3} \mathrm{~A}$ and $\mathrm{PSB}_{3} \mathrm{~B}$ ) obtained after purification were used in all subsequent experiments.

Reagents and standard conditions: All glassware was acid-washed with $5 \mathrm{M} \mathrm{HCl}$ and double distilled water before use. Double distilled water was used in all experiments. Buffer solutions used in the experiments were as follows: Na-Acetate $(\mathrm{pH} \mathrm{5)}$, phosphate $(\mathrm{pH} 6), \mathrm{MES}$ [2(NMorpholino) ethanesulfonic acid, pH 6], HEPES (N-2 Hydroxyethylpiperazine$\mathrm{N}^{\prime}$-2-ethanesulfonic acid, $\mathrm{pH}$ 7.5), and TAPS [N tris(Hydroxymethyl) methyl-3-aminopropanesulfonic acid, $\mathrm{pH} 8.5$ ]. The buffers were used at a concentration of $0.1 \mathrm{M}$. The $\mathrm{pH}$ of the titrated solutions was maintained constant within $\pm 0.02 \mathrm{pH}$ units of the desired value. The metal solutions $\left(\mathrm{Fe}^{3+}, \mathrm{Cu}^{2+}, \mathrm{Mn}^{2+}, \mathrm{Zn}^{2+}, \mathrm{Ca}^{2+}\right.$ and $\mathrm{Mg}^{2+}$ ) were prepared from $1000 \mathrm{mg} \mathrm{L}$ "atomic absorption standard" stock solutions (Riedel-deHaen, Germany). The ligands (L) used 
in competition experiments with PSB were EDTA (Ethylenediaminetetra-acetic acid, BDH, U.K.), and DFOB (Desferriferrioxamine B, Ciba-Geigy, Switzerland). Fluorescence spectra and changes in absorbance at $450 \mathrm{~nm}$ were recorded using a SLM 4800 spectrofluorometer (SLM instruments, U.S.A.) and a HP 8025 spectrophotometer (Hewlett-Packard, U.S.A.), respectively. The absorbance of the solutions was generally about 0.2 absorbance units per $\mathrm{cm}$ of light pathway. Measurements of fluorescence quenching were conducted at $400 \mathrm{~nm}$ and $460 \mathrm{~nm}$ for excitation and emission, respectively, except when otherwise, stated. All measurements were duplicated and all experiments were conducted at least twice.

Standard curves: Volumes of the appropriate metal solutions were added to a fixed volume (not exceeding $50 \mu \mathrm{l}$ ) of purified uncomplexed $\mathrm{PSB}_{3}$ solution in $4 \mathrm{ml}$ cuvettes. Buffer solution was added (not less than $2.3 \mathrm{ml}$ ) to a final volume of $2.5 \mathrm{ml}$. Thus, the metal concentration could then be varied, the $\mathrm{PSB}_{3}$ concentration being identical in all cuvettes (from 8.06.10 $\mathrm{M})$. Since the concentration of the free metal in the unsaturated $\mathrm{PSB}_{3}$ solution was assumed to be negligible, fluorescence quenching could be analyzed as a function of metal concentration. A non-linear regression curve was fitted to the experimental points within a $95 \%$ confidence level using the NLIN program (NLIN procedure, SAS institute Inc., Cary, NC) and the following Eq. (5):

$$
Y \%=(100-I) e^{-A \cdot C}+I
$$

where: $\quad Y=$ level of fluorescence at any metal concentration;

$\mathrm{I}=$ residual fluorescence of metal saturated $\mathrm{PSB}_{3}$;

$C=$ concentration of metal;

$\mathrm{A}$ and $\mathrm{n}=$ equation parameters. 
Fluorescence was found to be quenched upon addition of the metals until no change occurred and the level of residual fluorescence was reached. If the complex formed was of a 1:1 type, this should have occurred when the metal concentration equaled that of the ligand. Fluorescence intensity at any non-saturating metal concentration was related to the complexed-PSB 3 / free- $\mathrm{PSB}_{3}$ ratio. All the other parameters being known, the concentration of the metal- $\mathrm{PSB}_{3}$ complex and that of the free ligand could be calculated for any given value of $\mathrm{Y}$ in the standard curve. Titrations of metal-PSB complexes with competing ligands: Titration solutions were prepared as described above. Complexes of $\mathrm{PSB}_{3}$ with various metals $\left(\mathrm{Zn}^{2+}, \mathrm{Mn}^{2+}, \mathrm{Cu}^{2+}, \mathrm{Ca}^{2+}\right.$ and $\left.\mathrm{Mg}^{2+}\right)$ were used instead of uncomplexed $\mathrm{PSB}_{3}$. The competing ligand was dissolved in the appropriate buffer and added to the desired final concentrations. The experimental values of fluorescence intensity obtained for any given concentration of the competing chelate were used in order to calculate the concentrations of the complexed and the free forms of $\mathrm{PSB}_{3}$ and that of the competing ligand by fitting them to the appropriate standard curve with respect to $\mathrm{pH}$, buffer, metal and total concentration of $\mathrm{PSB}_{3}$.

Unsaturated metal-PSB ${ }_{3}$ complexes were used in some competition experiments. The following changes were introduced in order to take the fluorescence intensity of the unsaturated solution into account (Eq. 6):

$$
[\mathrm{FeL}]=\left[\mathrm{PSB}_{3}\right]-\left[\mathrm{PSB}_{3}\right]_{0}
$$

where: $\left[\mathrm{PSB}_{3}\right]_{0}=\left[\mathrm{PSB}_{3}\right]$ at the beginning of the titration, when no competing ligand was added $\left([\mathrm{L}]_{\text {total }}=0\right)$.

The various ligand and buffer solutions were checked for fluorescence at the working wavelengths and shown not to interfere with the measurements. The solutions seemed to have 
reached equilibrium after 24 hours since no further changes were evident after that time. The apparent stability constant of $\mathrm{PSB}_{3} \mathrm{~A}$ (A-first of the two major bands eluted in the purification procedure) with $\mathrm{Fe}^{3+}$ at $\mathrm{pH} 5$ in a $\mathrm{Na}$-acetate buffer was measured by determination of the fluorescence quenching by $\mathrm{Fe}^{3+}$ and the recovery of the fluorescence by titrating the complex with increasing concentrations of EDTA. The constant obtained was compared to the constant that was calculated on the basis of changes in absorption at $450 \mathrm{~nm}$.

Determination of the protonation constants: Three $\mathrm{mL}$ of $5.12 \mathrm{mM}$ purified $\mathrm{PSB}_{3}$ (H-form) in $0.1 \mathrm{M} \mathrm{KCl}$ were titrated with $\mathrm{CO}_{2}$-free $0.1 \mathrm{M} \mathrm{NaOH}$ from $\mathrm{pH} 2$ to $\mathrm{pH} 12$ using a Dosimat 665 titroprocessor (Metrohm, Switzerland) under $\mathrm{N}_{2}$ atmosphere. Temperature was held constant at $25^{\circ} \mathrm{C} \pm 0.1$. The $\mathrm{pH}$ electrode was calibrated using standard commercial buffers and was corrected for slope deviation. Protonation constants were determined by processing the titration data using the PKAS computer program (Martell and Motekaitis, 1988).

Potentiometric determination of stability constants: The complexes of $\mathrm{PSB}_{3}\left(\mathrm{H}-\right.$ form) with $\mathrm{Fe}^{3+}$, $\mathrm{Fe}^{2+}, \mathrm{Cu}^{2+}, \mathrm{Mn}^{2+}$, and $\mathrm{Zn}^{2+}$ in $0.1 \mathrm{M} \mathrm{KCl}\left(1.5\right.$ to $3 \mathrm{ml}$ of $5.12 \mathrm{mM} \mathrm{PSB}_{3}$ solution) were titrated with $\mathrm{CO}_{2}$-free $0.1 \mathrm{M} \mathrm{NaOH}$ in a Dosimat 665 titroprocessor from $\mathrm{pH} 2$ to $\mathrm{pH} 12$ under $\mathrm{N}_{2}$ atmosphere. The $\mathrm{pH}$ electrode accuracy was determined to be $99.6 \%$ (accuracy was corrected during data processing). Log $\mathrm{K}_{\mathrm{ML}}$ values were determined by processing the titration data using the BEST computer program (Martell and Motekaitis, 1988). The program computes the stability constant of any metal-ligand species from the differences in input data of potentiometric titration curves of the free ligand and those of the various metal complexes. The difference in the amounts of base consumed for the two titrations at any given $\mathrm{pH}$ reflects the affinity of the ligand for the metal. The overall stability constant, $\log \mathrm{K}_{\mathrm{ML}}$, was calculated from the apparent stability constant 
obtained by the various spectroscopic or titration methods for two $\mathrm{pH}$ values by the method described above according to the following equation (von Anderegg et al., 1963):

$$
\log \mathrm{K}_{\mathrm{apparent}}=\log \mathrm{K}_{\mathrm{ML}} \cdot \boldsymbol{\alpha}
$$

where $\alpha=1+[H] K^{H}+[H]^{2} K^{H} K^{H}+[H]^{3} K^{H} K^{H} K^{H}$

\section{RESULTS}

Determination of the stability constant of $\mathrm{Fe}^{3+}-\mathrm{PSB}_{3}$ by fluorescence quenching: The stability constant of the $\mathrm{Fe}^{3+}$ complex of the two pseudobactin bands (bands $\mathrm{A}$ and $\mathrm{B}$ ) extracted from the growth medium was measured by fluorescence and by visible (VIS) spectroscopy. The release of $\mathrm{Fe}^{3+}$ from the $\mathrm{PSB}_{3}$ complex resulted in an increase in fluorescence intensity proportional to the concentration of the free $\mathrm{PSB}_{3}$ and that of the competing chelate, and to their relative affinity for the metal ion under the experimental conditions used. Results obtained by the fluorescent method using various buffers and for both shaking flasks and fermentor produced PSB $_{3}$ are presented in Table 1. It should be noted that $\mathrm{PSB}_{3} \mathrm{~A}$ and $\mathrm{PSB}_{3} \mathrm{~B}$ from both shaking flasks and fermentor were found to be chromotographicality identical.

The apparent stability constant of the $\mathrm{Fe}^{3+} \mathrm{PSB}_{3} \mathrm{~A}$ was measured using fluorescence spectroscopy at pH 5.0 in Na-acetate buffer, with EDTA as the competing chelate. Changes in the absorbance at $450 \mathrm{~nm}$ upon increasing the concentration of the competing chelate was used to measure $\log \mathrm{K}$ under the same conditions. The two methods gave similar results, with Log $\mathrm{K}$ values of $19.15 \pm 0.10$ and $19.34 \pm 0.13$ for the fluorescence spectroscopy and the visible spectrophotometry, respectively. 
In a previous study we showed using visible spectroscopy that $\mathrm{PSB}_{3} \mathrm{~A}$ and $\mathrm{PSB}_{3} \mathrm{~B}$ had similar stability constants at $\mathrm{pH} 5[\mathrm{Log} \mathrm{K}=19.25$ and 19.00 respectively, (Jurkevitch et al., 1988)]. This similarity was confirmed by fluorescence spectroscopy at pH 6 . The stability constants of the $\mathrm{Fe}^{3+} \mathrm{PSB}_{3}$ complexes of bands $\mathrm{A}$ and $\mathrm{B}$ were 22.52 and 22.65 , respectively (Table 1). This could be expected as $\mathrm{PSB}_{3} \mathrm{~B}$ is probably an alkaline-hydrolysis product of $\mathrm{PSB}_{3} \mathrm{~A}$ (Demange et al., 1987) and no change occurs in the ligand groups. Since both $\mathrm{PSB}_{3} \mathrm{~A}$ and $\mathrm{PSB}_{3} \mathrm{~B}$ were found to be biologically active and are similar with respects to $\mathrm{Fe}$ binding, $\mathrm{PSB}_{3} \mathrm{~A}$ purified from a shaking flasks culture was used for most of the subsequent studies. The results showed that the value obtained in a phosphate buffer system was somewhat higher than with the MES buffer. Biological buffers are known to interact much less with metals than phosphate that can form insoluble salts (Lindsay, 1979). Biological buffers were therefore used in these experiments.

One of the advantages of fluorescence spectroscopy is that the choice of the competing chelate is not restricted to compounds that do not exhibit light (UV or VIS) absorbance at the working wavelength. Therefore, the chelate best suited for the needs can be used. Desferrioaxamine B, a trihydruxamate siderophore whose $\mathrm{Fe}^{3+}$ complex has an absorbance peak at $428 \mathrm{~nm}$ was used as the competing chelate with $\mathrm{Fe}^{3+} \mathrm{PSB}_{3}$. As expected, the value obtained was similar to the one measured with EDTA (Table 1).

Determination of the stability constant of divalent metals with PSB ${ }_{3}$ by fluorescence quenching: The natural habitat of $\underline{\mathrm{P}}$. putida is a heterogeneous medium in which many metals are present at concentrations higher than $\mathrm{Fe}$. One of the conditions required for the formation of a stable $\mathrm{Fe}^{3+} \mathrm{PSB}_{3}$ complex in the soil environment is to have a much higher affinity for $\mathrm{Fe}^{3+}$ than for any other metal. The complexes formed upon chelation of $\mathrm{Cu}^{2+}, \mathrm{Mn}^{2+}, \mathrm{Zn}^{2+}, \mathrm{Ca}^{2+}$ and $\mathrm{Mg}^{2+}$ by 
$\mathrm{PSB}_{3}$ do not show charge transfer bands that can readily allow measurements of the free and complex forms of the ligands in competition experiments. Stability constants of complexes with $\mathrm{PSB}_{3}$ were measured at $\mathrm{pH} 6,7.5$ and 8.5 by the following methods: (i) Quenching of fluorescence at $460 \mathrm{~nm}$ upon titration of pseudobactin with these metals; (ii) the release of fluorescence when EDTA was used as the competing chelate; and (iii) by potentiometric titrations. At slightly acidic $\mathrm{pH}$ values ( $\mathrm{pH}$ 6, MES buffer) no complex formation was detected and no quenching of fluorescence occurred when $\mathrm{PSB}_{3}$ was titrated with $\mathrm{Mn}^{2+}, \mathrm{Zn}^{2+}, \mathrm{Ca}^{2+}$ or $\mathrm{Mg}^{2+}$. However, a stable $\mathrm{Cu}^{2+}$ complex was formed under these conditions. The absorbance peak was shifted when this complex was formed from $380 \mathrm{~nm}$ to $408 \mathrm{~nm}$ at pH 6.0 without the formation of a charge transfer band. Since the absorption spectrum of the free ligand of $\mathrm{PSB}_{3}$ is $\mathrm{pH}$ dependant, this shift was strongly reduced at $\mathrm{pH} 7.5$ and 8.5 . The chelating capacity of the solution with respect to $\mathrm{Cu}^{2+}$ was determined by fluorescence spectroscopy at $\mathrm{pH} 6.0, \mathrm{pH} 7.5$ and $\mathrm{pH}$ 8.5. In contrast with other metals it was found that the chelating capacity of the solutions varied with $\mathrm{pH}$, and it also differed from the $\mathrm{PSB}_{3}$ concentration in solution $\left(1.10^{-5} \mathrm{M}\right)$. At $\mathrm{pH}$ $6.0,7.5$ and 8.5 the apparent chelating capacity as measured by fluorescence spectroscopy was found to be $1.3 .10^{-5}, 1.5 .10^{-5}$ and $2.1 .10^{-5}$, respectively. This suggests that with $\mathrm{Cu}^{2+}$, the $\mathrm{PSB}_{3}$ molecule may form more than one type of complex. The number of $\mathrm{Cu}^{2+}$ ions complexed per ligand molecule averaged $1.18,1.36$ and 1.91 at $\mathrm{pH} 6,7.5$ and 8.5 , respectively. Although the stability constants could not be calculated, it was observed that at all three $\mathrm{pH}$ values, the addition of equimolar concentrations of EDTA to those of $\mathrm{Cu}^{2+}$ produced a $100 \%$ recovery of the relative fluorescence, indicating that the complex formed is much weaker than the $\mathrm{Fe}^{3+} \mathrm{PSB}$ complex. 
Fluorescence quenching by titrating $\mathrm{PSB}_{3}$ with $\mathrm{Mn}^{2+}$ occurred at $\mathrm{pH} 7.5$ and $\mathrm{pH}$ 8.5. The results obtained for the titration at $\mathrm{pH} 7.5$ are shown in Fig. 1. The chelating capacity of the titration solutions was-very close to the concentration of $\mathrm{PSB}_{3}$ in the system, thus indicating that a 1:1 complex was formed (Fig. 1). A slight shift in the absorbance spectrum to $406 \mathrm{~nm}$ was observed at $\mathrm{pH} 7.5$ and 8.5. The residual fluorescence at, and beyond, the end-point of the titrations decreased from $13 \%$ at $\mathrm{pH} 7.5$ to $1 \%$ at $\mathrm{pH} 8.5$, probably due to loss of protons from the hydroxamate group on the ligand. No shift in emission nor in excitation spectra were detected. Upon titration of the $\mathrm{Mn}^{2+} \mathrm{PSB}_{3}$ complex with EDTA, fluorescence was fully recovered (Fig. 1) and the apparent stability constants were calculated accordingly (Table 2).

When $\mathrm{PSB}_{3}$ was titrated with $\mathrm{Zn}^{2+}$ the residual fluorescence level was about $35 \%$ that of the free ligand at $\mathrm{pH} 7.5$ and at $\mathrm{pH}$ 8.5. Results obtained for titration at $\mathrm{pH} 7.5$ are presented in Fig. 1. The decrease of fluorescence intensity at $460 \mathrm{~nm}$ was the result of a shift in the emission peak to $488 \mathrm{~nm}$. A back titration of the $\mathrm{Zn}^{2+} \mathrm{PSB}_{3}$ complex with EDTA resulted in a complete recovery of the fluorescence (Fig. 1). The apparent stability constants of the $\mathrm{Zn}^{2+} \mathrm{PSB}_{3}$ complex at $\mathrm{pH} 7.5$ and at $\mathrm{pH} 8.5$, were calculated based on competition with EDTA, and are shown in Table 2. The complex had an absorption peak at $416 \mathrm{~nm}$ at pH 7.5 and 8.5 , apparently without the formation of a charge transfer band: As for $\mathrm{Mn}^{2+}$, the titration indicated the formation of a $1: 1$ complex. $\mathrm{Ca}^{2+}$ and $\mathrm{Mg}^{2+}$, the most abundant divalent ions in solution of many soils were also studied. No interactions of these ions with $\mathrm{PSB}_{3}$ at any of the tested $\mathrm{pH}$ values were detected using fluorescence and UV-VIS spectroscopy.

pKa values: Three major pKa values of PSB that were detected between $\mathrm{pH} 2$ to $\mathrm{pH} 12$ after data processing by the computer program PKAS (Martell and Motekaitis, 1988) were: $\mathrm{pKa}_{1}-11.28$; 
$\mathrm{pKa}_{2}-7.74 ;$ and $\mathrm{pKa}_{3}-5.35$. These values were assigned to the catecholate, hydroxamate and hydroxy groups respectively (Blanc-Parasote, 1989).

Calculations and measurements of the apparent stability constant over a wide $\mathrm{pH}$ range: The apparent stability constant calculated using $\mathrm{Eq}$. (7) over a wide range of $\mathrm{pH}$ and the values measured by fluorescence quenching ( $\mathrm{pH} 5$ to 8.5) for $\mathrm{Fe}^{3+}, \mathrm{Mn}^{2+}$, and $\mathrm{Zn}^{2+} \mathrm{PSB}_{3}$ complexes are presented in Fig. 2. The calculated lines are an extension of the measured values to both higher and lower $\mathrm{pH}$ and they can be useful for further calculations. ?

Potentiometric determination of stability constants: The overall stability constant ( $\log \mathrm{K}_{\mathrm{MU}}$ ) for $\mathrm{Cu}^{2+} \mathrm{PSB}_{3}, \mathrm{Mn}^{2+} \mathrm{PSB}_{3}, \mathrm{Zn}^{2+} \mathrm{PSB}_{3}$, and $\mathrm{Fe}^{2+} \mathrm{PSB}_{3}$ were calculated from the potentiometric titration data of the free ligand and of the corresponding metal complex using Eq. (7) and the pKa values obtained by potentiometry and the BEST computer program (Martell and Motekaitis, 1988). Results of these calculations are presented in Table 3, in comparison to Log $\mathrm{K}_{\mathrm{ML}}$ values based on fluorescence as well as on visible spectra in the case of $\mathrm{Fe}^{3+}$. Stability constants determined by fluorescence spectroscopy were in good agreement with those calculated from the potentiometric titrations of the metal-PSB 3 complexes. The results obtained by the various methods show the high affinity of $\mathrm{PSB}_{3}$ for $\mathrm{Fe}^{3+}$ as compared to other metals, as the overall stability constants of the divalent metals were lower by 7 to 20 orders of magnitude. Determination of Log $\mathrm{K}$ by absorbance in the visible range was not feasible since the changes in absorbance due to metal complexing are minor except for $\mathrm{Fe}^{3+}$. Therefore, no data are presented in the "Visible" column of Table 3 for $\mathrm{Cu}^{2+}, \mathrm{Mn}^{2+}, \mathrm{Zn}^{2+}$ and $\mathrm{Fe}^{2+}$. The overall stability constant for the $\mathrm{Fe}^{3+} \mathrm{PSB}_{3}$ complex could not be determined potentiometrically due to the strong binding of $\mathrm{Fe}^{3+} \cdot \mathrm{PSB}_{3}$ at any given $\mathrm{pH}$ between 2 to 12 and $\mathrm{Fe}^{3+}$ hydroxide 
formation at neutral to high $\mathrm{pH}$.

\section{DISCUSSION}

Fluorescence spectroscopy has been used formerly to determine the apparent stability constants of the binding of $\dot{\mathrm{Cu}}^{2+}$ and other heavy metals to humic and fulvic acids (Ryan and Weber, 1982, Frimmel and Hopp, 1984). However, the models used in these studies were developed to quantify complexation by compounds exhibiting low affinity toward the metals characterized by $\log \mathrm{K}_{\mathrm{ML}}$ values ranging from 4 to 10 . Since $\mathrm{PSB}_{3}$ exhibits high affinity for $\mathrm{Fe}^{3+}$, and lower affinity for other metal cations, an alternative method was developed. The method included measurements of fluorescence quenching and recovery, a non linear regression curve fitting to the titration data, and calculations using the titration of the complex with a known chelate. The validity of the method was checked by comparing the values of the apparent stability constants obtained both by the fluorescence spectroscopy method and by visible spectroscopy. Based on the protonation constants determined by potentiometric titration, the overall stability (formation) constants (Log $\mathrm{K}_{\mathrm{ML}}$ ) were also calculated. Values of $\log \mathrm{K}_{\mathrm{ML}}$ obtained by various methods were compared and found to be similar (Table 3).

Persmak et al., (1990) found that the pseudobactin of $\underline{P}$. putida 589 exhibited an apparent stability constant (Log K) of 19.0 at pH 5 which is similar to the value found in this study (Log $\mathrm{K}=19.15$ ). At $\mathrm{pH}$ values higher than 6 , EDTA could not effectively compete for $\mathrm{Fe}^{3+}$ with $\mathrm{PSB}_{3}$. The binding of $\mathrm{Fe}^{3+}$ by $\mathrm{PSB}_{3}$ is $\mathrm{pH}$ dependent, as the ligand groups lose their protons with increasing basicity of the solution. At pH 5 and $\mathrm{pH} 6.0$, Log $\mathrm{K}$ equals 19.3 and 22.5, respectively, indicating the high affinity of PSB for $\mathrm{Fe}^{3+}$ at neutral to alkaline $\mathrm{pH}$. 


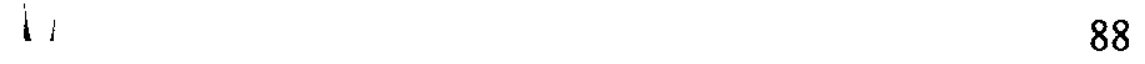

No differences in the UV-VIS and fluorescence spectra as well as in the stability of the $\mathrm{Fe}^{3+}-\mathrm{PSB}_{3}$ complexes were found between the chromatographical $\mathrm{PSB}_{3} \mathrm{~A}$ and $\mathrm{PSB}_{3} \mathrm{~B}$. These compounds which seem to differ only in the composition of a side chain attached to their chromophore (Demange et al., 1990) were practically identical in their spectral and complexation properties. It should also be noted that it was recently demonstrated that the differences in side chains bound to the PSB choromophore result from hydrolysis reactions in the growth medium (Schaefer et al., 1991).

Although Macdonald and Bishop (1984) who studied fluorescent and spectral properties of fluorescent compounds produced by $\underline{P}$. aeruginosa reported that upon complexation with various metals $\left(\mathrm{Al}^{3+}, \mathrm{Ga}^{3+}, \mathrm{In}^{3+}, \mathrm{Th}^{4+}, \mathrm{Zn}^{4+}\right.$ and $\mathrm{Mg}^{2+}$ ) fluorescence was affected, these properties have not been applied to stability constant determinations. The binding constants that were measured in this study show that complexes of $\mathrm{Mn}^{2+}, \mathrm{Zn}^{2+}$ and $\mathrm{Fe}^{2+}$ were far less stable than the $\mathrm{Fe}^{3+}$ complex, which is the most stable form of $\mathrm{PSB}_{3}$. The stability constants for the divalent cations increased slightly with $\mathrm{pH}$ (Table 2), but the increments were smaller than for $\mathrm{Fe}^{3+}$. $\mathrm{PSB}_{3}$ seems to interact very weakly with $\mathrm{Ca}^{2+}$ or $\mathrm{Mg}^{2+}$, two of the most abundant cations in neutral to alkaline soils. Although soluble inorganic $\mathrm{Fe}^{3+}$ is found at a much lower concentration in Fe-deficient soils than divalent metals such as $\mathrm{Zn}^{2+}, \mathrm{Cu}^{2+}$ and $\mathrm{Mn}^{2+}$, the large differences in the affinity of $\mathrm{PSB}_{3}$ for $\mathrm{Fe}^{3+}$ as compared to the other metals $\mathrm{Fe}^{3+} \mathrm{PSB}_{3}$ is expected to be the dominant species of $\mathrm{PSB}_{3}$ in soil solutions containing $\mathrm{PSB}_{3}$. Obviously, a situation at any specific soil solution can be easily calculated using computer models such as GEOCHEM provided the data presented in this paper are incorporated in the data base. Since stability constants were determined using various methods resulting in very similar values, we suggest the 
use of an average value, or the use of the relevant value according to the method of determination in any future use of our data. Thus, it seems reasonable to envision that $\mathrm{PSB}_{3}$ excreted in the rhizosphere would be found essentially as $\mathrm{Fe}^{3+} \mathrm{PSB}_{3}$. The fact that fluorescence facilitates determinations of stability constants using competing chelates exhibiting overlapping spectra is a definitive advantage if competition experiments are undertaken. We believe that fluorescence spectroscopy provides a useful tool for research designed to improve our understanding of interactions of fluorescent siderophores with metals, as well as the elaboration of their biological significance as $\mathrm{Fe}^{3+}$ carriers to plants and microorganisms. 


\section{REFERENCES}

von Anderegg, G., F.L. L'Eplattenier, and G. Schwarzenbach. 1963. Hydroxamatkomplexe II. Die Anwendung der pH-Methode. Helv. Chim. Acta 46:1400-1408.

Blanc-Parasote, S. 1989. Etudes Physico-Chimiques d'ionophores naturels: Antibiotiques carboxiliques et siderophores bacteriens. These Doctorat, Universite Louis Pasteur, Strasbourg.

Demange, P., S. Wendenbaum, A. Bateman, A. Dell, and M.A. Abdallah. 1987. Bacterial siderophores: structure and physicochemical properties of pyoverdins and related compounds. p. 166-187. In G. Winkelmann, D. van der Helmg, and J.B. Neilands (Ed.), Iron Transport in Microbes, Plants and Animals VCH, Weinheim.

Demange, P., A. Bateman, C. Mertz, A. Dell, Y. Piemont, and M.A. Abdallah. 1990. Bacterial siderophores: structures of pyoverdins Pt, siderophores of Pseudomonas tolaasii, and pyoverdins Pf, siderophores of Pseudomonas fluorescens CCM 2798. Identification of an unusual natural amino acid. Biochem. 29:11041-11051.

Frimmel, F.H., and W. Hopp. 1984. Fluorimetric investigation of the interaction of heavy metals with humic substances. pp. 200-206, Second Conference of the International Humic Substances Society In Hayes, M.H.B. and Swift, R.S. (Ed.), Birmingham University Press.

Hider, J.C. 1984. Siderophore-mediated absorption or iron. Struc. Bonding 58:25-87. 
Jurkevitch, E., Y. Hadar, and Y. Chen. 1988. Involvement of bacterial siderophores in the remedy of lime induced chlorosis in peanuts. Soil Sci. Soc. Am. J. 52:1032-1037.

Lindsay, W.L. 1979. Chemical equilibria in soils. Wiley and Sons, N.Y.

Macdonald, J. C., and G.G. Bishop. 1984. Spectral properties of a mixture of fluorescent pigment produced by Pseudomonas aeruginosa. Biochem. Biophys. Acta 800: 11-20.

Martell, A.E., and R.J. Motekaitis. 1988. Determination and use of stability constants. VCH Publishers, Inc. FRG. 216 pp.

Meyer, J.M., and M.A. Abdallah. 1978. The fluorescent pigment of Pseudomonas fluorescens: biosynthesis, purification, and physicochemical properties. J. Gen. Microbiol. 107: 319-328.

Neilands, J.B. 1981. Microbial irón compounds. Ann. Rev. Biochem. 50:715-731.

Persmark, M., T. Frejd, and B. Mattiasson. 1990. Purification, characterization, and structure of pseudobactin $589 \mathrm{~A}$, a siderophore from a plant growth promoting Pseudomonas. Biochem. 29:7348-7356.

Philson, S.B., and M. Llinas. 1982. Siderophores from Pseudomonas fluorescens. J. Biol. Chem. 257: 8081-8085.

Rosotti, J.C., and H. Rosotti. 1961. The determination of stability constants. McGraw Hill, N.Y. Ryan, D.K., and J.H. Weber. 1982. Fluorescence quenching titration for determination of complexing capacities and stability constants of fulvic acid. Anal. Chem. 54: 989-990.

Schaefer, H., K. Taraz, and H. Budzikiewicz. 1991. On the genesis of the dicarboxylic acids bound amidically to the chromophore of the pyoverdins. Verlag der Zeitschrift fuer Naturforschung 46:398-406. 
Sposito, G., and S.V. Mattigud. 1980. GEOCHEM: a computer program for the calculation of chemical equilibria in soil solutions and other natural water systems. Kearney Foundation of Soil Science, University of California, Riverside, pp 92.

Teintze, M., and J. Leong. 1981. Structure of pseudobactin A, a second siderophore from plant growth promoting Pseudomonas B10. Biochem. 20:6457-6462. 
Table 1. Stability constants with $\mathrm{Fe}^{3+}$ of $\mathrm{PSB}_{3}$ produced by $\mathrm{P}$. putida when grown in shaking flasks and in a fermentor (means and standard errors determined by fluorescence quenching, presented as $\log \mathrm{K}$; ionic strength $0.1 \mathrm{M}$; $\mathrm{pH}$ 6).

\begin{tabular}{|c|c|c|c|c|c|}
\hline Competing & Buffer & Shaking fla & & $\therefore$ Ferme & ntor \\
\hline chelate & & ${ }^{\dagger} \mathrm{PSB}_{3} \mathrm{~A}$ & $\mathrm{PSB}_{3} \mathrm{~B}$ & $\mathrm{PSB}_{3} \mathrm{~A}$ & $\mathrm{PSB}_{3} \mathrm{~B}$ \\
\hline EDTA & MES & $22.52 \pm 0.01$ & $22.65 \pm 0.05$ & $22.42 \pm 0.09$ & $22.48 \pm 0.08$ \\
\hline
\end{tabular}

EDTA Phosphate n.d. $23.11 \pm 0.07$ n.d. n.d.

DFOB Phosphate n.d. $22.84 \pm 0.07$ n.d. n.d.

† - $\mathrm{PSB}_{3} \mathrm{~A}$ and $\mathrm{PSB}_{3} \mathrm{~B}$ were obtained chromatographically during purification of $\mathrm{PSB}_{3}$.

n.d. - not determined 
Table 2. Stability constants ( $\log \mathrm{K}$; means and standard deviations) determined by fluorescence quenching for $\mathrm{PSB}_{3} \mathrm{~A}$ with $\mathrm{Fe}^{3+}, \mathrm{Mn}^{2+}$ and $\mathrm{Zn}^{2+}$ (ionic strength - 0.1 M; pH values 5, 6, 7.5 and 8.5).

$\begin{array}{llll}\text { Metal } & \mathrm{pH} & \mathrm{PSB}_{3} & { }^{\dagger} \mathrm{EDTA}\end{array}$

\begin{tabular}{llrl}
$\mathrm{Fe}^{3+}$ & 5.0 & $\ddagger 19.3 \pm 0.125$ & 18.55 \\
$\mathrm{Fe}^{3+}$ & 6.0 & $22.5 \pm 0.01$ & 20.35 \\
$\mathrm{Mn}^{2+}$ & 7.5 & $13.1 \pm 0.25$ & 14.13 \\
$\mathrm{Mn}^{2+}$ & 8.5 & $14.8 \pm 0.125$ & 15.14 \\
$\mathrm{Zn}^{2+}$ & 7.5 & $14.8 \pm 0.00$ & 16.66 \\
$\mathrm{Zn}^{2+}$ & 8.5 & $16.9 \pm 0.6$ & 17.67 \\
$\mathrm{Ca}^{2+}$ & \multicolumn{3}{l}{ no detectable reaction } \\
$\mathrm{Mg}^{2+}$ & no detectable reaction
\end{tabular}

${ }^{\dagger} \log \mathrm{K}$ values for EDTA were calculated using Eq. (6) based on $\log \mathrm{K}_{\mathrm{ML}}$ and $\mathrm{pKa}$ values from Lindsay (1979).

${ }^{ \pm}$The Log $\mathrm{K}$ at $\mathrm{pH} 5.0$ was also determined by VIS spectroscopy. The value obtained was 19.34 \pm 0.13 . 
Table 3. Overall stability constants ( $\log \mathrm{K}_{\mathrm{ML}}$ ) for $\mathrm{PSB}_{3}$ complexes determined by various methods (ionic strength $0.1 \mathrm{M} ; 25^{\circ} \mathrm{C}$ ).

Metal Method of determination

Visible Fluorescence Potentiometry

$\begin{array}{llll}\mathrm{Fe}^{2+} & \text { a } & \text { n.d. } & 8.3 \\ \mathrm{Fe}^{3+} & 29.6 & 29.6 & \mathrm{~b} \\ \mathrm{Cu}^{2+} & \text { a } & \text { b } & 22.3 \\ \mathrm{Mn}^{2+} & \text { a } & 17.5 & 17.3 \\ \mathrm{Zn}^{2+} & \text { a } & 19.4 & 19.8\end{array}$

n.d. - not determined

a Changes in the absorbance in the visible range were too small to beused for $\log K$ or $\log \mathrm{K}_{\mathrm{ML}}$ determinations.

${ }^{b}$ not measurable. 


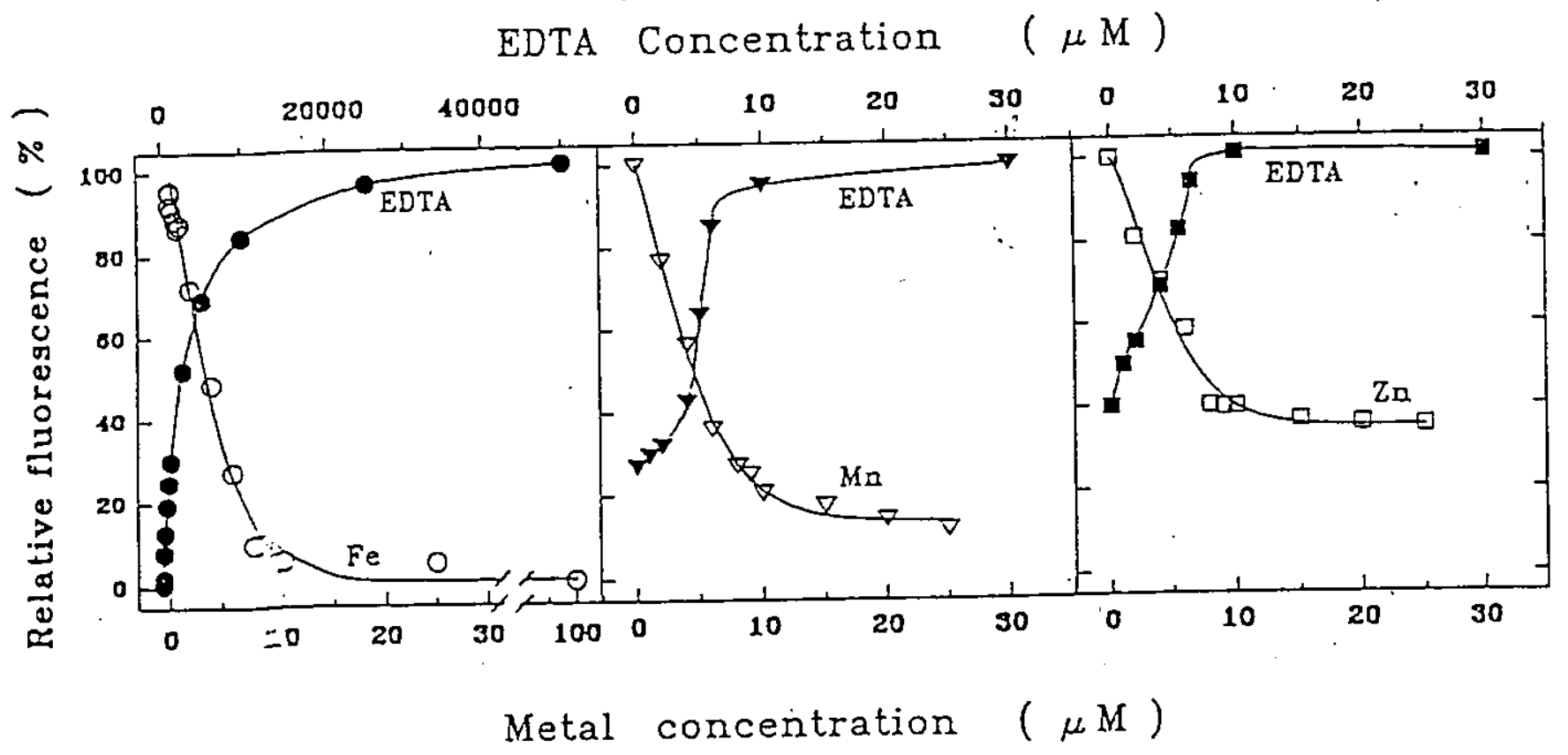

Fig. 1. Titration of $\mathrm{PSB}_{3}$ with $\mathrm{Fe}^{3+}$ ( $\mathrm{pH} 6$; MES buffer), $\mathrm{Mn}^{2+}$ and $\mathrm{Zn}^{2+}$ (pH 7.5; HEPES buffer) and the correspronding back titration with EDTA. Standard error bars were smaller than the graphic point, and therefore not presented. 


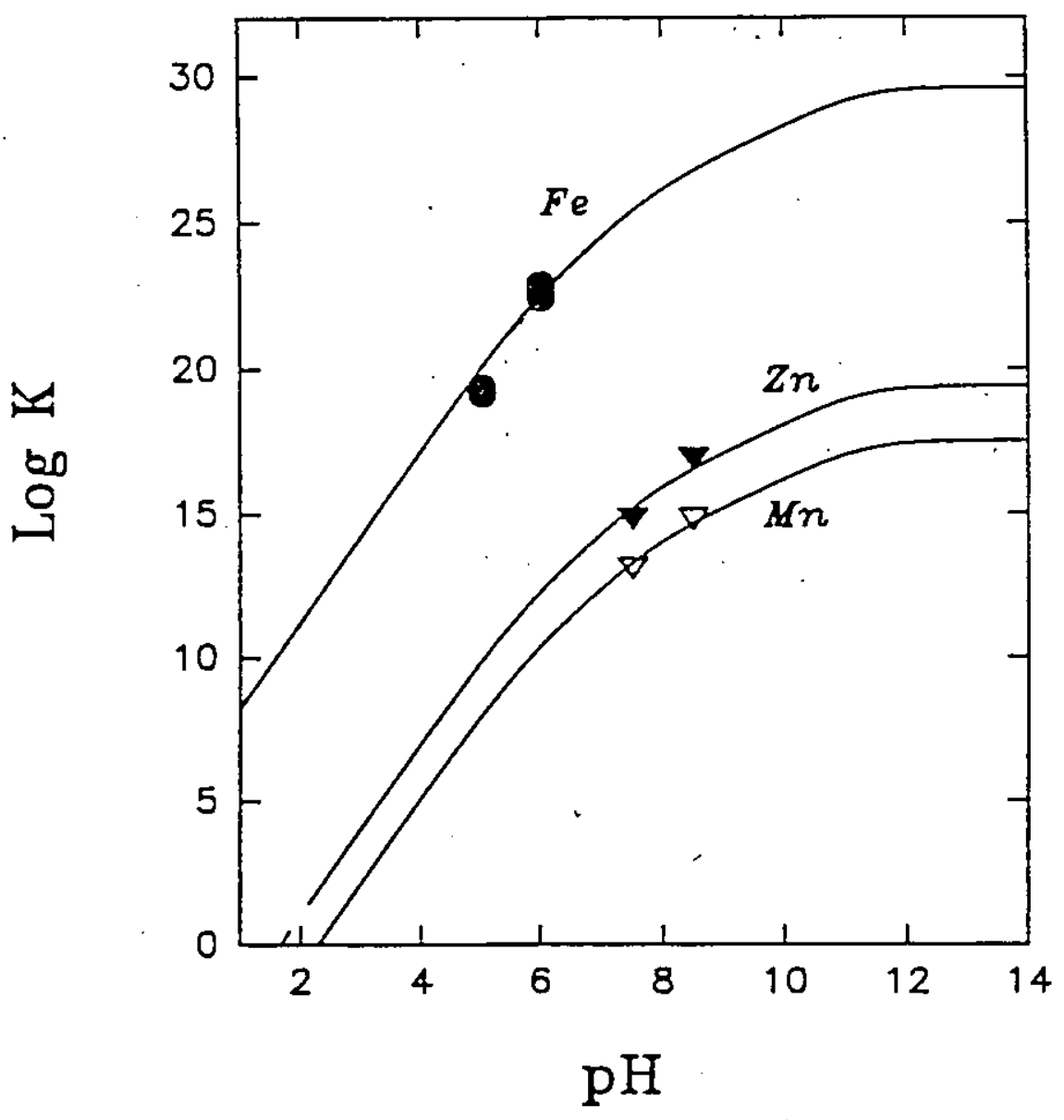

Fig.2. Calculated (using Eq.(7); solid line) and measured (by fluorescence quenching - symbols) Log $\mathrm{K}$ values for $\mathrm{Fe}^{3+} \mathrm{PSB}, \mathrm{Mn}^{2+} \mathrm{PSB}$ and $\mathrm{Zn}^{2+} \mathrm{PSB}$ complexes and their $\mathrm{pH}$ dependence. 
Utilization of the Phytosiderophore Mugineic Acid as an Iron Source by Rhizosphere Fluorescent Pseudomonads.

$\mathrm{Fe}$ is an essential element for most organisms. Due to the low solubility of its oxides, plants and microorganisms have developed various strategies operating to obtain sufficient supply of this essential element. Under Fe deficiency many microorganisms excrete siderophores which strongly and specifically bind $\mathrm{Fe}^{3+}$ (Nomoto et al, 1987). Dicoteledonous plants excrete protons, reductants and activate a reductase which reduces chelated $\mathrm{Fe}^{3+}$ to $\mathrm{Fe}^{2}+$ which is then absorded (Romheld, 1987). Gramineous plants produce phytosiderophores, which are $\mathrm{Fe}$ solubilizing biosynthetic chelates derived from nicotianamine (Nomoto et al, 1987, Shojima et al;, 1990). These compounds are known as mugineic acids (MAs). Some divergences exist as to the stability constant ( $\log K$ ) of MA with $\mathrm{Fe}^{3+}$. One study has determined it to be 18.1 (Nomoto et al, 1987), while in another a $\log K$ of 32 was reported (Murakami et al, 1989). MAs were shown to supply $\mathrm{Fe}$ to $\mathrm{Fe}$ stressed monocot plants, increasing the chlorophyll content of the leaf (Mino et al., 1983). MAs excretion and uptake take place at the root tip (Mihashi and Mori, 1989) which is not as heavily colonized by microorganisms as the elongation zone (van Vuurde and Schippers, 1980). This can somewhat protect MAs from microbial breakdown which has been shown occur rapidly (Watanabe and Wada, 1989). Bacteria which can thrive on MAs as their sole carbon source have been isolated, and a characterized strain belongs to the genus Pseudomonas (Watanabe and Wada, 1989). Pseudomonads are versatile bacteria as to their use of organic compounds as a carbon source, many of them having the ability to decompose a great number of substrates (Stanier et al., 1966).

Fluorescent pseudomonads are common rhizobacteria. They produce pseudobactin (PSB)-type siderophores which are not readily available as an $\mathrm{Fe}$ source to other rhizosphere bacteria (Jurkevitch et al., 1992), but they are able to utilize a wide variety of other siderophores. Thereby, fluorescent pseudomonads gain an ecological advantage (Buyer and Sikora, 1990, Jurkevitch et al.,1992). Since monocots may release phytosiderophores to the rhizosphere when stress prevails, it is of interest to study the availability of such chelators as $\mathrm{Fe}$ carriers to pseudomonads. Elaboration of the interactions of $\mathrm{Fe}^{3+}-\mathrm{MA}$ complexes with fluorescent pseudomonads was the aim of this study. 


\section{Materials and methods}

Bacterial strains: . putida WCS 358, its siderophore minus (sid ${ }^{-}$) Tn5 induced mutant JM 218, and P. putida B10 were obtained from of $P$. Weisbeek in Utrecht, The Netherlands, and J. Buyer, Beltsville, MD, USA, respectively. P. putida St3 has been isolated in our laboratory.

Siderophores: Mugineic acid (MA) and pseudobactin were purified as previously described (Mori et al., 1987, Jurkevitch et al.,1992).

Plate tests: The antibiosis plate test was carried out as described by Buyer and Leong (1986) with $0.6 \mathrm{ml}$ of soft agar inoculated with approximately $10^{3} \mathrm{CFU}$ poured over rhizosphere simulating medium (RSM) (Buyer et al., 1989) in $5 \mathrm{~cm}$ diameter Petri dishes. Twenty $\mu l$ of a $10^{-3} \mathrm{M}$ solution of the tested desferri compound were dropped onto a $6 \mathrm{~mm}$ diameter Whatman paper disk. The plates were incubated at $30^{\circ} \mathrm{C}$ and checked after $24 \mathrm{hrs}$.

For the iron-siderophore complex utilization test, the bacteria were grown in liquid RSM and $10^{3} \mathrm{CFU} / \mathrm{ml}$ were plated on RSM plates containing $201 \mu \mathrm{M}$ EDDHA (Buyer et al., 1989) treated as described by Rogers (1973). Ten $\mu$ of a $10^{-4} \mathrm{M}$ solution of the Fe-siderophore complexes were dropped on a Whatman paper disk. The plates were incubated as above.

Growth curves: The sid- strain JM 218 was used to test the efficiency of bacterial growth promotion in an $\mathrm{Fe}$ free liquid medium. Hepes-succinate medium (HSM), (succinate, $4 \mathrm{~g} / \mathrm{l} ; \mathrm{K}_{2} \mathrm{HPO}_{4}, 0.2 \mathrm{~g} / \mathrm{l} ;\left(\mathrm{NH}_{4}\right)_{2} \mathrm{SO}_{4}, 1 \mathrm{~g} / \mathrm{l} ; \mathrm{MgSO} 4.7 \mathrm{H}_{2} \mathrm{O}$, $0.2 \mathrm{~g} / \mathrm{l}$; Hepes, $11.91 \mathrm{~g} / \mathrm{l}$ ) was batch treated for $4 \mathrm{hrs}$ with Chelite $\mathrm{N}$ resin (10 $\mathrm{g} / \mathrm{l}$, Serva, Germany), decanted and filtered through a $0.45 \mathrm{~mm}$ filter. The $\mathrm{pH}$ was then raised to 7.2 by adding of $10 \mathrm{~N} \mathrm{NaOH}$ and the medium was autoclaved. Double-distilled water (DDW) was used and the glassware was washed with $6 \mathrm{~N}$ $\mathrm{HCl}$ followed by thorough rinsing with DDW.

Fifty-ml polypropylene test tubes were filled with $10 \mathrm{ml}$ of the Chelitetreated HSM. The $\mathrm{Fe}^{3+}$-siderophores were added to a final concentration of $10^{-6}$ $M$ and shaken in an inclined position at $28^{\circ} \mathrm{C}$. Samples were taken at desired intervals and turbidity at $620 \mathrm{~nm}$ was recorded. Each treatment was performed in triplicate.

$55 \mathrm{Fe}$ uptake: The procedure described by de Weger et al. (1988) was used with minor modifications. The bacteria were grown in liquid RSM to an $A_{620}$ of 0.6 to 0.7 , centrifuged for $15 \mathrm{~min}$ at $2500 \mathrm{rpm}$ then resuspended in liquid RSM to a final $A_{620}$ of 0.5 and incubated for $30 \mathrm{~min}$. in a water bath at $28^{\circ} \mathrm{C}$. In some 
experiments, $\mathrm{FeCl}_{3}\left(10^{-5} \mathrm{M}\right)$ was added to achieve $\mathrm{Fe}$ repleted conditions. The labelled $\mathrm{Fe}^{3+} \mathrm{MA}$ complex was added to a final concentration of $1 \mu \mathrm{M}$. Aliquots $(0.5 \mathrm{ml})$ were taken in duplicate, layered onto a mixture of octoil: dibutyl phtalate (1:2) and centrifuged as described. Cell growth during the time of the assay was measured by absorbance and accounted for in dry weight measurements. Counting was performed on a Beckman LS 1801 counter (USA).

Ligand exchange: Fe-MA (50\% saturated, 2.10-5 M MA, 10-5 $\mathrm{M} \mathrm{Fe}$ ) was dissolved in BES [N, N-bis(2-hydroxyethyl)-2-aminoethanesulfonic acid] buffer, $0.02 \mathrm{M}, \mathrm{pH} 7$ and was challenged by an equimolar concentration of free PSB St3 $\left(10^{-5} \mathrm{M}\right)$. Temperature was kept constant at $30^{\circ} \mathrm{C}$, and the formation of the $\mathrm{Fe}$ pseudobactin complex was followed by measuring the absorbance of the Fe-PSB complex at $450 \mathrm{~nm}$ (Meyer and Abdallah, 1978) on an HP8452A spectrophotometer (Hewlett-Packard, USA). At this wavelength FeMA virtually shows no absorbance (Nomoto et al, 1987). Absorption was measured every 10 sec. for $660 \mathrm{sec}$. then every $240 \mathrm{sec}$. In the reverse reaction, Fe-PSB $\left(10^{-5} \mathrm{M}\right)$ was challenged with an equimolar concentration of free MA under the same conditions.

\section{Results}

Growth promotion tests: Three of strains $\underline{P}$. putida were grown in an $\mathrm{Fe}$ deficient RS medium (RSM), which simulates the composition of the rhizosphere (Buyer et al., 1989). The bacteria were spread on RSM plates containing $201 \mu \mathrm{M}$ EDDHA and growth promotion tests with Fe-MA as the sole $\mathrm{Fe}$ source were performed. As shown in Table 1, Fe $3+-M A$ promoted the growth of all 3 strains, although B10 lagged behind St3 and WCS 358. After 18 hrs growth was apparent in strains St. 3 and WCS358 but significant growth of B10 developped only after $40 \mathrm{hrs}$. In antiobiosis-like plate tests in which the desferri MA was used none of the three strains was inhibited by MA.

The growth-promoting effects of Fe-MA was also studied in a Chelite-treated HSM liquid medium with the siderophore deficient mutant JM218. The Fe-MA complex was utilized as a source of $\mathrm{Fe}$, strongly promoting the growth of the bacterium (Fig. 1). These results indicate that the $\mathrm{Fe}^{3+}-\mathrm{MA}$ complex is used to provide the bacteria with $\mathrm{Fe}$.

$55 \mathrm{Fe}$ uptake: In order to confirm utilization of Fe-MA, experiments of MA mediated $55 \mathrm{Fe}$ uptake were undertaken. After $20 \mathrm{~min}$. an uptake of $0.92,1.34$ and 1.7 nmole Fe/mg dry weight (d.w.) was measured in strains St3, B10 and WCS358, respectively (Fig. 2). Uptake rates of $0.065,0.096$, and 1 nmole 
$\mathrm{Fe} /$ min.my d.w. were calculated from the linear part of the uptake curve. Uptake was completely abolished in the presence of cyanide anions indicating an active process (Fig. 2). The influence of the $\mathrm{Fe}$ status of the cells was investigated by culturing the bacteria in an Fe replete medium. Under these conditions no PSB is produced. Uptake of $55 \mathrm{Fe}$ mediated by $\mathrm{MA}$ in the Fe-replete cells was decreased by about 60,70 , and $70 \%$ in St3, B10, and WCS358, respectively (Fig. 2). This decrease is not as important as usually seen in the case of PSB-mediated Fe transport (de Weger et al., 1988, Hohnadel and Meyer, 1988). The intensity of uptake in $\mathrm{Fe}$ deficient cells as well as the uptake rates obtained are similar to data published for PSB mediated Fe uptake (de Weger et al., 1988, Hohnadel and Meyer, 1988). In order to clarify the reason for the high residual uptake in $\mathrm{Fe}$ replete cells, the Tn5 induced sid- mutant JM218 was challenged with $55 \mathrm{Fe}^{3+}$. MA after cultivation in an $\mathrm{Fe}$ deficient or in an $\mathrm{Fe}$ sufficient media. As shown in Fig.1, MA mediated $55 \mathrm{Fe}$ uptake in strain JM218 was independent of the $\mathrm{Fe}$ status of the cell. Moreover, the uptake curve is similar to the one obtained with the Fe-replete cells of the wild-type parent WCS358 (Fig. 2).

Ligand exchange: Strains St3, B10, and WCS358 excrete PSB when grown under Fe deficiency. During the time of the experiment $(50 \mathrm{~min}$ from resuspension of the cells in fresh RSM to the end of the uptake test) excretion of PSB occurs. This was proved by centrifugating the cells and testing the supernatant which showed a spectrum typical of free PSB (13). From this spectrum, a final concentration of about $2.10^{-5} \mathrm{M}$ was estimated. Therefore, the possibility of ligand exchange between MA and PSB excreted by the wild type bacteria exists. When the $\mathrm{Fe}^{3+} \mathrm{MA}$ complex was challenged by free PSB, almost total ligand exchange was achieved after $10.25 \mathrm{hrs}$ (Fig. 3). The spectrum of the resulting Fe-PSB was similar to that of fully chelated PSB Using the regression line obtained from this data a half-life of $2 \mathrm{hrs}$ was calculated. Under these conditions about $3.4 .10^{-6} \mathrm{M}$ moles of Fe-PSB could be formed by $\mathrm{Fe}$ exchange between MA and the St3 PSB in $1 \mathrm{hr}$ Fully chelated PSB was challenged with an equimolar concentration of $\mathrm{MA}$. In that case, virtually no ligand exchange could be detected (Fig. 3).

\section{Discussion}

In this study, it is shown that utilization of the $\mathrm{Fe}^{3+}$-MA complex as source of $\mathrm{Fe}$ by fluorescent pseudomonads occurs via an indirect mechanism. Since MA mediated $55 \mathrm{Fe}$ uptake in mutant JM218 was not enhanced by $\mathrm{Fe}$ depletion and since the kinetic data show that the high uptake rates observed in the wild type strains can be the result of ligand exchange, we assume that the $\mathrm{Fe}^{3+-M A}$ 
Table 1: Growth promoting effect of $\mathrm{Fe}^{3+-\mathrm{MA}}\left(10^{-4} \mathrm{M}, 10 \mathrm{mM}\right)$ on P. putida strains St3, WCS358 and B10 on RSM+EDDHA plates.

Strains*

St3

WCS358

B10

Time (hrs)

18

17

14

$11^{1}$

40

40

37

23

* Diameter of growth around a Whatman paper disk of $6 \mathrm{~mm}$ diameter, at $28^{\circ} \mathrm{C}$.

1Very small colonies.

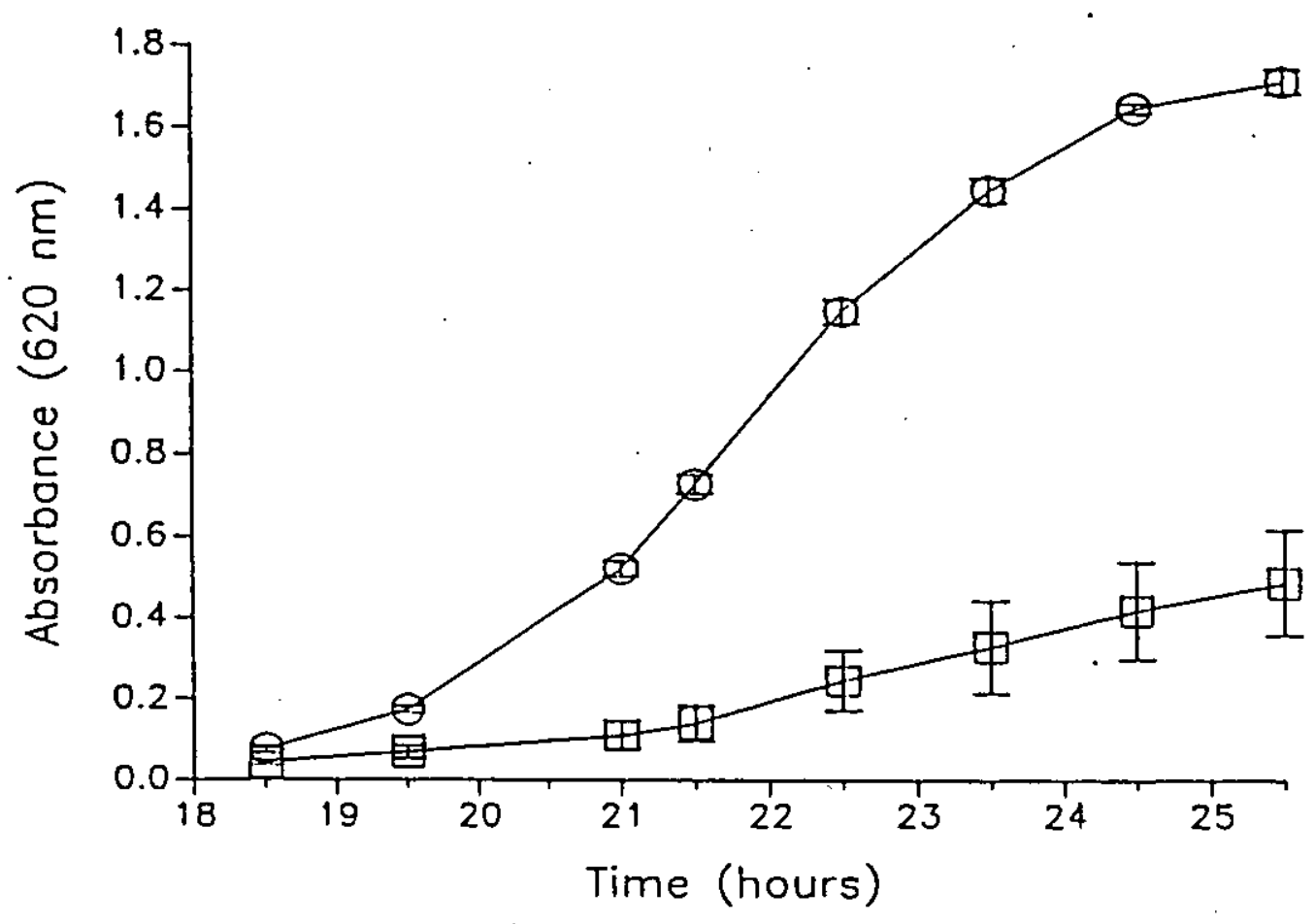

Figure : Growth of mutant JM218 in Chelite-treated HSM with mugineic acid (O) as an Fe source. Control $(\square)$, no added Fe source. Bars represent standard errors. 
complex is not recognized as a siderophore. Rather, it is maybe metabolized for other purposes, perhaps as a carbon source. $\underline{P}$. putida can grow on any of 18 amino acids, except methionine as sole carbon source (Jacoby, 1964). This amino acid has been shown to be used as sole nitrogen source by $\underline{P}$. aeruginosa (Kay and Gronhund, 1969a). P. aeruginosa possesses constitutive permeases for the active transport of amino acids, showing uptake rates and $\mathrm{Kms}$ of 0.2 to $8 \mathrm{nmole} / \mathrm{min}$. $\mathrm{mg}$ d.w. and $10^{-7}$ to $10^{-6} \mathrm{M}$ (Kay and Gronhund, 1969b).

The ecological significance of these findings deserve attention. As previously reported (van Vuurde and Schippers, 1980, Romheld, 1991), the spatial repartition of the MA release and of the high bacterial activity protects phytosiderophores from being quickly degarded by the bacterial flora. Using plants inoculated as to achieve different population levels or different bacterial composition, Bar-Ness et al. (1992a) were able to demonstrate that bacterial siderophore-mediated $\mathrm{Fe}$ uptake in roots is enhanced in inoculated as compared to sterilized roots. By using confocal microscopy this activity was shown to take place $40 \mathrm{~mm}$ from the root tips in maize, in a zone where dense mucigel was observed (Bar-Ness et al., 1992b). Similarly, it was recently showh that microbial inoculation of maize roots decrease hydroxymugineic acid-mediated Fe uptake and translocation (Crowley et al., 1992). Physical separation between the zones of active release and uptake of MAs and the heavily populated root segments could protect MA not only from microbial degradation, but also from competition for $\mathrm{Fe}$ with $\mathrm{PSB}$-and probably other bacterial siderophores. This spatial difference coupled with the very efficient uptake system of $\mathrm{Fe}^{3+} \mathrm{MAs}$ (Romheld, 1991) certainly could provide the basis for their high activity as $\mathrm{Fe}$ carriers in gramineous plants. 


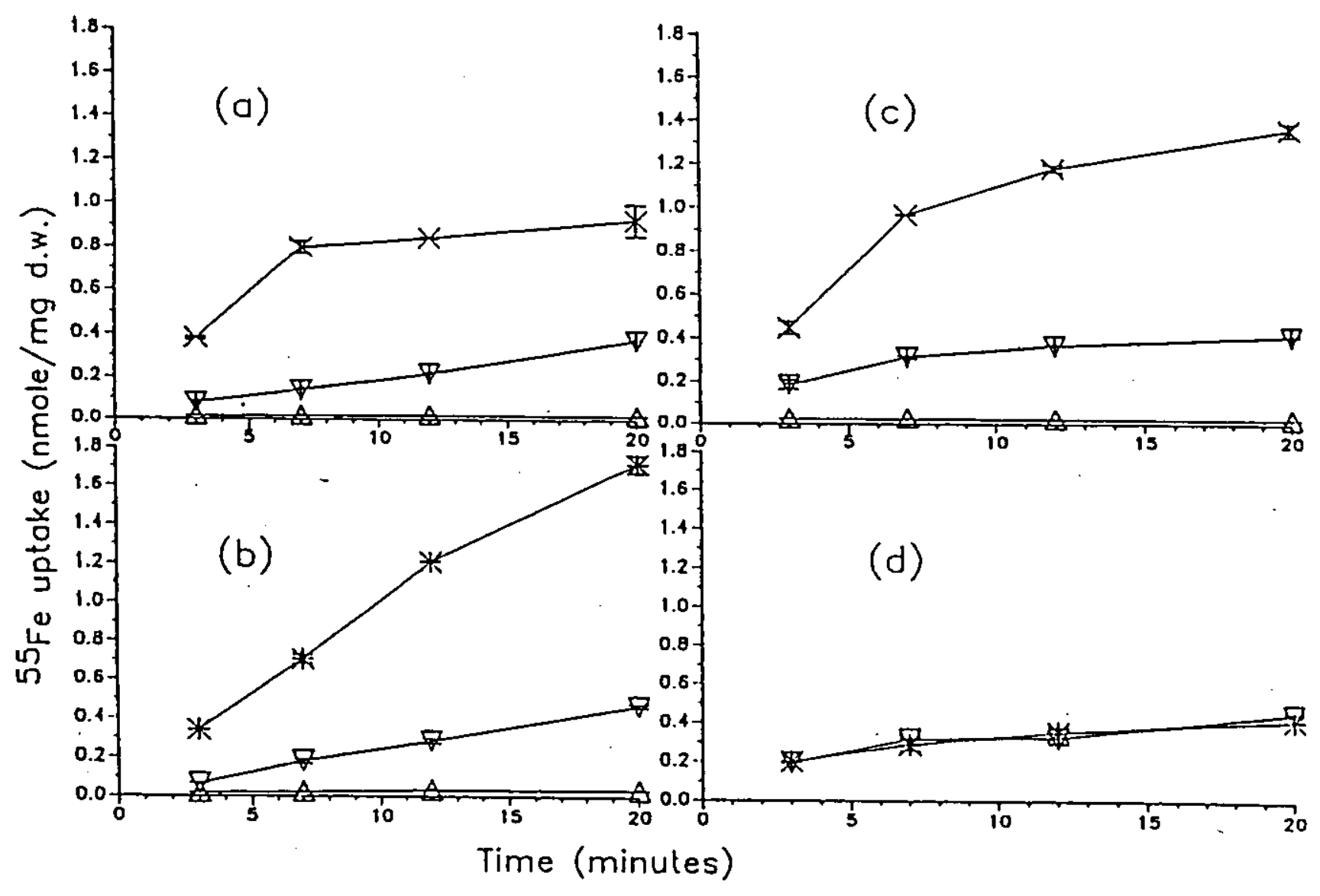

Eigure: ${ }^{55} \mathrm{Fe}$ uptake mediated by mugineic acid (MA) in p. putida strains St3 (a), WCS358 (b), B10 (c), and the siderophore deficient mutant JM218 (d). (*), Fe defictent cultures; $(\nabla)$, Fe sufficient cultures; $(\dot{\Delta})+10 \mathrm{mM} \mathrm{CN}^{-}$, added 20 minutes prlor to the start of the experiment. 


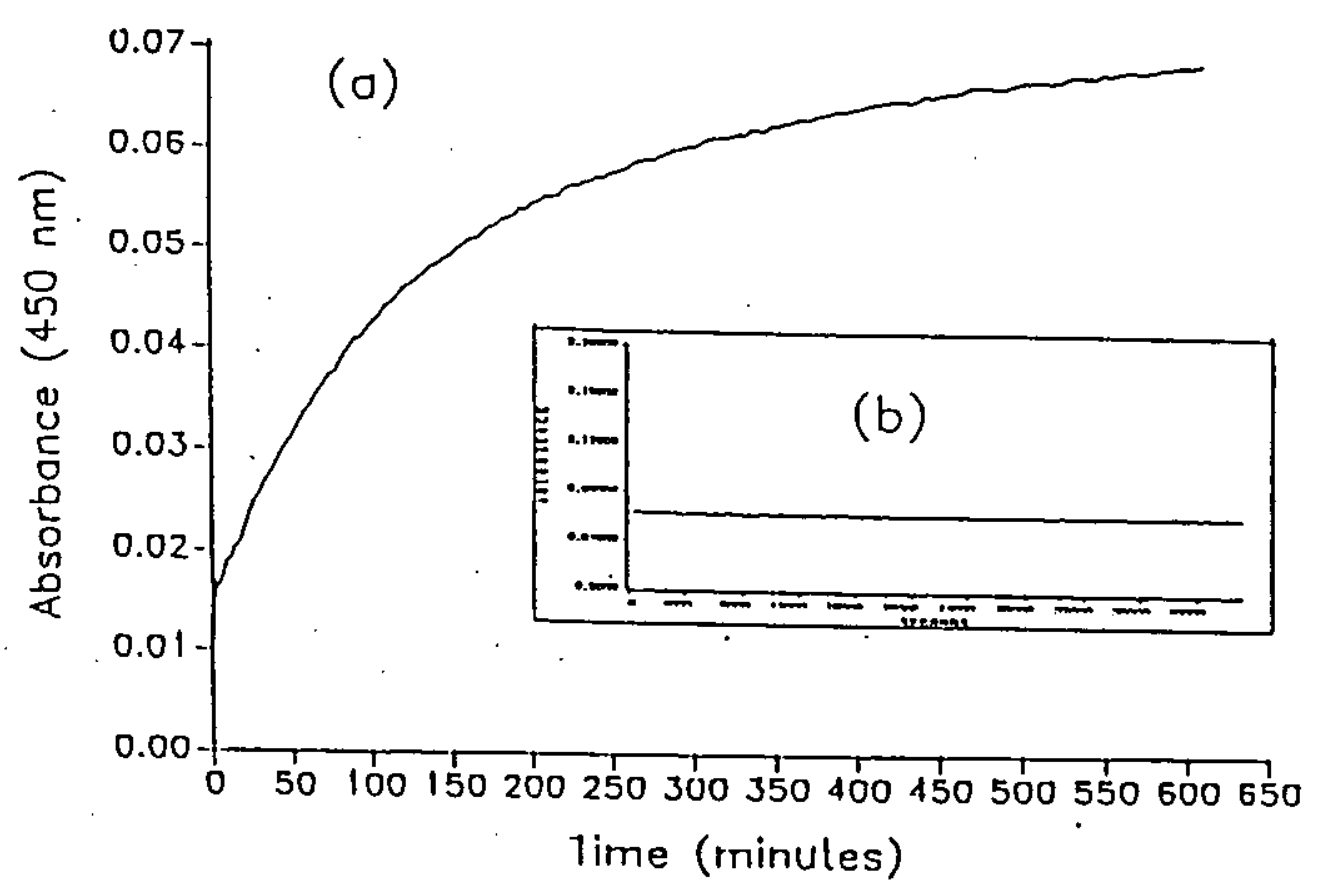

Figure Ligand exchange between Fe-MA $\left(2.10^{-5} \mathrm{M} \mathrm{MA}, 10^{-5} \mathrm{M} \mathrm{Fe}\right)$ and pseudobactin St3 $\left(10^{-5} \mathrm{M}\right)$ in BES buffer, $0.02 \mathrm{M}, \mathrm{pH} 7,30^{\circ} \mathrm{C}$ (a). Formation of Fe-pseudobactin is followed by measuring increase absorption at $450 \mathrm{~nm}$. Absorption was measured every 10 seconds for 660 seconds then every 240 seconds using a HP8452A spectrophotometer (Hewlett-Packard, USA). Ligand exchange between Fe-pseudobact in St3 and MA (b) . 


\section{References}

Bar-Ness E, Hadar Y, Chen Y. Romheld V, Marschner H. 1992a Short term effects of rhizosphere microorganisms on Fe uptake from microbial siderophores by maize and oat. Plant Physiol 100, 451-456.

Bar-Ness E, Hadar Y, Chen Y, Shanzer A, Libman J. 1992b Iron uptake by plants from microbial siderophores. Plant Physiol 99, 1329-1335.

Buyer JS, Leong J. 1986 Iron transport-mediated antagonism between plant growthpromoting and plant deleterious Pseudomonas strains. J Biol Chem 261, 791-794.

Buyer JS, Sikora LJ, Chaney, RL. 1989 A new growth medium for the study of siderophore-mediated interactions. Biol Fertil Soils 8, 97-101.

Buyer JS, Sikora LJ. 1990 Rhizosphere interactions and siderophores. Plant and Soil 129,101-107.

Crowley DE, Romheld V, Marschner H, Szaniszlo PJ. 1992 Root microbial effects on plant iron uptake from siderophores and phytosdierophores. Plant and Soil $142,1-7$.

de Weger LA, van Arendonk JJCM, Recourt K, van der Hostad GAJM, Weisbeek PJ, Lugtenberg B. 1988 Siderophore-mediated uptake of $\mathrm{Fe}^{3+}$ by the plant growthstimulating Pseudomonas putida strain WCS358 and by other rhizosphere microorganisms. J Bacteriol 170, 4693-4698.

Hohnadel D, Meyer JM. 1988 Specificity of pyoverdine-mediated iron uptake among fluorescent Pseudomonas strains. J Bacteriol 170, 4865-4873.

Jacoby J. 1964 The induction and repression of amino acid oxidation in Pseudomonas fluorescens. Biochem $J$ 92, 1-8.

Jurkevitch E, Hadar Y, Chen Y. 1992 Differential siderophore utilization and ionr uptake by soil and rhizosphere bacteria. Appl Environ Microbiol 58, 119-124.

Kay WW, Gronhund AF. 1969a Influence of carbon and nitrogen starvation on amino acid transport in Pseudomonas aeruginosa. J Bacteriol 100, 276-282. 
Kay WW, Gronhund AF. 1969b Amino acid transport in Pseudomonas aeruginosa. J Bacteriol 97, 273-282.

Meyer JM, Abdallah M. 1978 The fluorescent pigment of Pseudomonas fluorescens: biosynthesis, purification and physiochemical properties. J Gen Microbiol $107,319-328$.

Mihashi S, Mori S. 1989 Characterization of mugineic-acid-Fe transporter in Fedeficient barley roots using the multi-compartment transport box method. Biol Metals 2, 146-154.

Mino Y, Ishida T, Ota N, Inoue M, Nomoto K, Takemoto T, Tanaka H, Sugiura Y. 1983 Mugineic acid-iron (III) complex and its structurally analogous cobalt (III) complex: characterization and implication for absorption and transport of iron in gramineous plants. J Am Chem Soc 105, 4671-4676.

Mori S, Nishizawa N, Kawai S, Sato Y, Tagaki S. 1987 Dynamic state of mugineic acid and analogous phytosiderophores in Fe-deficient barley. J Plant Nutr 10, 1003-1011,

Murakami T, Ise I, Hayakawa M, Kamei S, Takagi S. 1989 Stability of metal complexes of mugineic acids and their specific affinity for iron (III). Chemistry Lett 1989, 2137-2140.

Neilands JB. 1982 Microbial iron transport compounds. In: Laskin AI, Lechevalier HA, eds. Handbook of Microbiology, Vol IV, 2nd ed. Boca Raton: CRC Press.

Nomoto K, Sugiura Y, Tagaki S. 1987 Mugineic acids, studies of phytosiderophores. In: Winkelman G, van der Heim D, Neilands JB, eds. Iron Transport in Microbes, Plants and Animals. Weinheim: VCH Verlagsgesellschaft. 401-. 428.

Raymond KN, Muller G, Matzanke BF. 1984. Complexation of iron by siderophores. A review of their solution and structural chemistry and biological function. Topics in Current Chem 123, 49-102. 
Rogers HJ. 1973 Iron-binding catechols and virulence in Escherichia coli. Infect Innun 7, 445-456.

Romheld V. 1987 Existence of two different strategies for the acquisition of iron in higher plants. In: Winkelman G, van der Heim D, Neilands JB, eds. Iron Transport in Microbes, Plants and Animals. Weinheim: VCH Verlagsgesellschaft. 353-374.

Romheld V. 1991 The role of phytosiderophores in acquisition of iron and other micronutrients in gramineous species: An ecological approach. In: Chen $Y$, Hadar Y, eds. Iron Nutrition and Interactions in Plants. The Netherlands: Kluwer Academic Publishers. 159-166.

Shojima S, Nishizawa N, Fushiya S, Nozoe S, Irifune T, Mori S. 1990 Biosynthesis of phytosiderophores. Plant Physiol 93, 1497-1503.

Stanier RY, Palleroni NJ, Doudoroff M. 1966. Aerobic pseudomonads: a taxonomic study. J Gen Micxobiol 43, 159-271.

van Vuurde JWL, Schippers B. 1980 Bacterial colonization of seminal wheat roots. Soil Biol Biochem 12, 559-565.

Watanabe S, Wada H. 1989 Mugineic acid decomposing bacteria isolated from rhizoplane of iron-deficient barley. Jpn J Soil Sci Plant Nutr 60, 413-417. 


\section{Iron Uptake and Molecular Recognition in Pseudomonas putida: \\ Receptor Mapping with Coprogen B. Ferrioxamine B \\ and Their Biomimetic Analogs}

Fluorescent pseudomonads are widely found in the rhizosphere (10). They can promote plant growth and act as biocontrol agents $(1,22)$. Since $F e$ forms insoluble ferric hydroxides in solution, the amount of soluble. $\mathrm{Fe}$ in the environment is minute (21). One of the mechanisms by which fluorescent pseudomonads exert their beneficial effects is by scavenging $\mathrm{Fe}$ via their own siderophore or via siderophores produced by other microorganisms $(1,17)$. Fluorescent pseudomonads are thus able to use various hydroxamate and catecholate siderophores produced by other bacteria and fungi, such as those of the ferrichrome (FC) family (15). The ability to utilize other migroorganisms' siderophores probably confers an ecological advantage in the competition for $\mathrm{Fe}(8,9)$. A knowledge of the structural requirements for siderophore uptake in fluorescent pseudomonads thus provides means to enhance or inhibit specific microbial populations.

siderophore-mediated $\mathrm{Fe}$ uptake in bacteria involves several steps: First, the $\mathrm{Fe}$ complex is recognized by a receptor. It is then transported through one or two membranes, the $\mathrm{Fe}^{3+}$ separated from the ligand, then the $\mathrm{Fe}$ is metabolized or stored (29). Recognition of the metal complex is usually receptor specific, a certain receptor being able to identify and transport one (or a few) siderophore(s) (having many structural features in common). In some cases, the domains which are important for recognition and transport have been determined. Relevant features involve the chirality of the coordination geometry around the metal center (which can either be of a $\delta$ or a $\checkmark$ configuration), the Fe-surrounding residues, and the threedimensional structure of the metal complex $(3,16,28)$. Some hydroxamate siderophores, which are produced by a wide range of fungi, actinomycetes and bacteria, adopt a $\delta$ configuration around the $\mathrm{Fe}$ center (coprogen); others are left-handed ( $\mathrm{FC}$ ), while still others form racemic mixtures (ferrioxamine).

Coprogen (Cop.) is a modified trimer of N5-hydroxyN5(5-hydroxy-3-methy1-1-oxo-2-penty1)-L-ornithine that adopts 


\section{Materials and Methods}

Bacterial strains: P. putida WCS358 and its siderophore minus (sid') Tn5 induced mutant JM218 were obtained from $P$. Weisbeek in Utrecht, the Netherlands. $\underline{p}$. putida B10 was a kind gift from J. Buyer, Beltsville, MD, USA. P. putida St3 was isolated in our laboratory.

Siderophores: FC and COP.B were from laboratory stock. FOB was purchased in the methylsuifonate form (Desferal ${ }^{\text {TM }}$ ) from Ciba-Geigy (Switzerland). Synthesis of the FC analogs B5 and B9 has been previously described (16).

Synthesis: The trishydroxamate analogs were prepared in essentially four steps: (i) preparation of the protected amino acid residue; ( $i$ ) coupling of the amino acid residue possessing a 3-N-hydroxy-benzyl-amino-propionic acid ester to the monomer and hydrolysis; (iii) trimerization of the monomers by the Merrifield method (2); and (iv) hydrogenolysis to the free ligands.

Plate tests: The antibiosis plate test was carried out as described by Buyer and Leong (6). Soft agar $(0.6 \mathrm{ml})$ inoculated with approximately $10^{3} \mathrm{CFU} / \mathrm{ml}$ of the tested bacterium was poured over modified King's $B$ (MKB) medium (16) in $5-\mathrm{cm}$ diameter Petri dishes. Twenty $\mu 1$ of a $10^{-3} \mathrm{M}$. solution of the tested desferri compound was dropped onto a 6-mm diameter Whatman paper disk. The plates were incubated at $30^{\circ} \mathrm{C}$ and checked after 24 hrs.

For the Fe-siderophore complex utilization test, the bacteria were grown in liquid MKB medium and about $10^{3}$ CFU were plated on MKB plates containing $400 \mu M \alpha, \alpha^{\prime}$ dipyridyl. The bacteria were also grown in a liquid rhizospheresimulating medium (RSM) and plated on RSM containing $201 \mu M$ of ethylenediamine di-o-hydroxyphenylacetic acid (EDDHA) (7). Ten $\mu 1$ of a $10^{-4} \mathrm{M}$ solution of the Fe-siderophore complex was dropped on a Whatman paper disk. The plates were incubated as above. 
a $\delta$-trans configuration around the metal center (30). Coprogen B (Cop.B) is a closely related compound that differs from Cop. by the substitution of the 3 -acetyl residue with a hydrogen atom (13). Both compounds have been shown to be actively taken up by fungi (13) and bacteria (5).

Ferrioxamine $B$ (FOB), produced by Streptomyces pilosus, is a linear trishydroxamic acid composed of alternating units of 1-amino-5-(hydroxyamino)pentane and succinic acid. (27). FOB represents an extreme case of configurational variability, in that it can form a total of five isomers when binding trivalent metal ions, each as racemic mixture (20). FOB mediates $\mathrm{Fe}$ uptake in fungi, actinomycetes, and bacteria $(23,24,26)$.

Uptake of FOB and COp. proceeds through two different receptors in Pantoea agglomerans, but it is unclear whether Escherichia coli possesses one receptor with dual function (5), or two distinct receptors, one for each compound $(4,25)$.

In a previous study, we showed that $\mathrm{Fc}$ promotes the growth of $\underline{p}$. putida and mediates ${ }^{55} \mathrm{Fe}$ incorporation (16). Using an original series of biomimetic analogs, we demonstrated that the $\checkmark$ configuration is an essential, but not sufficient feature for receptor recognition and further transport; the three-dimensional shape and the bulkiness of the projecting side chains are also determinants. In this study, we show that COP.B and FOB act as siderophores for $\underline{p}$. putida. In order to provide sensitive probes for the structural requirements of the $F O B$ receptor and their relation to Cop. recognition, we designed and synthesized synthetic $F O B$ analogs that would preferentially (if not exciusively) adopt the cis configuration, exhibit significant chiral preference, and possess minimal conformational freedom, as if "freezing out" specific conformation of the natural $\mathrm{Fe}^{3+}-\mathrm{FOB}$ complexes. 
Growth curves: The sid ${ }^{-}$strain JM218 was used to test the efficiency of bacterial growth promotion in an Fe-free liquid medium. HEPES-succinate medium [HSM, containing (in grams per liter) succinate, $4 ; \quad \mathrm{K}_{2} \mathrm{HPO}_{4}, 0.2 ; \quad\left(\mathrm{NH}_{4}\right)_{2} \mathrm{SO}_{4}, 1$; $\mathrm{MgSO}_{4} .7 \mathrm{H}_{2} \mathrm{O}, \quad 0.2$; and HEPES (N-2-hydroxyethylpiperazine$N^{\prime}$-2-ethanesulfonic acid), 11.91) was batch-treated for 4 hrs with Chelite $N$ resin ( $10 \mathrm{~g} / 1$, Serva, Germany), decanted and filtered through a $0.45 \mu \mathrm{m}$ filter. The $\mathrm{pH}$ was then raised to 7.2 by addition of $10 \mathrm{~N} \mathrm{NaOH}$ and the medium. was autoclaved. Double-distilled water was used, and the glassware was washed with $6 \mathrm{~N} \mathrm{HCl}$ followed by thorough rinsing with doubledistilled water.

Polypropylene test tubes $(50 \mathrm{ml})$ were filled with $10 \mathrm{ml}$ of the Chelite-treated HSM. The $\mathrm{Fe}^{3+}$-siderophores were added to a final concentration of $10^{-6} \mathrm{M}$, the tubes were inoculated with. about $4.10^{7} \mathrm{CFU} / \mathrm{ml}$ and shaken in an inclined position at $28^{\circ} \mathrm{C}$. Samples were taken at desired intervals and turbidity at $620 \mathrm{~nm}$ was recorded. Each treatment was performed in triplicate.

${ }^{55} \mathrm{Fe}$ uptake: The procedure for determining ${ }^{55} \mathrm{Fe}$ uptake described by de Weger et a1. (11) was used, with minor modifications. The mutant JM218 was used in all experiments. The bacterium was grown in a half-strength standard succinate medium (SSM) to an $A_{620}$ of 0.4 , centrifuged for $15 \mathrm{~min}$ at $2500 \mathrm{rpm}$ then resuspended in fresh half-strength SSM to a final $A_{620}$ of 0.3 and incubated for $1 \mathrm{hr}$ in a water bath at $28^{\circ} \mathrm{C}$. The labelled $\mathrm{Fe}^{3+}$ complex was added to a final concentration of $1 \mu M$. Aliquots $(0.5 \mathrm{ml})$ were taken in duplicate, layered onto a mixture of octoil:dibutyl phtalate $(1: 2)$ and centrifuged. Counting was performed on a Beckman LS1801 counter. 


\section{Results}

Design and Synthesis: The synthesized compounds are trimers of three monomers, each composed of a natural amino acid linked via hydroxamate bonds to $\mathrm{N}$-hydroxy-amino-propionic acid (Fig. 1). This design greatly facilitated synthesis by relying on natural amino acids as building blocks. Shortening the spacers between the binding sites relative to those of FOB ( $m=0$ and $m=2$, respectively $-F i g .1)$ restricted the number of possible coordination isomers to those possessing cis geometry. Incorporation of asymmetric centers induced chiral preference for either the right- or left handed cis configuration.

All intermediates and final products were characterized by their spectroscopic and analytical properties, which were in full agreement with the assigned structures. Titration with $\mathrm{FeCl}_{3}$ in aqueous methanol buffer established $1: 1$ ion binding stoichiometry for all compounds, and CD spectroscopy of the $\mathrm{Fe}^{3+}$ complexes demonstrated preferred right handedness when L-amino acid components were used. Quite remarkably, the extent of chiral preference for the $\delta$-cis configuration (when L-amino acids were used) varied substantially with the nature of the amino acid. This result was derived from the positive cotton effects of their $\mathrm{Fe}^{3+}$ complexes around $420 \mathrm{~nm}$. While the chiral preference was small for the Ala and Leu derivatives, it was larger for the Asp derivative, and particularly large for the Giu derivatives. The enhanced chiral preference of the Asp derivative suggests the presence of specific non-covalent interactions between the projecting amide groups $\mathrm{CH}_{2}$ CONEt $_{2}$ and the molecule's backbone and/or $\mathrm{Fe}^{3+}$ center. The greater optical purity of the Glu derivatives is attributed to the extended amino acid bridges, which tend to lower the strain in the complex. 
Growth promotion and antibiosis plate tests: Plate tests showed that $\underline{P}$. putida St3, WCS358, B10 and JM218 (the sid derivative of WCS358) are able to grow in the presence of the siderophores COP.B and FOB. When COP.B or FOB were used as sole $\mathrm{Fe}$ source in plates containing EDDHA or $\alpha, \alpha^{\prime}$ dipyridyl, growth halos of bacteria 25 to $45 \mathrm{~mm}$ and 35 to $50 \mathrm{~mm}$ in diameter respectively, were measured after 18 to $24 \mathrm{~h}$ incubation at $30^{\circ} \mathrm{C}$. None of the Fe complex of the synthetic siderophores p178, p191, p239, p254, and p271 could sustain bacterial growth.

Inhibitory activity of the desferri-compounds was also tested. Application of $20 \mu 7$ of a $10^{-3} \mathrm{M}$ solution of Cop.B or $F O B$ as free ligands resulted in normal growth of the colonies around the paper disks, again indicating that the bacteria were able to use the Fe-siderophore complex formed with residual $\mathrm{Fe}$ from the growth medium. The synthetic siderophore analogs p178, p19l and p239 did not exhibit antibiotic activity towards strain JM218. However application of the desferri compounds 2254 and p271 resulted in a clear zone of inhibition around the paper disks. This indicates that these latter compounds are totally unavailable as $\mathrm{Fe}$ sources for strain JM218. Since the control treatments, including the Fe complexes of the compounds did not show any deleterious effects, it can be concluded that $\mathrm{Fe}$ immobilization was the cause of the inhibition.

Growth in liquid medium: The growth-promoting ability of Fe$F O B$ and its biomimetic analogs was studied in a liquid medium treated with Chelite $\mathrm{N}$ to remove residual $\mathrm{Fe}$. As seen in Fig. 2 , the cells grew very poorly in the control treatment, while Fe-FOB promoted strong growth of the bacterium, with a doubling time of about $1.75 \mathrm{~h}$. The $\mathrm{Fe}$ complexes of the synthetic analogs p178, p191 and p239 promoted the growth of JM218, but not as efficiently as the natural siderophores. Although the lag period was longer the slope of the curves differed little and generation times of 1.8 to $2 h$ were recorded. In agreement with the plate experiments, the $\mathrm{Fe}$ complexes of p254 and its enantiomer p271 were totally ineffective in promoting bacterial growth. When Cop.B was 
i 115

tested in identical experiments, it behaved similarly to FOB.

${ }^{55}$ Fe uptake: ${ }^{55} \mathrm{Fe}$ uptake mediated by $\mathrm{COP} . \mathrm{B}$ and $\mathrm{FOB}$ was demonstrated (Fig. 3). The two compounds mediated ${ }^{55} \mathrm{Fe}$ uptake similarly, showing a linear uptake response during the 20-min experiment. About 90 and 120 pmole Fe/mg d.w. were incoporated after 20 min for Cop.B and FOB uptake, respectively. Uptake was strongiy reduced by the inhibitory compounds potassium cyanide $\left(\mathrm{CN}^{-}\right)$, and dinitrophenol (DNP), as in FC- and B9-mediated uptake (Table 1 ). The Km's of both FOB- and Cop.B-mediated ${ }^{55} \mathrm{Fe}$ uptake were calculated using data from concentration dependent experiments. The apparent $\mathrm{Km}^{\prime}$ 's were $0.09 \mu \mathrm{M}$ and $0.22 \mu \mathrm{M}$ for Cop.B- and FOB- mediated uptake, respectively. The synthetic analogs p178, pl19l and p239 mediated ${ }^{55} \mathrm{Fe}$ uptake, but showed a different uptake pattern (Fig. 3). After 3 min, the amount of ${ }^{55} \mathrm{Fe}$ associated with the cells was about three times higher than that for FOB- or Cop.B-mediated uptake (Fig. 3). The final concentration of $\mathrm{Fe}$ was about $110 \mathrm{pmole} / \mathrm{mg} \mathrm{d.w.,} \mathrm{resulting} \mathrm{in}$ a flatter uptake curve. Uptake of ${ }^{55} \mathrm{Fe}$ mediated by these three analogs was reduced by the addition of $\mathrm{CN}^{-}$to the incubation medium, demonstrating active uptake (Table 1). Compounds p254 and p271 did not promote appreciable ${ }^{55} \mathrm{Fe}$ uptake (Fig. 3).

Competition experiments: Competition experiments were performed to determine whether $\mathrm{Fe}$ uptake mediated by the siderophores FC, FOB and COP.B shares common determinators. The use of synthetic siderophores enabled us to determine the structural properties essential for recognition and uptake. Uptake of ${ }^{55} \mathrm{Fe}-\mathrm{Cop} . \mathrm{B}$ was inhibited by increasing concentrations of cold $\mathrm{Fe}-\mathrm{FC}$ and $\mathrm{Fe}-\mathrm{Bg}$ (Fig. 4). Equimolar concentrations of $\mathrm{Fe}-\mathrm{FC}$ and $\mathrm{Fe}-\mathrm{Bg}$ reduced ${ }^{55} \mathrm{Fe}$ uptake mediated by Cop. B by $55 \%$ and by $22 \%$, respectively. Similarly, FOB- mediated ${ }^{55} \mathrm{Fe}$ uptake was strongly affected by increased concentrations of the competing siderophores $F e-F C$, $\mathrm{Fe}-\mathrm{Cop} . \mathrm{B}$, and Fe-Bg (Table 2). The data suggest that these siderophores use at least one common determinant in their uptake systems, as they were increasingly inhibited by each 
other's presence at increasing concentrations. The biomimetic analogs were used in order to distinguish between the various putative receptors for the natural siderophores. The $\mathrm{Fe}$ complex of enantiomer $B 5(V)$ which blocks the $F C$ receptor (14) had no effect on ${ }^{55} \mathrm{Fe}$ uptake mediated by either Cop.B or FOB. These siderophores must therefore mediate $\mathrm{Fe}$ uptake through one or two receptors that are different from that of $\mathrm{Fc}$. The $\mathrm{Fe}$ complexes of compounds p178, p19l and p239, 1inear Cop. and ferrioxamine analogs, were all able to inhibit FOBand Cop.B- mediated ${ }^{55} \mathrm{Fe}$ uptake (Table 3 ). The synthetic $\mathrm{Fe}-\mathrm{p} 254(\delta)$ and Fe-p271 (v) did not inhibit ${ }^{55} \mathrm{Fe}$ uptake mediated by Cop.B. However, Fe-p254 and Fe-p271 had a prononced effect on FOB-mediated ${ }^{55} \mathrm{Fe}$ uptake, reducing it by 22 and $52 \%$, respectively (Table 3 ).

\section{Discussion}

This study focused on the linear siderophores Cop.B and $F O B$. We showed that these siderophores are active in fluorescent pseudomonads, promoting the growth of cells when supplied as the sole $\mathrm{Fe}$ source. Uptake of ${ }^{55} \mathrm{Fe}$ mediated by $F O B$ and COP.B, as well as by $F C$, was shown to be an active process, probably involving the proton motive force since it is inhibited by DNPas shown earlier for pseudobactin-mediated Fe uptake (11). Whether other siderophore uptake systems share common features with the uptake mechanism of pseudobactin is presentiy under investigation. FOB- and Cop.B- mediated uptake of $\mathrm{Fe}$ showed high $\mathrm{Km}$ values $(0.22$ and $0.09 \mu \mathrm{M}$, respectively). The uptake systems of these natural siderophores, as well as that of the $F C$ analog $B 9$, must share a common determinant(s) since ${ }^{55} \mathrm{Fe}$ uptake mediated by any of these compounds was decreased in the presence of "cold" complexes of the other siderophores. This observation is in agreement with Koster and Braun (18) who have demonstrated that in Escherichia coli the periplasmic FhuD protein is able to bind siderophores exhibiting widely differing chemical structures. such as Fc, Cop. and aerobactin, presumably. passing them onto the cytoplasmic membrane-bound FhuB protein 
(19). Whether FhuD is free in the periplasmic space is unknown (18). Huschka et al. (14) have demonstrated that a) though the transport system for FC and Cop. is shared in Neurospora crassa each compound has a specific receptor. More recently, Dori et al. (12) have shown that in Geuenanommyces graminis var. tritici, the siderophores dimerium acid, Cop.B, rhotorulic acid and FC share a common transport system.

In order to investigate the structural requirements for receptor recognition and transport of COP.B and $F O B$, and to determine whether these siderophores have different receptors than Fc, we made use of biomimetic analogs of various structures. Compound $B 5$ is a $F C$ analog of $\checkmark$ configuration which has been shown to block the Fc receptor (14). Compounds p178, p191, p239, p254, and p271 are linear compounds as are $F O B$ and COp.B. The synthetic siderophores did not support growth on Fe-limited plates, and did not exhibit no antibiotic activity. However, they enhanced growth in 1 iquid medium and mediated $55 \mathrm{Fe}$ uptake. The $\mathrm{Fe}$ chelators used in the plates might therefore have interfered with the synthetic analogs (4). The shape of the ${ }^{55} \mathrm{Fe}$ uptake curve suggests that after short exposure adsorption of the $F e$ complex occured due to higher hydrophobic interactions with the side chains. Analog B5 has earlier been shown to have receptorbinding capacity but to be transport inactive (16). In this study, we found that analog $B 5$ was unable to inhibit $F e$ uptake mediated by the siderophores COP.B and FOB. It therefore may be concluded that COP.B and $F O B$ are recognized by one or two receptors which are different from the one used for Fc-mediated $\mathrm{Fe}$ uptake. The shared determinant(s) between the three siderophores is probably located further downstream of the uptake pathway.

The linear ferrioxamine-Cop. analogs p178, p19l and p239 that form complexes of both $\checkmark$-cis and $\delta$-cis configuration inhibited ${ }^{55} \mathrm{Fe}$ uptake mediated by both $\mathrm{FOB}$ and Cop.B. Analogs p254 $(\delta)$ and $p 271(v)$, which were totally inactive in growth promotion tests as well as in transport activity, strongly reduced ${ }^{55} \mathrm{Fe}-\mathrm{FOB}$ incorporation, but did not affect cop.B-mediated uptake. This observation demonstrates the presence of two distinct receptors for FOB and COp.B. 
Moreover, the putative $F O B$ receptor showed preference for the $\checkmark$ configuration since FOB-mediated ${ }^{55} \mathrm{Fe}$ uptake was reduced markedly more by the $\mathrm{Fe}$ complex of p271 than by that of p254. However, the chiral preference is not absolute since the latter analog still showed rather high inhibitory activity. The activity of the lower homologs $(m=0)$ as $F O B$ and Cop.B analogs, independentiy of the nature of the amino acid component, is indicative of their fit to the two siderophore receptors and of their common transport system. This may be attributed to the rather small molecular diameter of these $\mathrm{Fe}^{3+}$ complexes which allows them to easily adapt themselves to the respective recognition sites. The action of the higher homologs $(m=2)$ as inhibitors of FOB, without affecting Cop. B, is indicative of higher discrimination by the latter $\mathrm{Fe}$ uptake system. It also demonstrates their fit to the FOB receptor, without interacting with the transport system. Most remarkable is the observed chiral discrimination by the $F O B$ receptor: the $\underline{D}-G 1 u$ derivative adopting the $\sqrt{-c i s}$ configuration was two- to threefold more potent than the enantiomeric $L-G l u$ derivative of $\delta$-cis configuration. This observation might imply that "archaic" FOB was not devoid of chiral centers.

Dual activity of compounds p178, p19l and p239 as Cop. and $F O B$ analogs has been shown in enterobacteria. Using various mutants, these analogs were shown to have FOB-like activity in Hafnia alvei, Cop.-like activity in E. coli and both activities in pantoea agglomerans (4). In the latter organism, lower and higher homologs showed both FOB- and Cop.-like activity, independent of their absolute configuration (G. Winkelmann, personal communication). These findings demonstrate that species-dependent differences in the structural characteristics of related siderophore uptake systems may prevail. Whether these differences can be employed for the synthesis of species-specific growth promoting or inhibiting agents remains to be established. 


\section{$\underline{\text { References }}$}

1. Bakker, P.A.H.M., R. van Peer, and B. Schippers. 1990. Specificity of siderophore receptors and biocontrol by Pseudomonas spp. pp. 143-164. In D. Hornby (ed.), Biological Control of Soil-Borne Plant Pathogens. C.A.B. International, Wallington.

2. Barany, G., and R.B. Merrifield. 1980. The Peptides: Analysis, Synthesis, Biology. E. Gross and E. Meinhofter (eds.), Academic Press, N.Y.

3. Bergeron, R.J., and W.R. Weimar. 1990. Kinetics of iron acquisition from ferric siderophores by Paracoccus denitrificans. J. Bacteriol. 172:2650-2657.

4. Berner, I., P. Yakirevitch, J. Libman, A. Shanzer, and G. Winkelmann. 1991. Chiral linear hydroxamates as biomimetic analogues of ferrioxamine and coprogen and their use in probing siderophore-receptor specificity in bacteria and fungi. Biol. Metals 4:186-191.

5. Braun, V., and K. Hantke. 1991. Genetics of bacterial iron transport. pp. 107-138. In G. Winkelmann (ed.), Handbook of Microbial Iron Chelates. CRC Press, Boca Raton, FL.

6. Buyer, J.S., and J. Leong. 1986. Iron transport-mediated antagonism between plant growth-promoting and plantdeleterious pseudomonas strains. J. Biol. Chem. 261:791-794.

7. Buyer, J.S., L.J. Sikora, and R.L. Chaney, 1989. A new growth medium for the study of siderophore-mediated interactions. Biol. Fert. Soils 8:97-101.

8. Buyer, J.S., and L.J. Sikora. 1990. Rhizosphere interactions and siderophores. Plant and Soi7 129:101-107. 
9. Crowley, D.E., Y.C. Wang, C.P.P. Reid, and P.J. Szaniszlo. 1991. Mechanisms of iron acquisition from siderophores by microorganisms and plants. Plant Soil 130:179-198.

10. Curl, E.A., and B. Truelove. 1986. The Rhizosphere. Advanced Series in Agricultural Sciences, Springer-Verlag, Berlin.

11. de Weger, L.A., J.J.C.M. van Arendonk, K. Recourt, G.A.J.M. van der Hofstad, P.J. Weisbeek, and B. Lugtenberg. 1988. Siderophore-mediated uptake of $\mathrm{Fe}^{3+}$ by the plant growth-stimulating Pseudomonas putida strain WCS358 and by other rhizospherè microorganisms. J. Bacteriol. 170:46934698.

12. Dori, S., Z. Solel, Y. Kashman, and I. Barash. 1990. Characterization of hydroxamate siderophores and siderophoremediated iron uptake in Gaeumannomyces graminis var. tritici. Physiol. Mol. Plant Pathol. 37:95-106.

13. Ernst, J., and G. Winkelmann. 1974. Metabolic products of microorganisms. 135. Uptake of iron by Neurospora crassa. IV. Iron transport properties of semisynthetic coprogen derivatives. Arch. Microbiol. 100:271-282.

14. Huschka, H., H.U. Naegeli, H. Leuenberger-Ryf, W. KellerSchierlein, and G. Winkelmann. 1985. Evidence for a common siderophore transport system but different receptors in Neurospora crassa. J. Bacteriol. 162:715-721.

15. Jurkevitch, E., Y. Hadar, and Y. Chen. $1992 a$. Differential siderophore utilization by soil and rhizosphere bacteria. Appl. Environ. Microbiol. 58:119-124. 
16. Jurkevitch, E., Y. Hadar, Y. Chen, J. Libman, and A. Shanzer. 1992b. Iron uptake and molecular recognition in Pseudomonas putida: receptor mapping with ferrichrome and its biomimetic analogs. J. Bacteriol. 174:78-83.

17. Kloepper, J.W., J. Leong, M. Teintze, and M.N. Schroth. 1980. Enhanced plant growth by siderophores produced by plant growth-promoting rhizobacteria. Nature 286:885-886.

18. Koster, W., and V. Braun. 1990. Iron (III) hydroxamate transport in Escherichia coli: substrate binding to the periplasmic Fhu D protein. J. Biol. Chem. 265:21407-21410.

19. Koster, W. 1991. Iron(III) hydroxamate transport across the cytoplasmic membrane of $\underline{E}$. coli. Biol. Metals 4:23-32.

20. Leong, J., and K.N. Raymond. 1975. Coordination isomers of biological iron transport compounds. IV. Geometrical isomers of chromic desferrioxamine B. J. Am. Chem. Soc. 97:293-296.

21. Lindsay, W.L. 1979. Chemical Equilibrium in Soils. Wiley \& Sons, N.Y.

22. Loper, J.E., and J.S. Buyer. 1991. Siderophores in microbial interactions on plant surfaces. Mol. Plant-Microbe Interact. $4: 5-13$.

23. Mor, H., and I. Barash. 1990. Characterization of siderophore-mediated iron transport in Geotrichum candidum, a non-siderophore producer. Biol. Metals 2:209-213.

24. Muller, G., and K.N. Raymond. 1984. Specificity and mechanism of ferrioxamine-mediated iron transport in Streptomvces pilosus. J. Bacteriol. 160:304-312. 
25. Nelson, M., C.J. Carrano, and P.J. Szaniszlo. 1992. Identification of the ferrioxamine $B$ receptor, $F o \times B$, in Escherichia coli K12. BioMetals 5:37-46.

26. Rabsch, W., and G. Winkelmann. 1991. The specificity of bacterial siderophore receptors probed by bioassays. Biol. Metals 4:244-250.

27. Tufano, T.P., and K.N. Raymond. 1981. Coordination chemistry of microbial iron transport compounds. 21 . Kinetics and mechanisms of iron exchange in hydroxamate siderophore complexes. J. Am. Chem. Soc. 103:6617-6624.

28. Winkeimann, $\cdot G .$, and V. Braun. 1981. Stereoselective recognition of ferrichrome by fungi and bacteria. FEMS Microbiol. Lett. 11:237-241.

29. Winkelmann, G. 1991. Specificity of iron transport in bacteria and fungi. pp. 65-106. In G. Winkelmann (ed.), Handbook of Microbial Iron Chelates. CRC Press, Boca Raton, FL.

30. Wong, G.B.. M.J. Kappel, K.N. Raymond, B. Matzanke, and G. Winkelmann. 1983. Coordination chemistry of microbial iron transport compounds. 24. Characterization of coprogen and ferricrocin, two ferric hydroxamate siderophores. J. Am. chem. Soc. 105: 810-815. 
Table 1: Inhibition (\%) of ${ }^{55} \mathrm{Fe}$ uptake mediated by Ferrichrome ( $F C$ ), Cop. B (Cop.B), and ferrioxamine B (FOB) and their biomimetic analogs by the respiratory inhibitors dinitrophenol (DNP, $2 \mathrm{mM}$ ) and potassium cyanide $\left(\mathrm{CN}^{-}, 5\right.$ $\mathrm{mM})$.

Siderophore

\begin{tabular}{llllllll} 
Inhibitor & FC & COP.B & FOB & B9 & p178 & p191 & p239 \\
\hline DNP. & 96 & 86 & 71 & 93 & - & - & - \\
$\mathrm{CN}^{-}$ & 95 & 91 & 72 & 99 & 78 & 89 & 81 \\
\hline
\end{tabular}

Table 2: Inhibition (\%) of ferrioxamine B (1 $\mu \mathrm{M})$ - mediated ${ }^{55} \mathrm{Fe}$ uptake by "cold" $\mathrm{Fe}$-Cop. B (Fe-Cop.B), Fe-ferrichrome $(\mathrm{Fe}-\mathrm{FC})$ and $\mathrm{Fe}-\mathrm{Bg}$.

\begin{tabular}{lccc}
\hline Siderophore & \multicolumn{3}{c}{ Concentration $(\mu \mathrm{M})$} \\
& 1 & 3 & 5 \\
\hline $\mathrm{Fe}-\mathrm{Cop} . \mathrm{B}$ & 47 & 50 & 59 \\
$\mathrm{Fe}-\mathrm{FC}$ & 49 & 58 & 71 \\
$\mathrm{Fe}-\mathrm{Bg}$ & 18 & 31 & 40 \\
\hline
\end{tabular}


Table 3: Inhibition (\%) of ferrioxamine B (FOB) - and Cop. B (Cop.B)- mediated ${ }^{55} \mathrm{Fe}$ uptake (I $\mu \mathrm{M}$ ) by "Cold" Fe-FOB analogs $(10 \mu \mathrm{M})$.

\begin{tabular}{llllll}
\hline & \multicolumn{5}{c}{ Biomimetic analog } \\
\cline { 2 - 6 } Siderophore & p178 & p191 & p239 & p254 & p271 \\
\hline Fe-Cop.B & 46 & 53 & 42 & 0 & 2.5 \\
Fe-FOB & 51 & 46 & 65 & 22 & 52 \\
\hline
\end{tabular}


Principle Design of Biomimetic Ferrioxamine Analogs

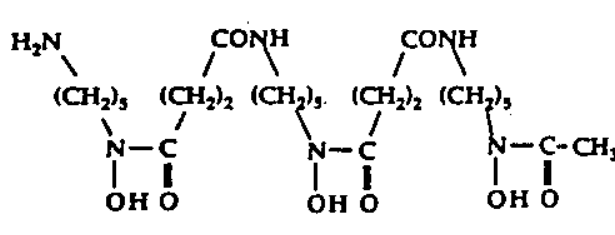

Ferrioxamine B

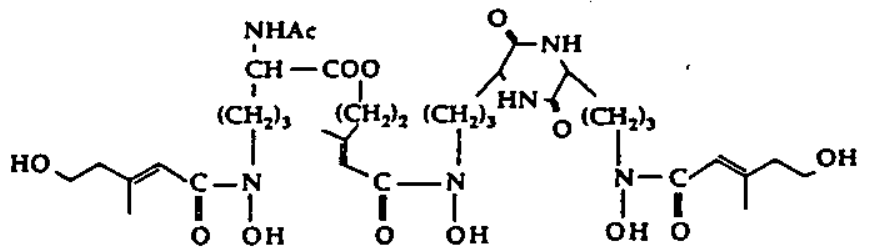

Coprogen

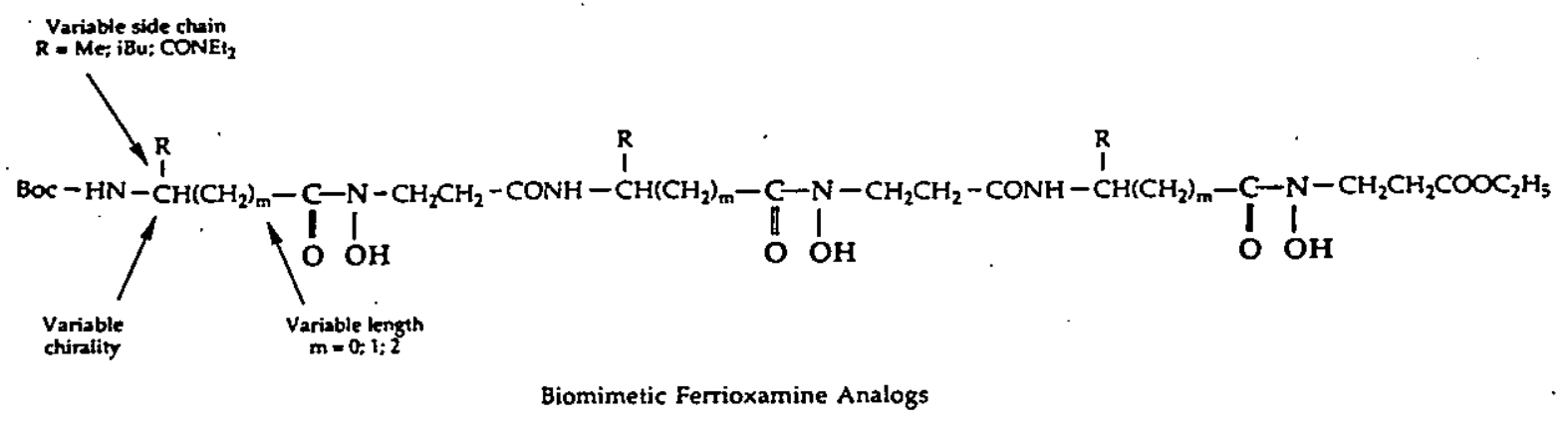

Fiqure 1: Ferrioxamine B, Cop. and their biomimetic analogs. 


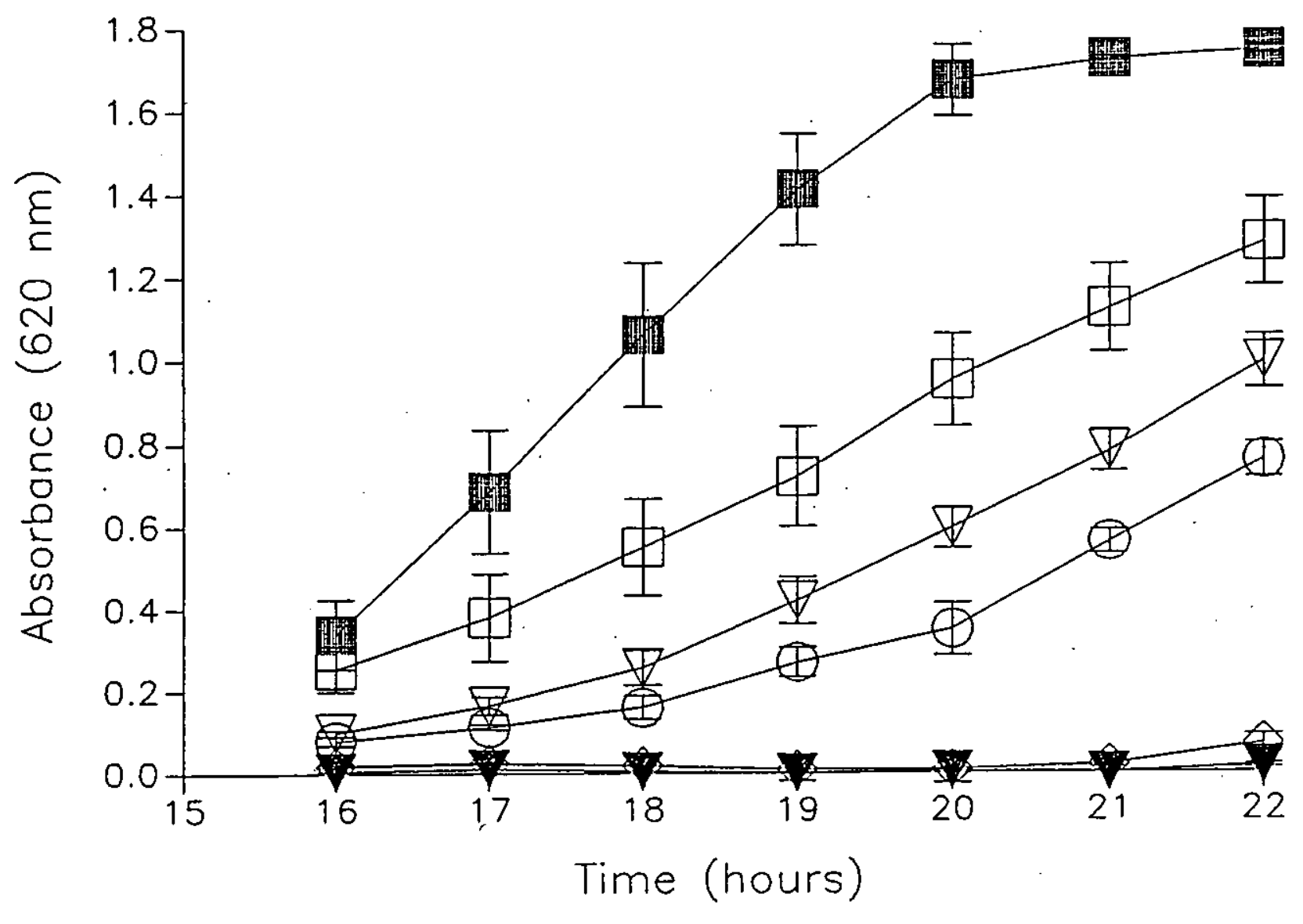

Figure 2: Growth of mutant JH218 in Chelite-treated HSM with ferrioxamine $B(A)$, and the ferrioxamine $B$ analogs p178 (O), p191 $(\square), p 239(\nabla), \quad 0254(\bar{\nabla})$, and $0271(+)$ as iron sources. Control $(\diamond)$, no added iron source. Bars represent standard error. 


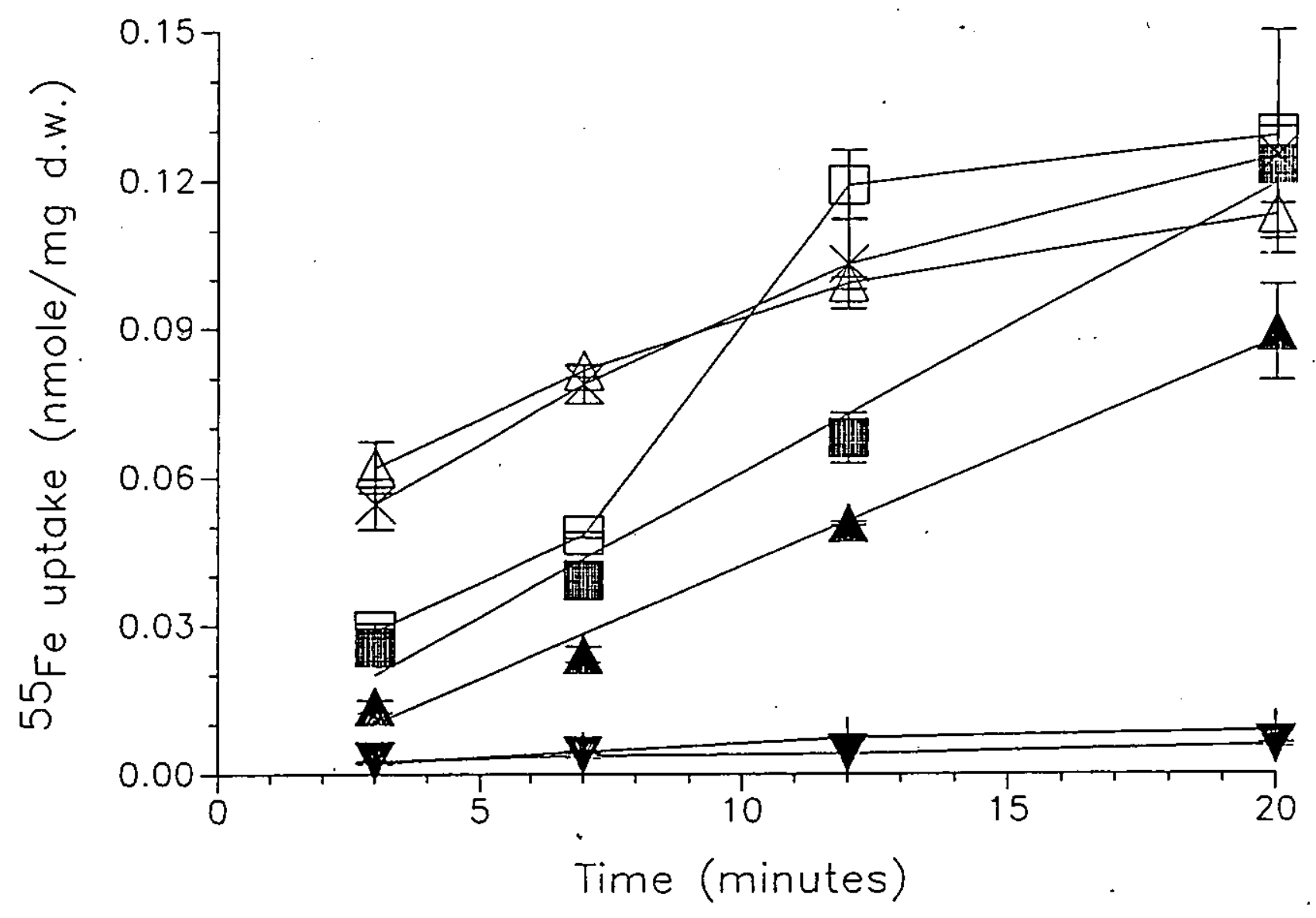

Figure $3:{ }^{55} \mathrm{Fe}$ uptake mediated by ferrioxamine $B(\mathbf{m})$, coprogen $B$ (A), p178 (X), p191 ( $\square), p 239(\triangle), p 254(\boldsymbol{\nabla})$, and p271 (+). 


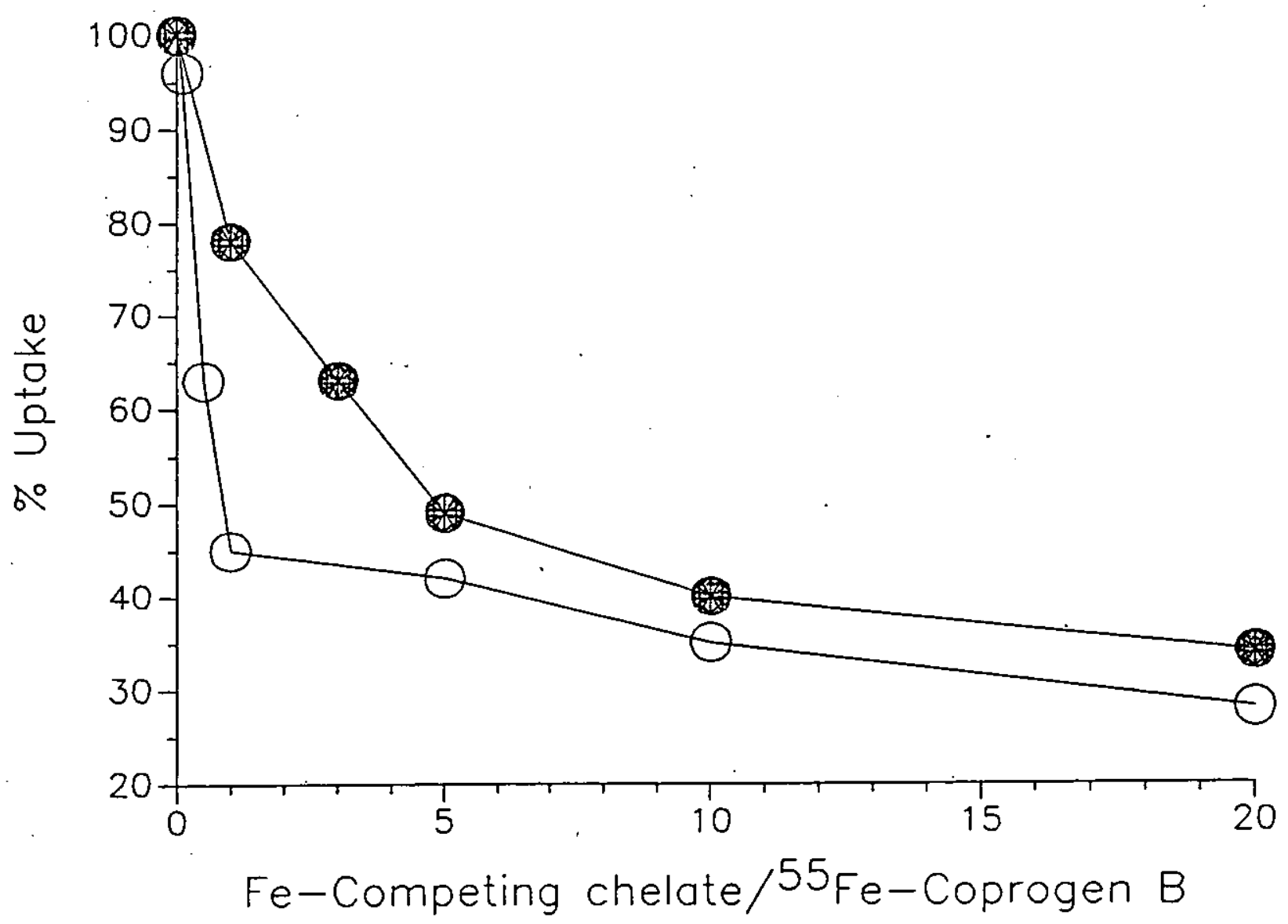

Figure 4: Percent of ${ }^{55} \mathrm{Fe}$ uptake mediated by coprogen $\mathrm{B}$ in the presence of increasing concentrations of Fe-ferrichrome (O) and $\mathrm{Fe}-\mathrm{Bg}$ (8). 
